Portland State University

PDXScholar

Fall 12-10-2012

\title{
Insights and Blind Spots: A Qualitative Analysis of Risk in Psychiatric Security Review Board Hearings
}

Abby Kealani Balfour

Portland State University

Follow this and additional works at: https://pdxscholar.library.pdx.edu/open_access_etds

Part of the Criminal Law Commons, and the Psychiatric and Mental Health Commons Let us know how access to this document benefits you.

Recommended Citation

Balfour, Abby Kealani, "Insights and Blind Spots: A Qualitative Analysis of Risk in Psychiatric Security Review Board Hearings" (2012). Dissertations and Theses. Paper 630.

https://doi.org/10.15760/etd.630

This Thesis is brought to you for free and open access. It has been accepted for inclusion in Dissertations and Theses by an authorized administrator of PDXScholar. Please contact us if we can make this document more accessible: pdxscholar@pdx.edu. 
Insights and Blind Spots: A Qualitative Analysis of Risk in Psychiatric

Security Review Board Hearings

by

Abby Kealani Balfour

A thesis submitted in partial fulfillment of the

requirements for the degree of

\author{
Master of Science \\ in \\ Psychology
}

Thesis Committee:
Janice Haaken, Chair
Robert Roeser
Melissa Thompson

Portland State University

2012 


\begin{abstract}
The prevalence and consequences of the insanity plea, titled "guilty except for insanity" in the State of Oregon, are fraught with misconceptions. The use of the plea requires a complex set of interactions between the mental health and criminal justice systems, and comes with severe costs for people who use it. Most of the research on the psychological aspects of the insanity plea emphasizes empirical validity in the form of risk assessment instruments and/or the biomedical model with its focus on disease and illness. This thesis analyzes from community psychology and critical theory perspectives the decision process of hearings held by the Psychiatric Security Review Board. The critical analysis draws specifically on Michel Foucault's (1977) theory of knowledge and power to address three questions:

1. Are there identifiable prototypical narratives of risk that are constructed around evidence admitted to a hearing?

2a. Are these risk narratives deployed differently in public PSRB hearing as opposed to an individual interview?

2b. Do the District Attorney, Defense Attorney, and clinician deploy risk narratives differently?

3. As professionals that create, administer, and interpret risk assessment instruments, how do clinicians use these risk narratives to support or refute the arguments of each side?
\end{abstract}


Transcripts and audio recordings of hearings were thematically content analyzed and compared to address these questions. One overarching theme and four subsidiary themes emerged from the data that describe how risk is indirectly discussed in the formal procedures of the hearings and in individual interviews. The overarching theme is Insight and the four subsidiary themes are Elopement, Compliance, Drug-use, and Treatment. Compared across settings, the hearings were highly structured whereas the individual interviews allowed for a more complex analysis and explication of positions. In the context of the PSRB hearings, the testimony of the clinician was of primary importance in determination of insight and the source of information on the patient along the subsidiary themes. 
Table of Contents

List of Tables

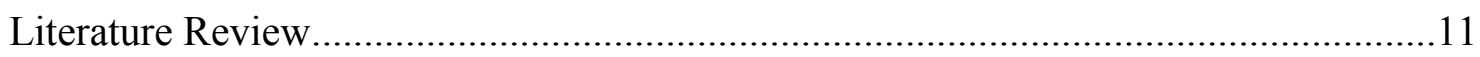

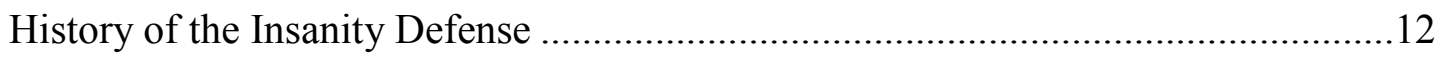

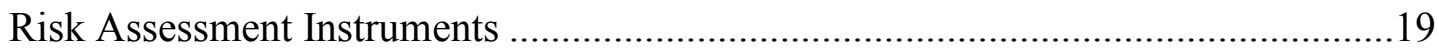

Short Term Assessment of Risk and Treatability. ...........................................23

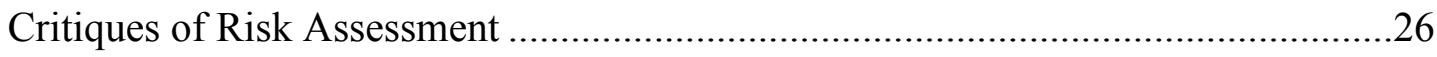

Theoretical Underpinnings of Power and Knowledge ...........................................29

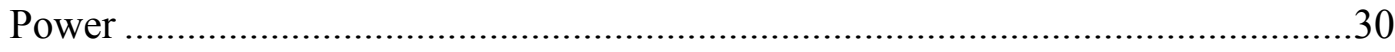

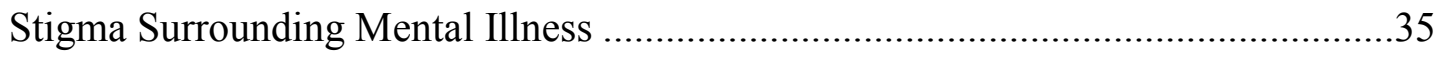

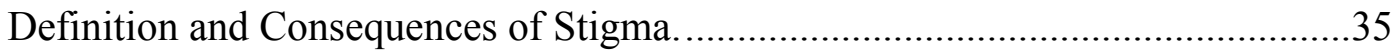

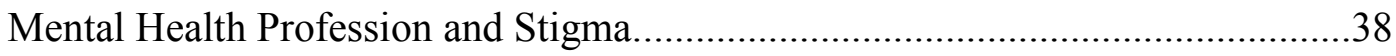

System Justification Model..................................................................... 41

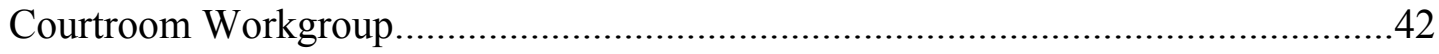

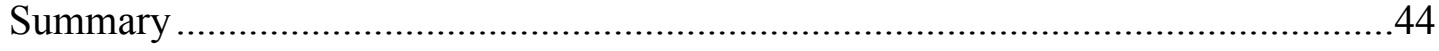

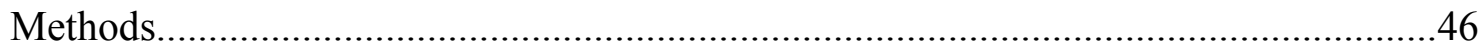

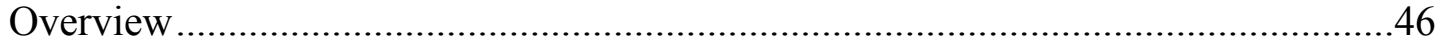

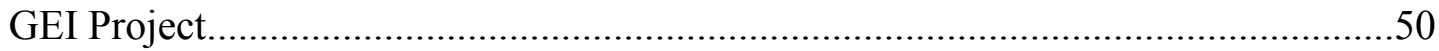

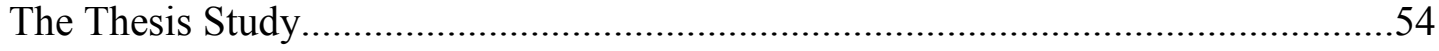

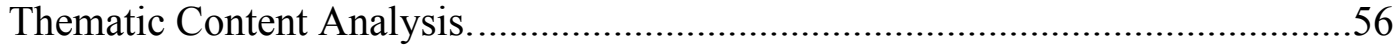

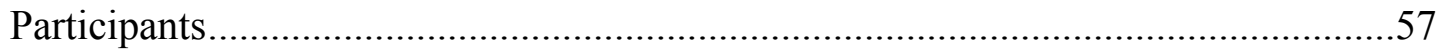

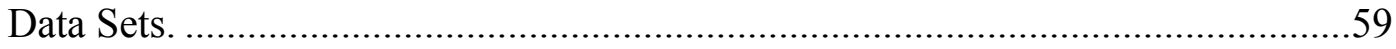

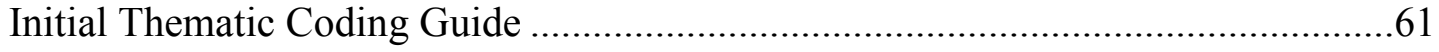

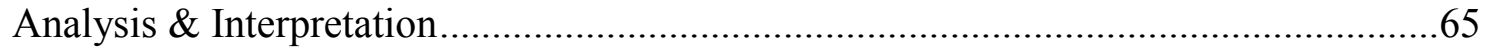

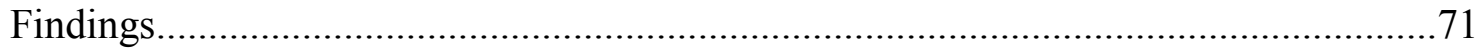

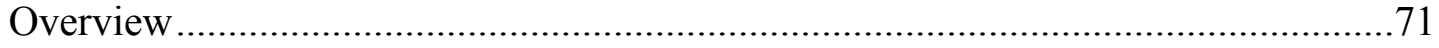

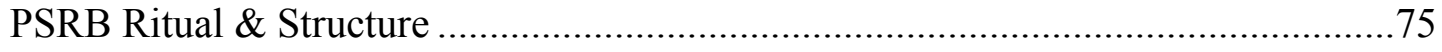

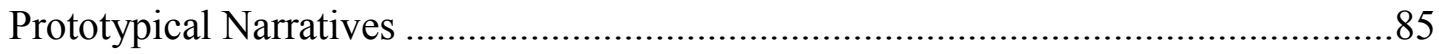

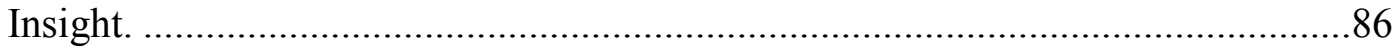




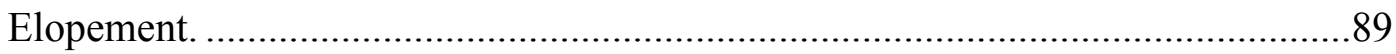

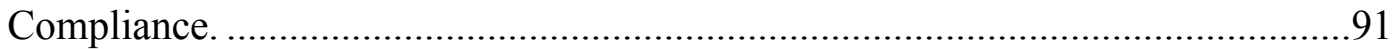

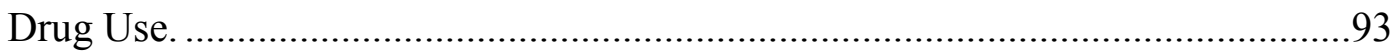

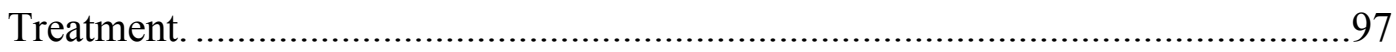

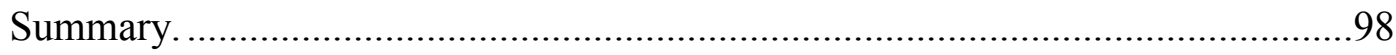

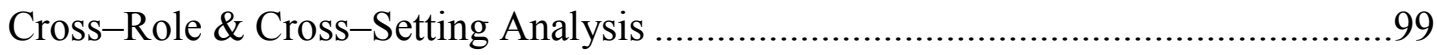

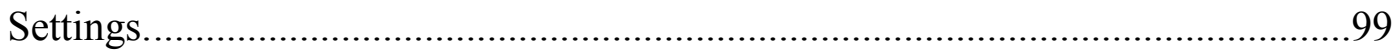

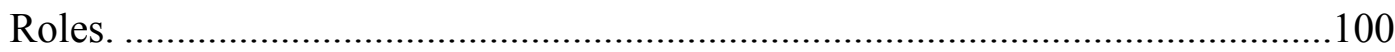

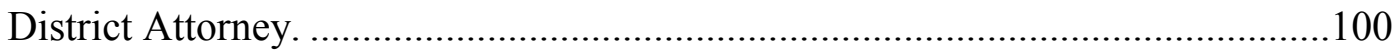

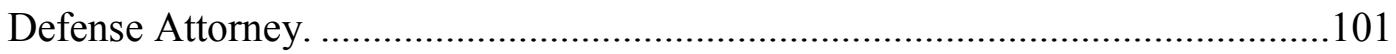

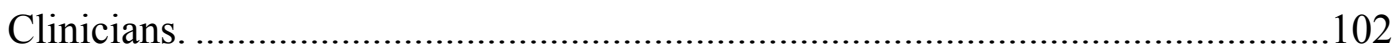

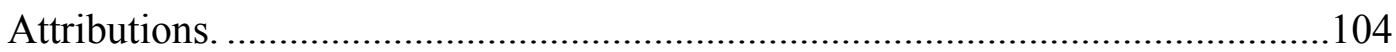

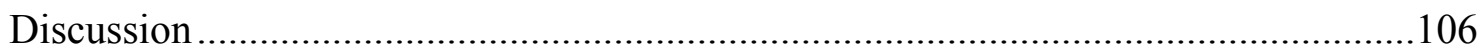

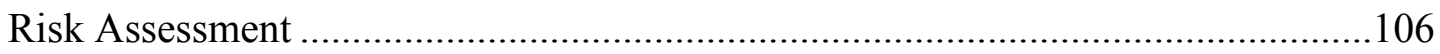

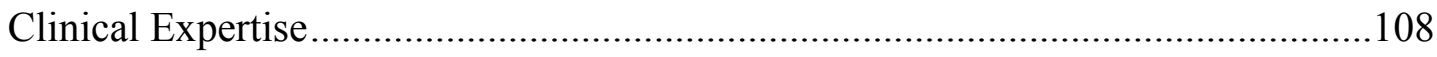

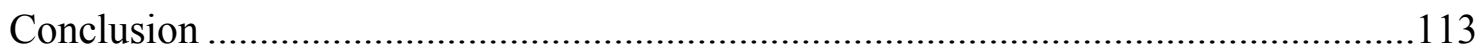

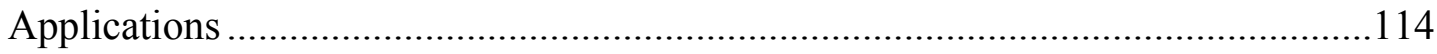

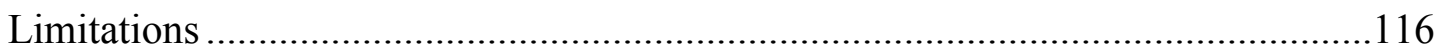

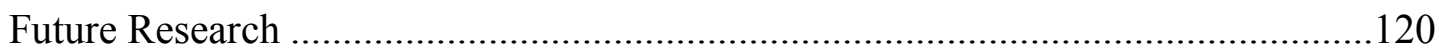

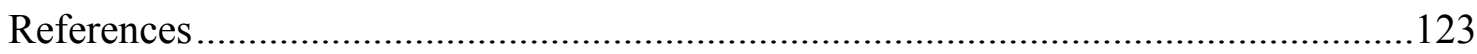

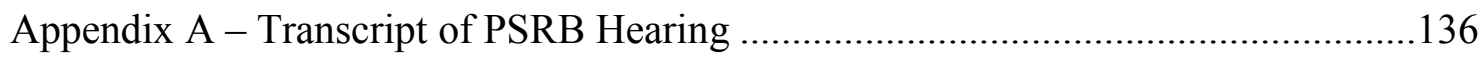

Appendix B - Transcript of Individual Interview: Clinician.........................................169

Appendix C - PSRB Proceedings Outline ...........................................................190

Appendix D - Compiled questions from District Attorney …………………………......193

Appendix E - Compiled questions from Defense Attorney .........................................201

Appendix F - Table: examples illustrating theme content ..........................................213

Appendix G - Table: Individual counts of themes by hearing ....................................219 


\section{List of Tables}

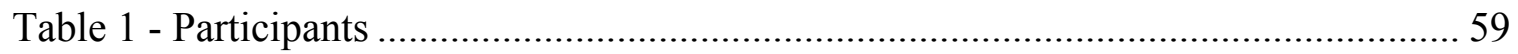

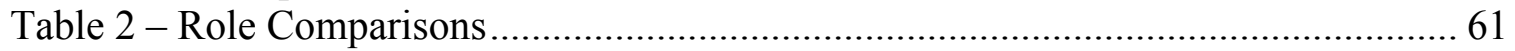

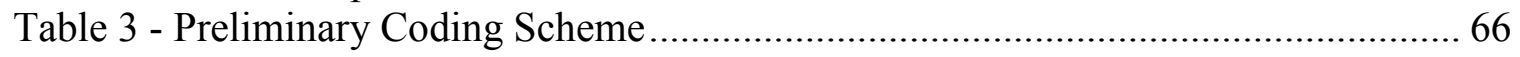

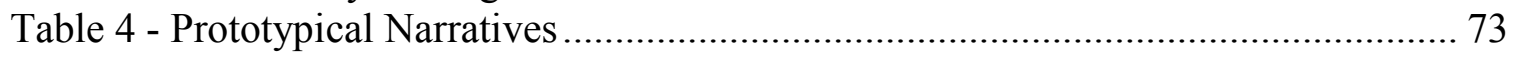

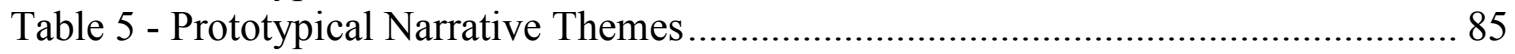




\section{Introduction}

This thesis grew out of a larger project that resulted in a feature length documentary film titled Guilty Except for Insanity: Maddening Journeys through an American Asylum. The documentary elicited the voices of people whose lives are intimately entwined with both the mental health system and criminal justice system (CJS) to examine the structures that have evolved to catch people who "fall through the cracks" (Haaken, J., 2010). This project originated in a course taught here at Portland State University wherein we examined current controversies surrounding the Oregon State Hospital (OSH), the state's primary forensic facility, and resulted in a paper on the history and areas of conflict at the Oregon State Hospital. Headed by Dr. Janice Haaken, the team filmed and interviewed over 40 individuals and several group discussions. Footage was transcribed by a team of undergraduate students lead by myself. This position allowed me to immerse myself in the data over a long period of time.

One key site of decision making - a place where decisions around status and disposition were made - centered on the Psychiatric Security Review Board (PSRB) hearings, a site where multiple forces converge around concepts of risk and risk assessment instruments. In the state of Oregon the intersection of the criminal justice system and the mental health system is expressed in the development of the PSRB. This multidisciplinary board was created by the state of Oregon in 1978 to address concerns of safety about people with mental illness that emerged in part from highly publicized cases; for example, the Hinckley trial, and reflected a nationwide trend towards greater criminalization of people with mental illness (Banks, Pandiani, Boyd, 2009; Cutcliffe \& 
Hannigan, 2001; Lee, 2009; Perez, Leifman, Estrada, 2003; Peterson, Skeem, Hart, Vidal, Keith, 2010; Rogers \& Bloom, 1985; Slate \& Johnson, 2008). Patients found Guilty Except for Insanity (GEI) are placed under the jurisdiction of the PSRB. The majority of persons begin their sentence at the Oregon State Hospital (OSH), Oregon's primary forensic hospital (PSRB factsheet, 2008). Under Oregon Revised Statues (161.336(10)) the first and primary priority of the PSRB is to assure public safety. As a function of this mandate the board has jurisdiction over individuals for the maximum sentence length allowed by law and provided by the statute of the crime (PSRB Factsheet, 2008). This policy has left the board open to critiques that conditional release processes are slow at best, often forcing patients to linger for months and years past the point where release would be clinically indicated or warranted from the perspective of public safety (Lund Report, 2011; Statesman Journal, 2011). Conditional release is a term that indicates that the person is given permission to live outside the OSH in a secure/non-secure residential treatment facility or in an independent living situation. Under Oregon Revised Statutes this occurs when the board "finds that the person is still affected by a mental disease or defect and is a substantial danger to others, but can be controlled adequately if conditionally released with treatment as a condition of release; and necessary supervision and treatment are available" (ORS 161.346(1)(b); ORS 161.336(1)(a)). Criticisms about conservative release numbers have increased over time and have led to current proposals that are working their way through the Oregon State Legislature to modify who has jurisdiction over these patients. These two bills focus on clarifying exactly which individuals fall under the jurisdiction of the PSRB, and allowing the Oregon Health 
Authority a voice in when patients are released (Statesman Journal, 2011). Debates that occur in the legislature and in the public forum of news media demonstrate the relevancy of disposition of patients and the importance of how these decisions are made. The primary focus on safety of the general public over attention to treatment and recovery of the individual places an inordinately strong emphasis on risk and risk assessment measures without a thorough understanding of how these measures interact with and influence decision making processes.

There is a significant body of research that addresses the development and predictive validity of risk assessment instruments, as is described in the literature review to follow, but little inquiry focused on perspectives outside of those of researchers and how such evaluations are used to make decisions. The purpose of this thesis is to examine narratives and perspectives of risk and risk assessment in PSRB hearings, and to explicate narratives of risk that are developed by varying and occasionally conflicting viewpoints. This analysis will enable an examination of the underlying ideologies and assumptions prevalent in the structures that have been constructed to manage and adjudicate people found GEI. Identification of these underlying beliefs and values will make explicit power-dynamics that can work to perpetuate oppression of people with mental illness in the criminal justice system.

How clinicians and review boards construct narratives around risk is still relatively uncharted territory from a research perspective, yet these constructions carry important consequences for individuals in the system, i.e. conditional release, maintenance of the status quo, transfer to a more or less secure ward, and level of 
privilege assigned which directly impacts the treatment options available to a patient, among others (Bloom, Rogers, Manson, 1982; Manguno-Mire et al., 2007). Not an immediate consequence of PSRB hearings but still a consequence of the proceedings are issues of stigmatization for people diagnosed with mental illness. Ideas of dangerousness and unpredictability are strongly associated with such persons, which in turn has consequences for their ability to find jobs and housing, as well as the psychological internalization of prejudice and discrimination (Brown \& Bradley, 2002; Corrigan, 2000; Corrigan, Larson, \& Kuwabara, 2007; Corrigan et al., 2002; Corrigan, 2005, 2010; Corrigan, Watson, Byrne, \& Davis, 2005; Faulkner, Irving, Paglia-Boak, \& Adlaf, 2010; Hayward \& Bright, 1997; Hinshaw \& Dante, 2000; Link, Yang, Phelan, \& Collins, 2004; Muir, 2008; Nairn, 2007; Rowe, Kloos, Chinman, Davidson, \& Cross, 2001; Watson, Ottati, \& Corrigan, 2003).

There has been a paucity of research focused on this critical area of forensic psychiatry. Of the few available published studies, findings raise questions about the legal and scientific discourses invoked at hearings. In probing the relationship between risk assessment instruments and release decisions in a maximum security forensic facility, Zoe Hilton and Janet Simmons found that risk assessment scores did not correlate significantly with decisions made by the facilities tribunal board. Instead, and contrary to their expectations, decisions correlated most strongly $(r(154)=.84, p<.001)$ with the testimony of the senior clinician (2001). In a second study, Lisa Callahan \& Eric Silver report major differences between four states as to what factors are relevant in deciding which patients if any are conditionally released. They concluded that 
demographic variables such as gender, race, and level of education were a large part in determining conditional release of an individual, and that in some states variables such as diagnosis and dangerousness, as measured by seriousness of the crime, did not even enter into the decision making model (Callahan \& Silver, 1998).

There is a long history of legal proceedings influenced by covert biases around these categories and generalizations. With the emphasis on clinical testimony and the disparity in which variables are used in adjudication processes, it is vital to examine the different perspectives that come together in a PSRB hearing and which perspectives are acknowledged and given greater weight. This thesis will unpack the various perspectives that converge in a PSRB hearing and examine the narratives that are developed and deployed by sometimes opposing sides in the area of risk and risk assessment. The project seeks to answer the call for additional research on how clinical practices affect decision points of forensic patients and strives to further a community psychology agenda in examining multiple perspectives and emphasizing the voices of the participants.

\section{GEI Process}

The OSH is a psychiatric facility that first opened its doors in 1883. It currently holds people who have been found GEI as well as patients who have been civilly committed, and those who are undergoing evaluation to determine mental competency. As this thesis concentrates on the location of PSRB hearing, its focus is on people who have been entered the GEI plea, their processes, and their stories. In Oregon a person may be found GEI if, as a result of mental disease or defect, the person lacked substantial capacity to appreciate the criminality of their conduct or to conform their behavior to the 
requirements of the law (ORS $\S \S 161.295)$. Meaning that the person in question did not know what they were doing was wrong or could not control their actions because of effects of a mental illness. This plea is the doorway into the PSRB's jurisdiction and management. This review of literature traces the evolution of and various incarnations of what is often called the insanity defense, and how it is and has been informed by psychology.

Though every person treads a different path into and through the system, there is a general pattern to the process that most people go through. As the point of entry to the criminal justice system (CJS), a precipitating event occurs that leads to arrest. Once in the system a person can be held or released, depending on the severity of the crime and decision of the judge at the time, while they work with their attorney. Most cases do not go to trial. Instead the district attorney's office works with the defense attorney to establish "a deal" - options for a plea bargain. Should the person in question use a GEI defense that is accepted by the DA, that person comes under the jurisdiction of the PSRB and goes to the OSH (Bloom, Rogers, \& Manson, 1982; Rogers, Bloom, \& Manson, 1986). Once there, the PSRB holds a hearing to determine if the person should stay in the hospital or be moved to a secure/non-secure residential treatment facility, or be released to independent living. After this initial hearing, a person has a mandatory review hearing by the PSRB every 2 years. Additionally a person may request a hearing of the PSRB board for a variety of different reasons, e.g., to apply for conditional release or step down in security level, or to request a higher level of privilege. The PSRB must 
hold a hearing within 60 days of this request (Bloom, Rogers, \& Manson, 1982; Rogers, Bloom, \& Manson, 1986).

The PSRB board was formed in order to supervise persons who have been found GEI. This was Oregon's response to debates over whether people with mental illness should be responded to as criminals or treated as patients; the PSRB rides the border between the mental health system and the CJS. It is a five member board consisting of a lawyer, a psychiatrist, a licensed psychologist, a parole or probation expert, and a member of the general public. Positions are filled by gubernatorial appointment for a period of four years and are part-time positions (Rogers, Bloom, Manson, 1986). The board meets regularly and holds hearings in which to address cases on an individual basis; these consist of the afore mentioned two year reviews and "hearings upon any application for discharge, conditional release, commitment or modification filed" (ORS $\S \S 161.346(1))$. In addition, we have observed that patients also come before the board to review and obtain approval for conditional release plans. Patients have a right to be present at all hearings (ORS $\S 161.346(6)$ (a)) and to have legal representation which may be appointed by the board should the person in question meet financial qualification (ORS §§ 161.346 (6) (b); (11)).

With these and other components of the Oregon Revised Statutes delineating procedures and policies of the PSRB and patient rights, hearings have a specific structure in which events unfold. There are generally four components of each hearing; the members of the PSRB Board, the patient and his or her legal representative, the State in the form of a District Attorney or Assistant DA, and finally the witnesses called to testify. 
Witnesses can be anyone the patient, represented by his or her lawyer, or state feels has information relevant to or that can support the case being made or refuted. In our observations of hearings we noted that the majority of witnesses called were clinicians or mental health professionals, though we did note that a few family members were called as well. Clinicians were often called upon to interpret reams of information that accompany patients in these hearings. In reviewing files of past PSRB hearings, the sheer volume of paperwork and information that is submitted as evidence is tremendous. Also available are patients past histories with mental health services and the CJS. Given previous findings of the importance of clinician testimony to hearing outcomes, it is important to examine the setting and process of how these narratives occur.

Although state statues offer descriptions of PSRB rules and roles, this thesis looks at how these procedures are put into practice. Outlining the procedures and analyzing the kinds of questions asked of witnesses, as well as the types of evidence clinicians are asked to pay more or less attention to, can lead to a deeper understanding of the hearing progression. These outlines will result in a timeline of the procedure that, in addition to thematic analysis, will indicate which perspectives are given greater or less attention by the deciding board, indicating those aspects of a patient's case and history that are given greater emphasis.

\section{The Study}

This thesis examines a portion of the system that is a key juncture for patients and one that characterizes this intersection of the mental health system and the CJS in the form of PSRB hearings. These hearings are the site where the forces of the State, patient 
perspectives, and mental health practitioner perspectives converge and which culminate in a final decision made by the PSRB. As such each perspective will be analyzed and explored in and of themselves through thematic content analysis of interviews collected, followed by an analysis of each in the context of a PSRB hearing. In addition the hearings themselves will be outlined to explicate the ritualized patterns that have developed over time in accordance with the governmental mandates by which each hearing is run. Working from the basis of the GEI documentary project, over 40 interviews have been collected to inform us of the public drama of these hearings. This project will use audio recordings of seven different hearings, interviews of three individuals that are associated with a hearing of the PSRB and portions of the paperwork admitted in the same hearing to begin to answer the following three research questions through the lens of critical realism (Sims-Schouten, Riley, \& Willig, 2007).

1. Are there identifiable prototypical narratives of risk that are constructed around evidence admitted to a hearing in addition to the three previously identified?

2a. Are these risk narratives deployed differently in public PSRB hearing as opposed to an individual interview?

2b. Do the District Attorney, Defense Attorney, and clinician deploy risk narratives differently?

3. As professionals that create, administer, and interpret risk assessment, how do clinicians use risk narratives to support or refute the arguments of each side? Coming from a mix of realism and constructionist paradigms, the theory of critical realism acknowledges both the ways individuals make meaning of their 
experience and the ways in which broader social context impacts on those meanings. The advantages of using this lens in this project are twofold. First, it recognizes that meaning is constructed in the interactions between individuals, primarily using language. However, it also recognizes that non-discursive elements are of equal importance (SimsSchouten, Riley, \& Willig, 2007; Willig 1999). Social mechanisms that are independent of individual thought and meaning-making processes affect the meanings created. This allows me to bring in a Foucaultian perspective in analyzing data in order to acknowledge structures of power that are inherent in any system, and that often these power structures are obscured by the dominant ideologies.

Also important to state is that I come from a community psychology (CP) background. This research is not undertaken solely to further the gathering and collection of information, but instead is approached with the idea that power structures often work to oppress and marginalize groups of people (Nelson \& Prilleltensky, 2010). An understanding of how such structures work to oppress some and lift others is important in order to appreciate avenues of change with full comprehension of progressive and regressive aspects of actions taken. This thesis is the beginning of such a process. Also made clear in a CP perspective is a solicitation of multiple viewpoints from groups and people involved in the phenomena of interest, particularly from marginalized groups. I believe we have accomplished that with this project, emphasizing the voices of the participants themselves in the use of unstructured interviews of people associated with many aspects of the mental health system, the CJS, patients, families, and members of the community. 


\section{Literature Review}

The literature review that follows describes the historical and present context in which this project is situated, followed by a discussion of theory that has informed the project's foundation. The first section contains a history of the insanity defense and its interaction with psychology over time along with a description of where it stands now as what is termed a Guilty but Mentally Ill (GBMI) or Guilty Except for Insanity (GEI) plea. This includes an account of several key cases that affected the insanity defense and leads into a description of the Tarasoff case, which brought risk assessment of violence to the forefront of psychological research, particularly since the case established legal liability of mental health professionals in their duty to warn potential victims of violence. This case spurred further research on risk assessment. After describing the insanity defense, I focus on the history of risk assessment, paying close attention to the ways in which these instruments have developed and changed. This is important because an examination of the creation and revision of such tools exemplifies what is central to the field, particularly in the aim of better prediction of behavior. These instruments also work to define risk itself as measured in the mental health field. Tracking its development over time as each instrument is created, critiqued, and replaced can provide insight into understanding risk. The short term assessment of risk and treatability (START) is then described from its inception and as is this method of assessment is implemented at the Oregon State Hospital (OSH).

This section on theory follows Michel Foucault's tracing of power as it moved from a more individually focused sovereign based form to a more diffuse populace based. 
This line of argument focuses on how professional expertise, in this instance psychological expertise, developed as a function of and in support of the system of power. Risk assessment instruments are discussed as a part of the current functional apparatus of the professional system of clinical expertise within the context of the criminal justice system. The theoretical framework lays the basis for an examination of psychiatric stigma and the role of professional expertise in rationalizing stigma. Finally, the actual risk of people diagnosed with mental illness is discussed in terms of comparative risks in relation to the general population.

\section{History of the Insanity Defense}

Risk assessment in the adjudication of GEI cases emerges out of a complex history of interactions between psychology and the criminal justice system. Criteria for the insanity defense have changed extensively over the course of history. This review follows the permutations of this defense and its many definitions over time in the United States and concludes with an explanation of the current federal definition of insanity. I focus on the major changes to the concept of the insanity defense that have occurred, beginning in the United Kingdom, where much of the United States court system and legal definitions originated, followed by changes in the U.S. and how these affect and are affected by psychology. These changes are relevant to the current project as they demonstrate the position of people with mental illness in the criminal justice system and how attitudes toward them have changed over time.

Insanity is not a psychological term, but rather a legal one. As such, each jurisdiction, which in the United States denotes individual states, has its own definition 
for what insane means. In Oregon, a version of American Law Institute's Model Penal Code Test is used. This will be discussed in greater detail and in relation to the changes it brought to previous methods that judged mental capacity.

Originally, tests for insanity that involved criminal courts were centered on the idea of decreased mental capacity characterized by comparisons to wild beasts (Robin, 1997). Defendants were compared to wild beasts and should their mental capacity be no greater than such, they were found insane (Robin, 1997). Donald Lunde explains that this test assumes that the judges and jurors had an understanding of the mental workings of a wild beast, and thus had no need for a large and complex body of evidence (1975). Here, as Gerald Robin explains, the burden of decision was considered to be one of commonsense carried out in large part by the judge and or jury. This definition of insanity held through the early 1800's where, through an assassination attempt and the subsequent trial, it became a separate verdict of acquittal entitled 'not guilty by reason of insanity' (Robin, 1997). That insanity became its own category and that it meant acquittal is important to note as indicative of how mental illness was thought of in this time frame and as a basis from which to observe future changes.

The next major change developed in the aftermath of another assassination attempt. The jury found Daniel McNaghten not guilty on the ground of insanity after his attempt on the current Prime Minister's life, and murder of his secretary (Robin 1997). This decision was met with outrage by both the public and the Queen of England, resulting in a review of the law and standards of the time. The McNaghten Rule, also called the right-wrong test of insanity, originated in this special session. This rule 
recognized the defendant's ability to determine whether a behavior was right or wrong as the central deciding factor in establishing a defense based on insanity. Here the role of professional in the court system became much more explicit. Psychologists were required to testify on the actions of the defendant and establish a body of evidence based on expertise; there were no more wild animal comparisons and a greater emphasis on empiricism with corresponding demonstration of proof. Though Daniel McNaghton was found not guilty, he was still incarcerated. It was not the punishment that the public objected to, but the label of not guilty. So much attention was focused on this verdict that few knew or cared about what actually ended up happening to him. In response to critiques of this rule, which argued that people with mental illness may know very well what they are doing is wrong but be unable to control their behavior, many states included an 'irresistible impulse' or control or volitional test with some recognizing this as another basis of insanity (Robin 1997; Lunde, 1975). This last has also come in for its share of criticism from prosecutorial perspectives, according to Robin. Foremost among their opposition are the arguments that people rarely have a "complete inability to resist committing a crime", that there is great difficulty distinguishing between impulses that are a result of mental disease and those that come from ordinary temptation, they exonerate too many defendants, and finally that it undermines the "doctrine of free will, a cornerstone of criminal law" (Robin 1997, pg. 228).

Under the McNaghten Rule, many psychologists expressed discomfort that their testimony to the court needed to include what they termed a moral judgment (Robin, 1997; Zeifert, 1957). The Durham Rule was enacted in 1954 to address this issue as well 
as a feeling in the legal system that the McNaghten Rule was archaic and narrow minded in its conceptualization of mental illness. Specifically it established a broader test, also called the 'product test', that stated "an accused is not criminally responsible if his unlawful act was the product of mental disease or defect" (Bazelon, 1954 as cited in Slovenko, 2009). According to Robin, the intent of this new rule was to create better communication between courts and expert witnesses by reformulating the insanity defense to be more compatible with the mental health field and to increase the number of people eligible to use the defense (1997). An important consequence of the Durham Rule was the codification of and shift of burden of proof; here should the defense introduce "some evidence of mental illness" it became the responsibility of the prosecution to prove sanity beyond a reasonable doubt (Robin, 1997).

Though the Durham Rule was meant to solve the problems of the McNaghten Rule, it was not without troubles of its own. Cited as a primary problem of the Durham Rule, psychiatrists and psychologists ultimately had a strong influence on the outcome of trials without any systems of checks and balances (Arens, 1967; Robin, 1997). Arens describes testimony given in favor and against the sanity by those with little or no clinical knowledge of the particular defendant (1967). When this occurs, Arens argues, the mental health professional appropriates the jury's role in deciding the criminal responsibility of the defendant (1967). As courts became more sophisticated in their use of the Durham Rule, courtrooms also became the arena of battling psychologists. Both sides would offer expert testimony for or against the sanity of the defendant; juries would then need to decide which psychologist to believe rather than the merits of the case. 
As the Durham Rule was proving unworkable in actual usage, the American Law Institute developed the Model Penal Code (ALI). This code went back to the McNaghten Rule and modified it by adding two principle advancements which added to the courts ability to determine criminal responsibility (Johnson, 1985; Robin, 1997; Weihofen, 1967). The first "excused anyone who lacked substantial capacity to appreciate the criminality of his conduct" ( $\mathrm{p} 222,1985)$; Johnson explains the use of the above quote as clarifying that the defendant need not be completely unaware of the criminality of his or her act. A defendant might know that something was wrong on one level, yet still commit the act, and this knowledge would not preclude the use of an insanity defense (1985). Robin refers to this statement as an acknowledgement that there are "gradations of criminal responsibility", with total impairment not a necessitating factor for absolution of responsibility (1997 pg. 230). The second advancement was in the addition of a volitional component to the ALI code, "substantial capacity to conform his conduct to the requirements of law" was the terminology introduced (Johnson, 1985; Weihofen, 1967). In other words, people who cannot control their own behavior are not criminally responsible for their actions. Critics here decried the reversion to an older model, and claimed that this made it easier for malingerers to exploit the system.

Another assassination attempt, this time on President Ronald Reagan, was the spark that ignited another round of debates around the insanity defense. John Hinckley was acquitted on all counts in 1981, as the jury found him to be insane by the standards of the ALI test (Johnson, 1985). This next round of debates had two consequences that are relevant here. First, states began to pass legislature creating a new category for the 
courts, Guilty but Mentally Insane. These verdicts allowed that a defendant may have been acting under the influence of mental illness, with the inability to determine right from wrong and/or the inability to control ones actions, but still be criminally responsible for those actions (Robin, 1997). This trend took hold after the Hinckley verdict, and gained even more states as converts after the Insanity Defense Reform Act (IDRA) of 1984, the second consequence of the Hinckley verdict (Robin, 1997). The IDRA removed the volitional component of the ALI code, leaving only the cognitive component where only those who "as a result of severe mental disease or defect, were unable to appreciate the nature and quality of wrongfulness of his acts" are able to use the insanity defense (Robin, 1997). Important to note as well, is that the burden of proof was shifted to the defense. It is now the defendant's responsibility to prove that he or she is suffering from mental disease or defect and that this defect left them unable to tell right from wrong.

The IDRA is the current legislation that is used to define the insanity defense federally. Most states, including Oregon, have adopted the federal government's lead and shifted the burden of proof to the defendant while creating a new category of Guilty but Mentally Insane; in Oregon Guilty Except for Insanity (GEI). This classification has had some profound effects on the CJS in putting the burden of proof for mental illness on the defense, requiring them to call up testimony of experts and prove a specific diagnosis; and although confinement was often the consequence previous to this legislative act, it now became the official rule. Persons who have used the GEI plea are under the jurisdiction of the Psychiatric Security Review Board (PSRB), the governing board that 
has jurisdiction over all persons found GEI in Oregon, and generally placed in the Oregon State Hospital OSH, the state's primary forensic facility or an associated residential treatment facility. Here the person, now identified as a patient, is to be given and participate in treatment that is determined by a treatment team while simultaneously being held to ensure the safety of the public.

It is important to further clarify the role and responsibilities of the mental health expert in the criminal justice system. Psychologists are often called up in their roles as experts in mental health issues to, among other things, testify in trial, assess the mental health status of people accused of crime, and assess the risk of violence or danger associated with a person. These assessments of risk have long been a part of the role of the expert, however, research and development of risk assessment gained new importance after the Tarasoff v. Regents of the University of California (1976) case as it broadened the scope of responsibility treating psychologists had toward their patients and third parties. This case linked the mental health professional to the consequences of their risk assessment by delineating the level of responsibility they had to people who may be harmed by future violent behavior of a client.

The Tarasoff case brought risk assessment to the attention of the research community who embraced the development of such measures wholeheartedly and with empirical fervor. In the case, a graduate student attending the UC Berkeley, Prosenjit Poddar, began seeing a psychologist after being rejected by a woman, Tarasoff. The patient expressed his obsession with her, and his intention to kill her upon her return from an international trip. The psychologist in question notified the police verbally and in writing 
about Poddars' statements and requested he be held and evaluated. After being picked up and held briefly, Poddar was then released as "he seemed rational" (Tarasoff v. Regents, 1976). The head of the department of psychology then directed that all copies of the letter to the police be destroyed and that no action should be taken against Poddar in the future. Two months after that, Tarasoff returned home, and Poddar killed her.

The parents of Tarasoff later sued the UC, stating that the mental health professionals in question had a duty not only to notify the police, but to notify the individual at risk and her family. The courts released the police from responsibility, but held the psychiatrists accountable; saying that they should have notified the individual at risk of harm from the client. Thus mental health professionals have a legal responsibility to assess the risk of violence associated with each client, define the context, and to monitor changes in the client and context (Haggård-Grann, 2007; Heilbrun et al., 1997; Steadman et al., 1994). This focus on predicting violence on the part of clinicians and the relationship between mental health professionals and the courts in the form of NGRI or GEI, are contributing elements to the development of instruments that assess risk.

\section{Risk Assessment Instruments}

The focus of this study is perspectives on risk assessment as used by mental health professionals on people with mental illness who have been convicted GEI in Oregon. This next section defines what a risk assessment is and outlines the incarnations of assessments as they have been used in the mental health context from clinical judgments through structured clinical judgments. As each method of assessment is discussed, specific critiques are explored leading to a more general critique of risk 
assessment as a whole. This is followed by a more thorough exploration of one specific method, Short Term Assessment of Risk and Treatability (START), a structured clinical judgment that is the current method of choice at the Oregon State Hospital.

Risk assessment is an area of psychology that includes, according to Borum (1999), instruments that produce probabilistic estimates of a continuous variable, in this case violence, based on person-based and situational variables. Controversies around methods of prediction have existed for 70 plus years. Traditionally the battle has been between clinical methods of judgment and statistical methods of prediction. With events like Hinckley's acquittal and the Tarasoff case spurring research forward, these debates have been revived though in a somewhat different form. The following section delineates the evolution of risk assessment in forensic locations through clinical judgments, actuarial approaches, structured clinical judgments, and outlines calls for alternative ways of understanding. Critiques of approaches to risk assessment are discussed as each method gains empirical legitimacy in psychological research.

Clinical judgments were the method of choice as psychology developed and began to interact with the CJS. The clinical method, also called unstructured clinical judgments, is a method in which clinicians develop an understanding of the patient through interaction and gather information that they feel is relevant to the client and the context, then use an "informal or intuitive processes to combine and integrate client data" (Ægisdóttir et al, 2006, pg. 342) resulting in an evaluation of the potential risk of the client (Haggård-Grann, 2007). Though this method has been critiqued as inconsistent and non-rational (Mulvey \& Lidz, 1995), proponents of it consider it to be insightful and 
flexible. Clinicians are able to tailor their judgments to the particular situation, client's history, emotions, and environment (Skeem, Mulvey, \& Lidz, 2000). Robert Holt also defended this method against critics who derided clinical judgments as non-scientific by explaining that decisions were not based on feelings alone, but on sophisticated data that are "both qualitative and quantitative, have been gathered in a systematic manner, and have known relationships with what is being predicted" (as cited in Ægisdóttir et al, 2006, pg. 344).

Despite multiple supporters over the years the majority of studies have indicated through box-score reviews and other variants of meta-analysis that actuarial assessments, defined below, tend to have greater predictive accuracy than clinical Methods (Grove et al., 2000). As the above review of the history of psychological participation in the courts has shown in critiques of the Durham rule, expert testimony has often contradicted itself resulting in criticism and concern that mental health professionals cannot clinically assess dangerousness accurately (Monahan, 1984). Given the past history of conflict in the witness stand among different psychologists, many CJS/legal systems since the 1970's and 80 's require assessments to be empirically validated and structured in order to be admissible as evidence in court (Andrews, 1989; Grann \& Långström, 2007). One result of such constraint is that unstructured clinical judgments were replaced in many areas by Statistical, often called actuarial assessments. Though there are a number of variations on the theme, in general actuarial assessments are systematic and numerical in nature. Grann and Långström describe a typical actuarial assessment as comprised of risk factors generally found by empirical testing and or previous literature (2007). These factors are 
scored by a mental health professional as present or not, and to a lesser or higher degree, then collated to a total score that indicates how high the level of risk is associated with the individual in question (Grann \& Långström, 2007). The variations are a result of the types of risk factors included and in the method of scoring used. However, actuarial assessments of risk for the population in general have not been found to be very accurate (Coid et al., 2011; Haggaard-Grann, 2007; Kroner, 2005; Monahan, 1984; Mulvey \& Lidz, 1995; Skeem, 2000; Skeem \& Monahan, 2011; Webster, Nicholls, Martin, Desmarais, \& Brink, 2006), which has resulted in assessments being developed for groups of people that share common characteristics; for example, youth, sexual offenders, and people with mental illness. Depending on the groups in question, different risk factors are said to be of greater or lesser salience and lead to greater accuracy (Banks et al., 2011; Singh, Grann, Fazel, 2011).

A major critique of actuarial techniques is that the risk factors used are static and historically based (Banks et. al 2011; Skeem \& Monahan, 2011; Coid et. al., 2011; Grann \& Langstrom, 2007). As such they are not subject to change nor can treatment or change of circumstance or environment be factored in. This lack of change in the risk factors used in creating a final risk assessment score results in a score that itself cannot change, no matter the type or quality of change in a person. An underlying assumption of this method of assessment is that people do not change; the overall score of predictive risk stays the same. Another critique of this method is that factors that are empirically validated for large groups of people may not be as valid for individuals (Cooke \& Michie, 2010). Many of the studies done on large groups have of necessity been based on 
relatively homogeneous populations, largely consisting of men, primarily white, and often, as in the case of the MacArthur Study, civilly committed. Researchers also cite a growing awareness of the need to focus on risk management rather than risk prediction (Nonstad et al., 2010). In other words, using knowledge gained through research about the factors that both promote and prohibit future violence in order to prevent this violence from happening.

As part of this next step in development of assessment tools, researchers have attempted to integrate the positives of clinical methods into actuarial tools, called structured clinical judgments. These instruments work to integrate biological, social, and cultural factors where they intersect with the individual over time in the form of more dynamic factors rather than static or historical (Nicholls, Brink, Desmarais, Webster, Martin, 2006; Skeem \& Monahan, 2011; Webster, Nicholls, Martin, Desmarais, \& Brink, 2006). The Short Term Assessment of Risk and Treatability (START), is one such structured clinical judgment and is the instrument currently in use at the OSH.

\section{Short Term Assessment of Risk and Treatability.}

Christopher Webster et al. reports on the origins and premise behind START as developed in a minimum security forensic institution where the previous risk assessment instrument was of necessity discarded (2006). The staff and administration recognized the need for a replacement and initiated a discussion on that topic in weekly team meetings. A registered nurse, on staff and part of the weekly meetings, compiled a list of possible factors from her own experience and experiences solicited from colleagues. A working group was established consisting of the $\mathrm{RN}$ who originated the list, a 
psychologist, a clinical nurse specialist, and a mental health researcher (Webster et al. 2006). This group along with their fellows created an instrument and worked with it over time as it evolved through their experiences and changing definitions. Eventually the group broadened to include all disciples and the administration. Many, if not all, of the assessments created so far under the label of structured clinical judgments focused on maintaining safety for the community at large and third parties; not taking into account the clients themselves. START methodology changed that by including risk of self-harm in the outcome of the assessment. The health professionals who developed the START project tried to examine both perspectives, that of the community and of the individual patient, thus they included the concept of treatability, and, at the insistence of the nursing staff, included strengths of each individual evaluated on par with the risks or weaknesses traditionally measured. This helped broaden START into an instrument that was more in keeping with the larger risk management paradigm, and also added some measure of flexibility into the system to account for factors unique to each individual or environment. There is also a space that includes risks that may be specific to the situation and client in addition to the seven already listed in the instrument; suicide, selfharm, being victimized, unauthorized leave, substance abuse, self-neglect, and violence against others (Webster et al., 2006).

A structured clinical judgment is the amalgamation of an actuarial method and a clinical one where the clinical judgment is based on researched, developed, and well defined factors. In START this was achieved by the addition of multiple evaluative factors and an emphasis on risk management as well as risk assessment. This was done 
by developing an instrument that not only predicts future risk, but also strives to reduce it. The patients in question are not only considered as risks or the source of dangerousness, but as vulnerable to risk themselves. This is indicated by the inclusion of victimization within the measure, as well as the focus on treatability. Treatability shows an interest in going beyond measuring dangerousness to determining how best to treat the person within the specific situation. Lastly, by including dynamic factors that can be measured as strengths as well as weaknesses, and by allowing change and flexibility to be a part of the instrument, its creators endeavored to include the treatment itself as a catalyst to enact change to the risk assessment values assigned to their patients.

As START is a fairly recent development in Risk assessment the research on its predictive validity is sparse. Preliminary research though, suggests that it is a good tool for prediction, however, it is important to remember that under the aegis of the creators of START, prediction is not the end result of the instrument, but part of a greater risk management paradigm (Nonstad et al., 2010). That being said, the first study separated out both the strength and the weaknesses portions of the instrument and assessed them separately. Participants $(\mathrm{N}=61)$ were sentenced to mandatory psychiatric care and housed in a high security unit in Norway; multiple assessments were conducted on each participant at multiple time points during a 9 month period of time. Receiver Operator Characteristic (ROC) analysis resulted in an Area Under the Curve (AUC) statistic of .77, $p<.001$ for vulnerability and an AUC statistic of .77, $p<.001$ for strengths (Nonstad et al., 2010). ROC analysis is used to evaluate the predictive validity of a psychological instrument and results in AUC statistics which represent the probability of randomly 
selecting an individual who exhibits the target behavior of violence given higher vulnerability scores and lower strength scores on the START compared to a person who is not violent. In reading AUC scores, .5 represents a finding equal to chance, and 1.0 represents a perfect prediction. An AUC score of . 77 indicates predictive accuracy significantly higher than chance for the sample in question. The second study found an AUC of .66, $p<.001$ for vulnerabilities and .65, $p<.05$ for strengths (Braithwaite et al., 2010). Here the study was longitudinal over 2 years with participants situated in a Risk Management and Rehabilitation Center unit of a civil psychiatric hospital in Canada. Both studies indicate positive results for the predictive validity of START over the short term, 1-3 months and in mental health facilities according to the standards of acceptability currently in the literature.

\section{Critiques of Risk Assessment}

The critiques briefly discussed above are model or instrument specific. This section addresses larger issues in risk assessment. Richard Rogers notes the overwhelming positivity of the literature surrounding risk assessment in psychology and as he calls it the "prizing" of risk factors over protective factors (2000). Though the START includes a way to incorporate strengths, it is one of the few assessments that does so. This focus on risk factors and assignment of an actual numerical value of risk on to individuals "creates unwarranted perceptions of violence and may evoke detrimental countertransference" (Rogers, 2000, pg. 598). In this instance the constant focus on negativity along with attention on historical factors promotes an image of chronic and irreversible dangerousness that can contribute to client stigmatization; this relationship is 
addressed in further detail below. Additionally, risk-only assessments in criminal systems can lead to skewed resource allocation where forensic patients, though often higher functioning than non-forensic inmates who also suffer from mental illness are allocated more resources in the mental health system than non-forensic patients (Rogers, 2000). A study by Linhorst \& Dirk-Linhorst examined levels of functioning in both groups (forensic and non-forensic) and found that often forensic patients in Missouri tend to be higher functioning, with $26.1 \%$ having mild or no symptoms, while non-forensic patients tend to be more assaultive (1997). However, with a criminal history as a historical risk factor, forensic patients were much less likely to be placed in the community, leaving fewer beds for non-forensic placements in the long term state psychiatric facilities regardless of level of need (Rogers, 2000; Lindhorst \& DirkLindhorst, 1997).

Another critique of assessment is the poor interpretation of results. Assessment instruments do not give comprehensive case studies of individuals, instead the outcome is a dichotomous outcome of violent or not, a percentage of prediction of violence, or score on a scale of violence. These can be easily misinterpreted by juries, judges, lay-persons, attorneys, and mental health professionals not adequately trained in reading results. This misinterpretation can and does occur even when the results are clearly explained to parties in question, and can have severe repercussions in the courtroom and in the forensic setting (Rogers, 2000).

An additional critique of current risk assessment instruments that is a cause for debate is whether or not assessments empirically created for groups, are useful for people 
on an individual level. Risk factors are empirically derived from aggregate data on large groups of people. Though these factors are significant, Hart, Michie, and Cooke argue that future predictions of risk literally cannot be achieved in the case of the individual as the margins for error on the individual level are so very wide (2007). Though this argument has some validity given the dichotomous nature of the outcome variables in risk assessment, the general view is that group data can still be highly informative when making predictions on an individual level in that a large amount of data are available on behavior as correlated with characteristics and group membership (Skeem \& Monahan, 2011).

The final critique that I draw upon here is delineated by Mulvey \& Lidz (1995) as they question a basic assumption of risk assessment - that dangerousness is a key concern for mental health professionals. Though multiple sources, including researchers, mental health professionals, and legal theorists, argue that the dangerousness standard is inappropriate for use in the court system with people who have mental illness, it has become a standard for use in most states (Mulvey \& Lidz, 1995). Under this standard it has become the requirement, often court mandated or a required part of the system, that mental health professional's judge who is and who is not dangerous. Though there has been critique in the past, it has not stopped the standardization of this aspect of assessment from gaining legitimacy in the system, which allows many psychologists who work within the CJS to implement these instruments and the consequences of them without questioning the instruments or the underlying system that supports them. This increase in mandated risk assessment increases the urgency with which research on the 
impact of these instruments is needed and, I argue, from the perspectives of those who implement these assessments on a daily basis, and especially from the perspective of those most affected by the assessments; the patients.

\section{Theoretical Underpinnings of Power and Knowledge}

Risk assessment instruments are a well-researched and accepted part of psychology in general and forensic psychology specifically that has highly impactful consequences on an already marginalized group of people. In learning about such assessments from the point of view of community psychology, it became obvious that the perspectives and ways in which this concept is explored and researched are remarkably one sided. Research has focused strongly on more and better ways to improve predictive validity with the experiences and needs of the administrators of assessments a primary motivator of change. Though assessments like START are beginning to look at risk from the perspectives of the patient as well as those of the public, it is still the voices of administrators, nurses, and researchers etc. that are being solicited and heard. As community standpoints have taught us, when a vulnerable group is being researched, assessed, and or otherwise measured it is vital that we work to hear and understand their perspective and also seek to examine and understand the dynamics of power that help to keep this group on the edges of society. In the quest to understand the relationship between psychology, mental illness, and the criminal justice system there is no better place to start than with Michel Foucault (1977)and his treatise of the complex and intertwined links at work here. Examining how the current system evolved helps us to see what is often hidden, and allows us to ask questions of a more critical nature. 


\section{Power}

In his writing, Foucault (1977) traces the shift of power from a sovereign form of government to governance 'by the people' or disciplinarity, as Foucault calls it, through the use of social control (Foucault, 1977). Derek Hook (2007), a social psychologist strongly influenced by Foucault informs this analysis in his break down and description of power and knowledge in the mental health system. I use the term 'by the people' loosely to indicate governance by groups of people who are said to represent the people of the nation. In Foucault's description of historical movement and echoed by Hook's later analysis, humanist activists protested the extreme forms of power held solely by one individual who was at once an individual and the bodily representation of the nation. Also protested were the extreme forms of punishment used by the sovereign on the bodies of those who were deemed criminal. These punishments, brutal in nature, are described by Hook as incomplete, as "not saturating all possible spaces of illegality" (2007, pg. 9). The crimes that were deemed punishable were those that were dramatic in nature, but as Hook emphasizes, there were many areas of illegality that were not covered by the current system. This focus on violent punishment was needed to enforce a sovereign structure of power, as the shift to disciplinarity occurred, the need for violent spectacle lessened; the humanistic argument that accompanied this shift argued that punishment was justified only by the role it played in preventing repetition of a crime (Hook, 2007). Also with the shift to disciplinarity came a broadening of definitions of criminality needed to enforce a new system of control. The safety of the people became paramount, criminal behavior became an offense not to the sovereign but to the people. 
The importance of deterrence and correction rather than punishment alone, helped to move the emphasis from violent bodily harm to rehabilitation (or not) of the mind or soul of the individual (Foucault, 1977). This set the stage for individualization, objectification and as Hook calls it, a quasi-psychological attention to problematic souls or minds (2007). This change in thinking is characteristic of modern forms of discipline and has led to people being grouped into objectifying categories' for example criminal, or criminally insane. These categories then become the basis by which mental health experts both learn about and predict the behavior of individuals.

The consequences of this shift in power were more acceptable as they followed the humanist line of reasoning of equity and ethics. But accompanying these progressive aspects were regressive consequences outlined by Foucault; that of power rendered more effective and more constant yet less and less obvious than the previous brutal demonstrations of sovereign power (1977). This form of power was more effective, more constant than before and "enabled the insertion of power ever more deeply into the social body" (Foucault, 1977, pg. 82). The level of individualization and this hidden form of power gives the illusion of individual agency that is vital to the legitimacy of the power structure. Much of the system of rules and mores that is set in place by the system of power is taken as a given and not questioned. Individuals believe in this promise and much of the consequences of the systems power are attributed to individual level factors, even though the centers of authority and control reside in levels far from the individual.

The development of psychology as a science grew with modern evolutions of justice and ideas of criminality. Foucault's knowledge-power loop can be seen in how 
much of psychologies research in this area has focused on the justification and use of categories of people and in tinkering with the assessment instruments themselves rather than questioning their use. Knowledge produced by the experts that are immersed in the system that supports them, again in ways that are not always obvious. In the case of risk assessment this has resulted in the continued development of each type of instrument clinical, actuarial, structured clinical judgment as described previously, and the continued tinkering of these tools to improve the predictive validity of each. We can see that these measures also reinforce modern power structures in continuing the use of objectifying categories. Assessments are not used for people in general, but are focused on groups of people based on categories like youth, criminality, mental illness etc. In fact, the very best of these instruments, i.e. those that have the greatest predictive validity, are narrowly directed toward the above mentioned groups. The development of psychology as a science simultaneous with the modern criminal justice system has resulted in "a corpus of knowledge, techniques, scientific discourse [being] formed and becoming entangled with the practice of the power to punish" (Foucault, 1977, p. 23). Psychology needed the legitimacy of the CJS in order to establish itself as a relevant science while the CJS also needs scientific legitimacy, not to establish itself but rather to create rules both written and not that are accepted as given, as unquestioned. Courts still mandate today that a risk assessment be given that are well established and backed by empiricism. These tests establish the measure of dangerousness that can be applied to an individual. As Derek Hook states in describing the inevitable proliferation of professionalism in this modern system, "The rights of punishment and modification in disciplinary times are entrusted 
only to the most suitable authorities and specialists" (2007, p. 18). Meaning that the spread of more systematic forms of power are matched and supported by a new type of professional agent of power, here the psychologist or clinician. An agent who carries the expertise on decisions of mental illness, danger, competency etc. which strongly affects the ability of the CJS to make decisions on the part of that person and the decisions themselves. This focus on the individual and his or her abnormality in connection with a criminal offense and mental illness places that blame in the individual and points to the moral deviance in the person, not the person's position in the overall system. Though the newer structured clinical judgments do try to include more dynamic and contextual factors, they are still embedded in a system that holds the focus on the person and their mental illness and responsibility for recovery.

Foucault discusses the total power used and needed by the disciplinary agent and uses the asylum as an example, with the psychiatrist at the head of the asylum having final say over issues of treatment and divorcing the individual entirely from his or her usual familial and societal domain in order to force a cure (1977). But here in Oregon the role of asylum director is taken by the PSRB, a governmental body that over and above the treatment team of the hospital has final authority over the body's captivity. As a result of the PSRB's role mental health professionals do not carry the final say in the decision process, the CJS in the form of the PSRB has jurisdiction over individuals who are found Guilty Except for Insane. The mental health professionals in the institution work to produce data that inform the decisions made by the PSRB. Risk assessment instruments are a part of the information taken into account. These assessments are 
themselves developed according to the aegis of the CJS and as part of its structure, part of a critique of such tools is discussed above, that they do not question and in fact reinforce basic ideas of non-normalcy and dangerousness ascribed to certain groups of people. In order to continue the status quo of ascendency held by these expert professionals, who in turn support the greater system of power, such instrument must be designed for reinforcement of these ideas. These instruments give scientific legitimacy to stereotypes that contribute to the objectification of people with mental illness as dangerous and unpredictable. This reinforcement of power structures on a governmental level also serves to maintain the power structure inherent in the "expert" label. It is a mutually reinforcing system that ultimately serves itself. Court systems give credence only to assessments that are done by credentialed experts and that have been researched and validated, and experts continue to tinker with these instruments to improve validity. However, what constitutes validity is something that is also decided by the experts and the system. Unsurprisingly research that questions the validity of these outcome variables (dangerousness, violence, etc.) has been met with intense defensiveness and interpreted as an attack on the rights and power of psychology in an attempt to deprive patients themselves of liberty or that such questioning will deprive patients of much needed treatment (Mulvey \& Lidz, 1995). These defenses and the assessments themselves strengthen the almost unquestionable scientific discourse that in part lends power to the decisions of the courts and increases the "rightness" of their actions in terms of punishment those who 'pose a danger to society as a whole'. Risk assessment 
instruments give an actual numerical value of dangerousness to individuals who have a mental illness.

\section{Stigma Surrounding Mental Illness}

According to Patrick Corrigan et al. stigma is a mechanism that supports the status quo, the current power structures in use $(2002,2004,2005)$. I first discuss stigma in general - what it is and what the consequences of stigma are for people on both sides of the stigmatized line. This is followed by a brief discussion of the general ways in which stigma is taught and transferred, then a more specific look at risk assessment and stigma including the role of mental health professionals in stigmatizing processes and as individuals who may also have stereotypical ideas. Last, I explain Corrigan's model of stigma and status quo as mentioned above.

\section{Definition and Consequences of Stigma.}

Erving Goffman described stigma as "an undesired difference" that is unexpected and can be an obvious mark easily observed or more hidden, with its existence marked by labels that can be self-identified or given by others (1963 pg. 5). In this paper I use a social cognitive definition that grew from Goffman's work and is widely accepted in stigma research today. Stier \& Hinshaw describe stigma as "a visible or concealable mark that is considered by the majority of a given social group to indicate deviance or immorality" (2007, pg. 107). Where the social cognitive comes in is in the breakdown of this definition as a process. Four cognitive structures comprise stigma: cues or signal, stereotypes, prejudice, and discrimination (Corrigan, 2007). A cue is the actual mark or label that indicates to another the inclusion of the individual in a stigmatized category. 
The stereotype is a characterization of the people included in the social group that are rigid and global (Stier \& Hinshaw, 2007). Arguments about the inherent nature of stereotypes in general abound, but for the purposes of this paper, they generally have negative connotations. Prejudices are attitudes that are definitively negative toward groups and are often held without full knowledge or in the face of contrary evidence (Hinshaw, 2000). Discrimination describes the treatment of one group differently from another and generally involves less access to opportunities or loss of rights (Stier \& Hinshaw, 2007). Stigma includes all of these components in sum or in part, and though much stigma research is focused on racial or ethnic minorities, here we will focus on people with mental illness.

The consequences of stigma for this group of people are many and greatly affect their lives. Corrigan gives three areas of impact specifically, label avoidance, blocked life goals, and self-stigma (2007). The first, label avoidance, indicates that people are aware of the stigmas surrounding mental illness, and will often avoid mental health care or only peripherally participate in treatment regimens once given. Research on avoidance of treatment has shown that people worry about what others will think of them or how they will be treated by others once labeled as a mental patient (Kessler et al. 2001). Further, endorsement of stigma was found to correlate with treatment compliance, where greater amounts of endorsement was associated with higher levels of discontinuation of treatment three months later (Sirey et al. 2001). Previous research has also shown that the stigma of mental illness has blocked people from opportunities in the job market, obtaining and keeping housing and in the quality of medical care received (Baillargeon, 
Hoge, \& Penn, 2010; Corrigan, 2000; Corrigan, et al., 2005; Corrigan, Watson, Byrne, \& Davis, 2005; Dear, 1992; Hayward \& Bright, 1997; Hinshaw \& Dante, 2000; Link, Yang, Phelan, \& Collins, 2004; Muir, 2008; Penn \& Martin, 1998; Stier \& Hinshaw, 2007). Self-stigma, the third area of impact, describes the process by which individuals believe the negative stereotypes that are attributed to themselves as members of a stigmatized group (Corrigan, 2007). These beliefs result in feeling less valued and can lead to thoughts and emotional reactions like shame, low self-esteem, expectations of stigma and diminished self-efficacy (Corrigan, 2007; Phelan \& Link, 1998). A meta-review that contained 45 articles relevant to self-stigma of those who have mental illness found a very strong negative relationship between internalized stigma and a broad number of psychosocial variables, including levels of hope, social-support, self-esteem, and selfefficacy (Livingston \& Boyd, 2010). Also of note is the positive association between internalized stigma and psychiatric symptom severity; the most studied variable of all included studies. Stigma affects those with mental illness in profound and deep ways both in their social interactions and in internal beliefs.

In discussing what stigma is and how it affects people with mental illness it is important that I discuss what stereotypes are typically associated with this group and the affects these ideas can have. Past research has shown that the common stereotypes associated with mental illness are dangerousness and unpredictability (Corrigan et al., 2002; Corrigan, Watson, Warpinski, \& Gracia, 2004; Cutcliffe \& Hannigan, 2001; Dear 1982; Link et al., 1999). Though many people do not consciously endorse stereotypes, implicit biases still work to influence behavior and attitudes and can lead to structural 
discrimination, where behavior is influenced by privately or unconsciously held beliefs but justified with more socially acceptable explanations (Stier \& Hinshaw, 2007). However, researchers also acknowledge that of the many groups that are stereotyped, belittling people with mental illness tends to remain more common and generally acceptable than expressing prejudice about some other groups (Stier \& Hinshaw, 2007).

These ideas of violence that are associated with people who have mental illness are promulgated often by the news media. In a study on how newspapers report topics of mental illness in the United States it was found that the largest category, 39\%, of stories involved dangerous criteria and were much more likely to be on the first page or front section, and a total of $25 \%$ were related to violent crime (Corrigan et al. 2005). The next highest category was treatment and recovery (26\%) followed by Advocacy (20\%) and Blame (15\%). These results have been replicated with both television and radio with percentage of dangerous narratives ranging from $30-62 \%$ and in countries outside of the U.S. including the UK, Scotland, and Whales among others (Cutcliffe \& Hannigan, 2001). Though negative attitudes about people with mental illness range back much further than the existence of modern news outlets, these already damaging views can be influenced further by links with more and greater levels of violence.

\section{Mental Health Profession and Stigma.}

As we can see from above examples, stigma has harmful consequences for people who have mental illness. Corrigan maintains that there are ways in which the mental health system and the people whose job it is to help may in fact be increasing levels of stigma. He argues that clinical diagnosis is one such way as the classification labels 
given individuals by mental health professionals can act as a cue that signals stereotypes. Further, the processes that help inform diagnosis, like group-ness and homogeneity of members, also work to increase stereotypes (2007b). Phelan and Link, in a study involving people who were civilly committed, meaning persons who have been committed to a psychiatric institution without their consent without having committed a crime, examined changes in public perception of dangerousness. They found that since 1950 the percentage of people who mentioned violence increased from 7.2 in 1950 to 12.1 in 1996 (1998). What was telling about this study was the increase of persons who used specific phrases that are present in legal criteria for commitment. This number increased from $4.2 \%$ in 1950 to $44.0 \%$ in 1996 (1998). Phelan and Link hypothesize that using dangerous criterion "injects a potent phrase into the culture that is connected specifically to mentally ill people, and that without knowledge that many psychiatric patients are hospitalized voluntarily, knowledge of the dangerousness criterion may lead people to the logical conclusion that psychiatric patients must be dangerous" (1998, pg. S10). I would contend that though this study focused on civilly committed patients alone, this trend may be just as true and possibly more so, for those who are incarcerated for committing an actual crime. I would also argue that in addition to clinical diagnosis, risk assessment of potential dangerousness or violence also increase stigma around people who have mental illness.

It is not only the general public that holds and enacts the components of stigma. Sometimes we forget that we as psychologists as well as other mental health professionals are also members of the public. It is just as important to look at the attitudes 
of these care providers as they often see people with mental illness in their most vulnerable or traumatic times; how mental health professionals view those with mental illness has significant effects on their treatment outcomes and quality of life (Wahl \& Aroesty-Cohen, 2010). Additionally, mental health professionals are educators and their attitudes influence their students (Gray, 2002). Though there is an idea that mental health professional's attitudes toward mental illness are all positive, this has not always proved to be the case. A review of 10 studies published in the late 90's to mid-2000's indicated that $75 \%$ of the studies showed that mental health care providers attitudes were the same as or more negative than the general public with reports from people with mental illness and their families "often include instances of disrespectful treatment and negative attitudes" (Schulze, 2007; Wahl \& Aroesty-Cohen 2010, pg. 2). Another later review looked at a more specific sample of psychiatrists, psychologists and psychiatric nurses specifically in the mental health disorder field and included more studies from 2004 and later. Otto Wahl and Eli Aroesty-Cohen (2010) found both positive and negative results. The majority of the studies returned overall positive results with professionals holding positive attitudes toward people with mental illness overall and in comparison with the public (2010). However, 26\% of the studies reviewed found the professionals held negative views including that people with mental illness were more dangerous, doubted the ability to recover, and should not marry or have children (Wahl \& Aroesty-Cohen 2010). Also important to note is that even in the studies that returned positive results, negative attitudes were present most especially in the area of dangerousness. These reviews of research on attitudes of mental health professionals show mixed results, which 
given the position and influence of this group of people is troubling. It shows that professionals and researchers need to expand the ways in which they think about stigma and pay greater attention to the attitudes and beliefs transmitted in training and in practice.

\section{System Justification Model.}

Corrigan, Watson, \& Ottati in a theoretical article examine the question of where mental illness stigma comes from. Where this is relevant to the current project is in the system justification model. It is the system justification model however, that goes beyond the individual and group models to assert that stigma confirms the system itself (Jost \& Banaji, 1994; Corrigan, Watson \& Ottati, 2003). “Once a set of events produces specific social relationships, whether by historical accident, biological derivation, public policy or individual intention, the resulting arrangements are explained and justified simply because they exist" with these justifications "evolving over time as a result of historic, economic, or social pressures" (Corrigan, Watson, \& Ottati, 2003, pg. 7-8). This argument corresponds well with the theoretical models put forth by Foucault and Hook (discussed above) of power that seeks to legitimize itself. The system of governance and discipline needs to be in place because of societies need for safety as people with mental illness are dangerous and unpredictable. That these institutions and laws exist suggests that this is a group of people that need to be controlled (Corrigan, Watson, \& Ottati, 2003), I add to this line of reasoning that as risk assessment instruments are part of the system, legally called for and required in many cases, and add to the implication that dangerousness and violence are characteristic of people with mental illness. 
In discussing the existence and justification of stereotypes of dangerousness for people who have mental illness it seems important to address the actual levels of danger or risk that this group of people poses. There are many studies that assert that people with severe mental illness have a greater likelihood of committing violent acts than people who do not have such labels (Monahan, 1992; Mulvey, 1994). Yet this higher association with violence is rather small statistically, and similar to risk levels associated with teenagers, men, and elementary school graduates (Link \& Phelan, 1999; Corrigan, Watson, \& Ottati, 2003). Link \& Phelan further add that risk of violence is generally limited to a specific set of individuals who are experiencing threat/control-override symptoms which can cause a person to misperceive a non-threatening situation as hazardous and react to it in a self-protective manner (1999). With the difference between average levels of violence amongst those with mental illness and those without being modest at best, the stereotypes of dangerousness as applied to all who have mental illness are greatly exaggerated and leads to stigma which as discussed above leads to harmful consequences in many areas.

\section{Courtroom Workgroup}

In projects, where the analysis is centered on legal proceedings it is important to acknowledge that the ritual nature of the hearings has developed over time in response to legal and human needs. In the interest of fairness and as our legal code has changed over time processes have been established to attempt to eliminate biases based on man-made categories, the effectiveness of these procedures it should be noted can be compromised by many aspects of the criminal justice system - most of which are not addressed in the 
current paper. What is of note is the effect of the courtroom workgroup on the findings of this project. According to James Eisenstein and colleagues (Eisenstein, Flemming, Nardulli, 1988; Eisenstein \& Jacob, 1977), courtroom workgroup consists of individuals who share a common workspace, interact in the performance of their jobs and who have a collective purpose that includes disposition of cases. Typically the courtroom work group consists of the prosecutors, defense attorneys, judges, and assorted other persons who work together on decision making processes. The initial studies Eisenstein and colleagues performed found that differential patterns of sentencing occur because courtroom work groups perceive cases differently and that the structure of each workgroup explains much of the variance in sentencing outcomes (Eisenstein et al., 1988).

Further research has shown that additional workgroup factors of similarity, proximity and stability affect decisions to incarcerate, imposition of fines and restitution (Haynes, Ruback \& Cusick, 2010). Similarity, as measured by demographic characteristics such as gender and race and personal characteristics like what law school/college attended and political party was found to affect punishment. The greater the similarity in a workgroup the lower the probability of incarceration or restitution being assigned to the defendant. Proximity was measured by physical closeness of relevant offices and was also associated with lower likelihood of incarceration but a greater probability of being assigned fines and restitution. Stability as measured by turnover was associated with lower probability of fines and restitution. These individuals share a workspace and continually interact in the performance of their jobs towards a 
common goal of disposition of cases. As such, interdependencies and common understandings develop which then influence sentencing decisions. Though PSRB hearings do not consist of the exact same players, roles and legal context are so similar that it is likely such a "courtroom workgroup" has developed around the disposition of GEI patients under the jurisdiction of the PSRB.

\section{Summary}

As the above literature review delineates through the changes in the insanity defense, the legal system has over time come to view people with mental illness with greater culpability. Rather than finding such a person not guilty with subsequent release, they are now found guilty and subject to incarceration for longer periods of time. This changed view of people with mental illness is reflected in the emphasis on violence and dangerousness in the courts insistence and reliance on assessments of risk. By the empirical nature and use of the scientific discourse, risk assessment instruments imply that people with mental illness are in fact more dangerous than the general public and contribute to existing stigma that surrounds the label of insanity. Inherent in the scientific discourse is the inference that this label of danger is not to be questioned, which contributes to the obfuscated relationship between the mental health profession and the system of laws and punishment that govern society's behavior. Also somewhat hidden is both a basic question and answer surrounding risk assessment, that of 'risk to whom?', the answer being the public, followed by the "necessary" confinement and separation of people with mental illness for the basic requirement of safety. This stigma of dangerousness as discussed above comes with severe and long lasting consequences for 
people with mental illness while simultaneously reinforcing both the position of and need for the professional and the system of power in place as shown in Corrigan's system justification model. 


\section{Methods}

\section{Overview}

This thesis is a part of a larger social action research project, described in greater detail below, that utilized secondary data collected for the original project to endeavor to understand how people understand the ideas of risk, perceptions of dangerousness, the instrument of risk assessment as well as what meanings assessment might carry that are not explicit in the scientific discourse that surrounds the concept. We used the forum of public hearings of the PSRB as the location where the forces surrounding patients that have been found GEI converge and are negotiated according to specific mandates and resulting in a final decision. Interviews from the varied viewpoints represented in the hearings will be systematically analyzed using thematic content analysis at the latent level to construct meaning around the dynamic perspectives involved. As part of a larger project that is itself qualitative in nature, and due to the emphasis on perspectives other than the researcher, the multidimensionality of the work, and a focus on the narratives put forth by the participants necessitated a qualitative methodology.

This study is primarily situated in a critical realist paradigm, which acknowledges that meaning is constructed in the interaction between persons often through language, but that non-discursive elements, i.e. material structures such as a person's state of health or institutional policy and structure, exist and impact the meaning and structure of the constructed interaction (Willig, 1999; Sims-Schouten, Riley, Willig, 2007). This paradigm is particularly fitting to the current project because of the centrality of the PSRB hearings to the analysis, itself a structure of government that follows a certain 
script wherein participants construct meaning according to their perspectives and access to power, but with an end result that must recognize and adhere to mandates inherent in the law of the state of Oregon.

This project has two phases of analysis. In the first phase I went over the PSRB hearing transcripts to get a holistic overview and general feel for the data. The underlying structure and format of the PSRB hearings were then outlined to identify recurring themes and motifs in the data. From these, an initial coding scheme was developed. The second phase of analysis involved applying the initial coding scheme to the hearings and other material.

The first phase concentrated on the proceedings of seven PSRB hearings to identify the focus of testimony and the importance of topics or issues as demonstrated by the amount of time and attention devoted to each. The outline will result in a layout of the process or procedure of the hearings "Appendix C". The seven hearings span a total of five hours and were purposefully chosen because of the diversity of viewpoints represented by gender, psychiatric diagnosis, and circumstances of arrest. All cases are presented under the GEI plea. Five individuals are the focus of these hearings and are accompanied by interviews of related persons and available data on their legal and medical cases. Although all patients were under the jurisdiction of the PSRB at the time of the hearings, they have varying sentences and are at different places in their progression through the system.

In the second phase of analysis, the seven PSRB hearings were transcribed and thematically analyzed along with three individual interviews. As described above, 
hearings consist of several subject participants or roles. The hearings include board members, the District Attorney, Defense Attorney, clinicians, the patient, and other witnesses called to testify. In this phase I identified the prototypical narratives of risk and risk assessment in the hearings and of three central perspectives: the District Attorney, Defense Attorney, and clinician. The individual interviews selected for analysis were also purposefully chosen. The Defense Attorney chosen is the attorney for six out of seven of the hearings selected and brings with him many years of experience in cases involving individuals who have used a GEI plea. To explicate the position of the state, an interview with the District Attorney was selected. Though the people who represent the state in the PSRB hearings are Assistant District Attorneys, the position is rotated through a pool of individuals, resulting in no single person consistently appearing in the hearings. Rather they represent the position and beliefs of the Attorney General's office which is best represented by the interview with the District Attorney. The clinician selected was an individual who was present in three of the hearings used for analysis, and was the treating clinician for two of the focal patients included in the analysis. Risk assessment uses psychological instruments constructed to determine the probable level of dangerousness or likelihood of dangerous behavior posed by the patient in question. Assessments are often conflated with ideas of risk or dangerousness in general and, as Hilton \& Simmons found, can be of greater importance to decisions made by the ruling board (2001). Thus it is important to include not only assessment findings, but also address risk and dangerousness in general as mental health professionals and other experts are not free of biases where mental illness is concerned (Wahl \& Aroesty-Cohen, 
2010). The analysis of individual participants followed the analysis of the PSRB hearings wherein I identified themes around risk, and found that many of the assumptions I entered into analysis with were not accurate. The analysis took into account these changed assumptions and coded themes of risk indirectly, working to answer the following research questions:

1 Are there identifiable prototypical narratives of risk that are constructed around evidence admitted to a hearing in addition to the three previously identified?

2a. Are these risk narratives deployed differently in public PSRB hearing as opposed to an individual interview?

2b. Do the District Attorney, Defense Attorney, and clinician deploy risk narratives differently?

3. As professionals that create, administer, and interpret risk assessment instruments, how do clinicians use these risk narratives to support or refute the arguments of each side?

The first question reflects a community psychology orientation which emphasizes the experiences and stories of participants as vital to explanations of relevant phenomena. The second question recognizes that knowledge can be constructed differently in different contexts and that a comparison between contexts and also between roles can highlight similarities and differences that can provide insight into underlying ideologies held by participants. The third question delves deeper into the role of the clinician, a position that is central to many aspects of a patients experience and to the decision 
making process. As the experts most often called upon in the context of the hearing, it is vital to explore the beliefs around risk, risk assessment, and their patients.

The next section describes in greater detail the original project and resulting data sets that were analyzed for this thesis. This is followed by a discussion of the current project and my work on the original project and this thesis including my social location in relation to the work in progress. A thorough description of the planned analysis follows, inclusive of participant information and the ethical considerations of the project.

\section{GEI Project}

In the fall of 2008 we began a research project on the Oregon State Hospital $(\mathrm{OSH})$ which at the time was the center of controversy as the focus of a federal investigation for violation of patients civil rights in the over use of restraints and insufficient supervision (FED report, 2008). The hospital became the subject of much media attention and debate over the aged state of the physical institution and over patients' rights. This spurred the interest of Dr. Jan Haaken, herself a clinician, social action researcher and documentary filmmaker, to take a deeper look at the OSH's unique position between the criminal justice system and the mental health system. As a part of the research group, I began by delving into the history of the hospital and its integration into the larger criminal justice system. The complexity of the system was immediately obvious, in part because of the continued negotiation between the CJS and MHS as to the jurisdiction, placement, and treatment of those who have been found guilty except for insanity, the arbiter of which is the court system, which then relinquishes jurisdiction to the Psychiatric Security Review Board (PSRB). In an effort to dissect the interwoven 
pieces of this system and to examine the issues in a deeper more systematic way than was being done in the news media, Dr. Haaken came to the decision to create a documentary film eliciting the perspectives and voices of the people most involved with and affected by the system.

In the spirit of community psychology and social action research, the stories and perspectives of the participants were paramount. Beginning at public hearings of the PSRB, Dr. Haaken and team began to talk to patients. The PSRB was established in 1978 to manage people who have been found GEI. It consists of five members, a lawyer with criminal trial experience, a psychiatrist experienced with the CJS, a licensed psychologist also experienced with the CJS, a parole and or probation expert, and a member of the general public (Rogers \& Bloom, 1983). It is an independent agency of the state government, not a part of either the CJS or the Oregon Mental Health Division whose members are appointed by the governor for 4 year terms (ORS $\S \S 161,385$ ). Individuals under the PSRB jurisdiction are also given certain rights that include among others, periodic hearings, to be present at hearings, to have counsel, and to have the right to request a hearing. These hearing can be held for several different reasons with one being required every 2 years to evaluate a patient's progress. Patients can request a hearing to petition for changes in location; for example, to request a move from the OSH to a residential treatment facility in the community, or further privileges in access to various location of the hospital, visitations, or application to different work and other programs offered at the OSH. We also witnessed in some of our observations of hearings that patients could petition to be released from the jurisdiction of the PSRB entirely, 
though this was a rare occurrence. We began the research on this process observing the hearings of the PSRB, which we found to be the confluence of many perspectives and contexts, and the site of decisions made. We began soliciting interviews that explicated these perspectives and ultimately led to the greater examination of the system that was the subject of the documentary film. In broadening the subject of the documentary into a system wide analysis, we lost the PSRB hearings as being central to our analysis. This thesis brings the focus of the project back around to its beginnings with the current analysis centered on the PSRB hearings and bringing in interviews from people who represent the different interests and participants that play a part in the hearings themselves to explicate the dynamic and varied contexts from which they come from.

These interviews were not limited to patients alone. As the project progressed Dr. Haaken and the team filmed conversations with administrators, members of the PSRB, various staff, members of the police force, lawyers, concerned community members, mental health practitioners as well as group discussions and staff training sessions. Though most of these groups are not members of a marginalized population, as we often focus on in community psychology, they have a profound impact on the lives of people with mental illness in their care, interaction with patients, and more to the point of this project, administration and interpretation of the results of risk assessment instruments and a perspective of risk assessment that is important to obtain. A thorough knowledge of this group's belief system in this area can contribute to the illumination of underlying assumptions and dominant cultural narratives that work to maintain systems of oppression (Mankowski \& Rappaport, 2000). As the team moved about the hospital and 
spoke with a few patients, others interested in the study and the documentary began to approach us and ask to be included. Over all, nine patients were interviewed, with a core group of five interviewed from two to seven time points. These were all people who were in the hospital under a GEI plea, and who were fairly high functioning; able to understand and give informed consent according to the projects IRB.

Over the next two years filming continued, resulting in over 40 individuals and groups who were interviewed, some on multiple occasions and in various settings. This was followed by a period of approximately a year where each interview and group discussion was closely transcribed by members of the GEI team including myself. During this time Dr. Haaken, with the input of the research team, began to analyze the data for main themes which became the basis for the development of the documentary film. We met most weeks throughout this time period to discuss the process of collecting data, collating it, and general methods of social action research, specifically documentary film-making, with a substantial amount of time spent on the attention to ethics a community psychology based researcher using visual methods to disseminate her findings requires, a more thorough discussion of which follows. Working from the transcripts, Dr. Haaken constructed various film sequences in many incarnations covering these main themes around which many of our discussions were structured.

In the final stage of the project Dr. Haaken and the research teams work in resulted in a feature length documentary film entitled Guilty Except for Insanity: Maddening Journeys through and American Asylum, organized around the main themes developed in the qualitative analysis process. The documentary itself is an overview of 
the system set in place to catch those who fall through the cracks of the criminal justice system; however, the net of the OSH as a part of the CJS is itself an institution of incarceration and holds a group of people with far tighter restriction than is perhaps necessary, or even best for their treatment and re-integration into society.

\section{The Thesis Study}

One of the recurring and pervasive themes that we continually ran across in our analysis of the transcripts and film footage, and that was of particular interest to me, was that of risk and risk assessment. The PSRB hearings are the location where these debates and assessments about future risk culminate. Multiple sides contend as to the dispensation of the patient that meets the mission of the PSRB Board, which according to Oregon state law, is a primary concern with public safety (ORS $\S \S 161.336(10))$. People present at the PSRB hearings address the topic of risk from very different perspectives. A comparison of these themes developed from analysis, where they overlap and where they converge, will enable us to perceive meanings that are political in nature but such a part of dominant culture that they can be invisible to us. Risk assessment, as defined in the above literature review, is an instrument that gives probabilistic estimates of a continuous variable, in this case violence, based on person-based and situational variables (Borum, 1999). We use these terms, risk and risk assessment, in this analysis because of an overlap we have observed in the data in the ways in which people discuss these topics. Practitioners discuss risk assessment more often than patients do, yet when patients discuss risk alone there seems to be similar meanings behind the term, this is one area that I would like to clarify through thematic content analysis. 
Because of the reoccurrence and pervasiveness of risk themes in the transcripts of interviews and hearings, its centrality in consequences for patients, operations at $\mathrm{OSH}$, and relevance to the theories of power discussed in the above literature review, as well as psychologists position in both the criminal justice system and mental health system; we felt that this was an area that needed further and systematic analysis. From immersion in the data and analysis for the documentary, we already know that there are different ways in which people talk about risk. There are two main discourses that have been identified so far, scientific and power-dynamic. A scientific discourse is one in which the technical development, use, and or refinement of instruments that predict specific instances of violence or future dangerousness is addressed. Here a mental health professional who works at the OSH describes a method for assessment, "Using demographic variables they calculate a base rate for violence, in much the same way that insurance actuaries for the auto industry or for insurance industry determine who's likely and who is not likely to get involved in an auto accident". We can see from this quote and its reference to methods of mathematical calculation that the emotional and transactional aspects of a violent act are removed from the equation, instead there is an appeal to scientific fact. Practitioners seem to be much more likely to speak of risk scientifically than are patients. A powerdynamic discourse is one in which there are acknowledged features of assessment, either in its development or use, that go beyond scientific variables and into consequences of and beyond prediction. Another practitioner discusses this, "Society tends to not want to tolerate an enormous amount of risk, particularly out of somebody who did something horrific or that would be viewed as horrific, like murder or 
arson or a serious assault. The average layperson is going to assume that the appropriate reaction to that sort of an event is punishment".

Here the practitioner allows that risk may have a greater meaning in society that carries with it consequences for the person assessed in the form of beliefs around the character of the person, and that the uninformed opinion advocating for punishment may not be the best. Patients too have viewpoints about risk that are important to attend to, "I honestly don't think I'm a threat to others, I want the safety of all and desire to have my common fellow man at ease around me. To be able to be my friend and accept me for what I am about". This patient recognizes that "threatening" is how others perceive them, a viewpoint that is indicative of power-dynamics as it indicates fear, one of the justifications for incarceration.

\section{Thematic Content Analysis.}

Thematic Content Analysis as defined by Braun and Clarke is a method for identifying analyzing and reporting patterns or themes within data that minimally organizes and describes a data set in rich detail (2006). It involves searching across a data set to find repeated patterns of meaning. For this analysis I use the theoretical paradigm of critical realism as defined by Willig, (1999) which acknowledges the ways individuals make meaning of their experience and, in turn, the ways the broader social context impinges on those meanings, while retaining focus on the material and other limits of 'reality'(Sims-Schouten, Riley, \& Willig, 2007). I also use Foucault's theoretical writings on power-dynamics and the power-knowledge loop as delineated in the literature review to expand the focus on a broader social context into an exploration 
of power and how this can affect how individuals create and negotiate meaning. Themes will be identified on the latent level, where underlying ideas, assumptions, and ideologies will be used to inform the semantic context of the data (Braun \& Clarke, 2006). Through this constructionist perspective I will seek to theorize the sociocultural context and structural condition that enable and shape the data gathered from individuals.

Following the outlining procedures, thematic content analysis was used to identify themes in the hearings and the individual interviews using Braun \& Clarke's six stages of analysis described below (2006). Upon which the themes and coding manual were compared across settings and subject participant roles.

\section{Participants}

Participants range in ages from mid-twenties to late forties, and are under the jurisdiction of the PSRB for crimes ranging from assault to murder. In all cases the index crime was a violent crime involving another person. Two of the participants are women and three are men. Of the seven hearings analyzed, two of the patients had two hearings each. This overlap enables a broader view of the process over time. The patients and hearings used in this analysis were chosen from within the range of documentary participants. All participants at the time of the data collection resided in the OSH or the Portland branch of the OSH. Participants were approached directly following public PSRB hearings by Dr. Haaken for inclusion in the documentary film from which the data for this project was taken, although in one case a patient approached the crew and asked to be included. The sample used for this analysis is not representative of the population of people who have used a GEI plea for two key reasons; this project aimed for near 
gender equality in the sample, and the index crimes are all violent. It is important to note that the GEI tends to be enlisted for relatively serious crimes.

This analysis of actual recordings of the PSRB hearings and interviews based on actual professional decision-making lends ecological validity to the data. Sixteen patients were approached during hearings and invited to participate in the project, ten agreed to participate. Of the ten, six agreed to continue after consultations with their attorneys and therapists. Four patients were selected on the basis of their representativeness of the larger hospital population and their capacities to understand the project and withstand the process of participating over time. Consents included signatures by patients and their legal representatives. As filming progressed other participants were added, including the additional female patient included in the findings here.

As I listened to and read the data, I took notes on my reactions and observations apart from the transcriptions. These are part of a self-reflective process, essential to qualitative methods in the field of community psychology and continued throughout the analysis process. Each piece of data that I read, listened to, or observed was filtered through the lens of my own experience and biases. Though objectivity is a quality that researchers strive for and many claim, community psychology acknowledges the impossibility of this task, recognizing that researchers bring subjectivity into their programs of study (Fine \& Vanderslice, 1992; Nelson \& Prilelltensky, 2010). With this premise in mind, it is important to confront the experiences and biases that can impact this thesis, including those based on my social location in relation to the project. As a woman who has very little experience in the mental health system but a strong 
commitment to researching power inequities and oppressed groups, I have had to be and have been made aware of my tendency to want to paint the side of the dominant group as bad or negative and the oppressed groups as good and in need of help. This inclination can and will cause me to interpret data in a dichotomous manner. I cannot eliminate this tendency entirely, but can work to minimize it through the practices of self-reflectivity, immersion in the data, and discussion with my adviser. Also, within a system where people are binarily categorized as mentally healthy and mentally ill, I can be categorized as healthy, in part because of the privileges I have had access to in my life.

\section{Data Sets.}

As the description of the original project made clear we have transcriptions of interviews prepared and ready for analysis. The analysis corresponds with secondary data that we have available to us from the original documentary project. These are secondary data that were collected as a part of the original project and will be used in this project as a thematic discursive analysis centered on one particular patient. There are seven audio recordings that were transcribed and comprise the first data set. The second data set consists of interviews from three participants, a treating clinician, Defense Attorney, and the District Attorney. Please see table 1.

Table 1 - Participants

\begin{tabular}{|l|l|}
\hline Settings & Participants \\
\hline \multicolumn{1}{|l|}{ PSRB Hearings } \\
\hline \multirow{7}{*}{} & PSRB Members \\
\cline { 2 - 2 } & District Attorney \\
\cline { 2 - 2 } & Defense Attorney \\
\cline { 2 - 2 } & Patient \\
\hline
\end{tabular}




\begin{tabular}{|c|c|}
\hline & Clinician \\
\hline & Other \\
\hline Individual Inter & views \\
\hline & District Attorney \\
\hline & Defense Attorney \\
\hline & Clinician \\
\hline
\end{tabular}

PSRB hearings as described in the introduction are held for review of patient progress every two years, and for any application for discharge, conditional release, commitment or modification filed. Each hearing is run according to a specific pattern, audio recorded and transcribed by the support staff of the board. In the original project, we attended and observed several hearings as a place to begin examination of the system. Audio files of seven PSRB hearings in which patients who were featured in the documentary participated were obtained through the PSRB for analysis. These hearings are a matter of public record available upon request. The audio recordings cover the entirety of each hearing except for the period of deliberation. At this point, all parties and observers are asked to leave the room while the members of the board discuss the evidence and testimony given and come to a final decision with accompanying recommendations. Once the hearing is called back together, the process once again goes on record and the Board spokesperson gives the decision made. This is sometimes supplemented by an explanation of why they came to the decision they did. The structure and proceedings are described in detail in the findings section.

The second data set used in this project consists of unstructured interviews of three participants. These individuals represent three of the major perspectives that are present in a PSRB hearing. Interviews were conducted by Dr. Jan Haaken in settings convenient for each person. The role of Defense Attorney is represented by a very 
experienced individual who works with many clients under the jurisdiction of the PSRB. This person represented the patients in all but one of the hearings presented for analysis. To represent the side of the state, an interview with the District Attorney was selected. Though he is not present in the hearings themselves, his interview elucidates the paradigm under which the DA's office approaches PSRB hearings and GEI cases in general. Last, an interview of a clinician was chosen. She is the treating clinician in two of the selected hearings, and represents mental health practitioners. As discussed above, much of the questioning at the hearing is focused on her clinical interpretations of admitted evidence.

Table 2 - Role Comparisons

\begin{tabular}{|c|c|}
\hline \multicolumn{2}{|c|}{ Role Comparisons } \\
\hline $\begin{array}{l}\text { Participant } \\
\text { Roles }\end{array}$ & Role Premise \\
\hline $\begin{array}{l}\text { District } \\
\text { Attorney }\end{array}$ & Safety of Public \\
\hline Clinician & Arbiter \\
\hline $\begin{array}{l}\text { Defense } \\
\text { Attorney }\end{array}$ & Patient requests \\
\hline \multicolumn{2}{|c|}{ Setting Comparisons } \\
\hline PSRB Hearings & $\begin{array}{l}\text { Individual } \\
\text { Interviews }\end{array}$ \\
\hline
\end{tabular}

Once thematic content analysis was complete, a comparative analysis across settings and across roles was completed to address the second research question. Please see table 2.

\section{Initial Thematic Coding Guide}

The following is a breakdown of the thematic coding scheme by which speech acts in the PSRB hearings as well as individual interviews were initially to be coded. These macro codes are the prototypical narratives of risk organized around assumptions made from initial work with the data. The macro codes of elopement, non-compliance, and unauthorized drug use are demonstrative of the on-going risk that justifies continued incarceration according to the mandate of public safety. However, in order to examine latent themes and for disconfirmation purposes, a 
second set of codes, labeled Cessation of Risk, was developed that tests the data for narratives of redemption, treatment, and aging out. In the first pass through the data, narratives were coded for these larger prototypical stories with particular note taken of which narratives were and were not used in each context.

Level 2 are the micro codes, or themes within the larger narratives developed and used by the participants. Here it was thought that themes that saturate stereotypical schemas of people with mental illness, e.g. dangerousness and unpredictability, could be parsed out while also searching for data that disconfirms the status quo of stereotypical ideologies. How these secondary themes are utilized was compared across contexts and across participants.

The final level of the initial coding guide focused on the attributions that each theme made explicitly about the patients behavior. Analysis was to lead to a view of how different attributions were deployed by the various participants in different contexts to explain behavior.

\section{Level 1 - Macro Codes}

A) On-going Risk - The patient or resident is seen as likely to re-offend and or pose a physical danger to the general public.

- Elopement - The Oregon State Hospital's (OSH) term for the unauthorized leave of a patient from the grounds and supervision of appropriate personnel.

- Non-compliance - Disobedience from a patient or resident in behavior or lack of behavior in the areas of ward life, residential life, or treatment. 
Running Head: WHAT INSIGHT CANNOT SHOW

- Unauthorized Drug Use - the use of unauthorized or illegal drugs or the use of authorized drugs in a manner inconsistent with the treatment plan of a patient.

○ Other

B) Cessation of Risk - The patient is not likely to re-offend or pose a physical danger the general public.

○ Redemption - The patient or resident has "paid for" their crime, by serving their sentence, applying themselves to the community in a conscientious manner, or bettering themselves through available resources, e.g. education.

○ Treatment - The patient or resident through treatment compliance has gained control over their mental illness.

- Aging Out - The patient or resident is no longer a risk as they have grown beyond the age where they will commit the same or similar crime as the precipitating event.

O Other

Level - 2 Micro Codes, Themes

C) On-going Risk

- Dangerousness to self or others - The patient is likely to physically harm others or themselves through neglect, drug-use, or deliberate action.

- Unpredictability - The behavior of the patient is not foreseeable by mental health professionals or people in the general public; nor is it possible to 
predict behavioral reactions to common stimuli and is not under the patient's direct control.

- Other

D) Cessation of Risk

- Harmlessness - The patient is not likely to physically harm themselves or others due to neglect, drug-use, or deliberate action.

- Predictability - The patients behavior in various stimuli and situations is predictable and under their own personal control.

O Other

Level - 3 Mini Codes, Attribution

E) Causal Attributions

- Individual

- Bad traits (Within Person) - The patients behavior is a result of a desire to perform behaviors that have negative consequences for others.

- Adaptive Coping - The patient's behavior is situational, and though may be on the surface negative, is an adaptive reaction to a negative context.

○ Contextual - The patient's behavior was entirely caused by the context in which it themes occurred rather than internal motivation.

As the findings section will describe, this initial coding guide was substantially revised when the analysis began as many of the initial assumptions and informal 
hypothesis upon which this guide was based were found to be unsupported. The following section describes the process of analysis and the themes and latent ideologies that emerged in the coding process which had a profound effect on the

\section{Analysis \& Interpretation}

The multi-layered approach to the data called for a complex plan of analysis. I needed to attend to three tiers of codes from two sources of data and transcripts from PSRB hearings and from individual interviews, while using the ritual of the PSRB hearings to explicate the latent or underlying assumptions of each perspective. In this section, I review the process of laying out the procedures of each hearing followed by analysis and interpretation of the two primary data sets.

The PSRB hearings are central to this thesis in addition to being a very rich and multifaceted source of data. The structure of the hearing makes analysis both easier, as each speech act is scripted and measured, and more difficult in those intricacies of understanding are often masked by these same scripted procedural processes. As the hearings are a fundamental aspect of the analysis, I began by delineating their structure. The hearings were transcribed into separate word documents and carefully examined. In separate word documents, the outline of each hearing was drawn out of the proceedings. In this iteration of the analysis the focus was on the sequence of events that occurred in a hearing as it was run by the PSRB spokesperson. These outlines were then compared to determine which events were present in most if not all of the hearings. A final document combining the events that were found in all hearings was prepared and used to inform the thematic analyses that followed as the next step in the analysis. During preparation of the 
outlines, initial impressions and interpretations of the data emerged and were recorded in an analysis journal that was used throughout the process.

Given the centrality of the hearings for the analysis, I continued working with the hearing transcripts as I initiated the thematic coding process. The coding began with the scheme outlined in the thesis proposal. The proposal outlined prototypical narratives of risk I conjectured would occur as each perspective present in the hearing argued their case. These proposed narrative categories were uploaded into the analysis software, NVivo9. Using this tool, coding categories were created around the prototypical narratives of risk that each perspective was thought to argue. In this program, excerpts or speech acts from within transcripts can be highlighted and "dragged and dropped" into the chosen code.

Table 3 - Preliminary Coding Scheme

\begin{tabular}{|r|r|}
\hline District Attorney & Defense Attorney \\
\hline Elopement & Redemption \\
\hline Non-compliance & Treatment \\
\hline Unauthorized Drug Use & Aging-out \\
\hline Other & Other \\
\hline
\end{tabular}

Moving through the hearing transcripts, I found that my original model did not fit the data well. A new structure that incorporated some of my preliminary themes as well as emerging themes was developed. Rather than placing speech acts into the codes that were assigned to each perspective, I placed text from any subject participant into the code that best fit. Transcripts were read a number of times to ensure that as many themes as 
possible were identified with the coding structure. In phase two of the data analysis I elected not to eliminate any categories and added categories as needed as recommended by Braun \& Clarke (2006).

Once this first round of coding was completed I examined the contents of each code to ensure that the data collated under the code was appropriate. Because of the initial broadening of the categories, I noted that each code contained both sides of the argument. These categories of codes were not constructed to contain opposing arguments, thus different positions that speak to the same theme are included in the same category. For example, the code labeled "elopement" contained speech acts by the District Attorney arguing that the patient demonstrated a risk of escape, and the Defense Attorney arguing that the patient did not pose such a risk. This sparked the second round of coding where these prototypical narratives of risk were further examined for level 2 codes that indicate ongoing risk or cessation of risk.

In this second round of coding I concentrated on the prototypical narratives of risk and coded for ongoing risk or cessation of risk. Originally, I created subcategories under the ongoing and cessation codes of dangerousness, unpredictability, harmlessness, and predictability. However, because of the change in coding structure, I found that the arguments made by the District Attorney spoke to the ongoing risk of the patient and the arguments made by the Defense Attorney spoke to the cessation of risk of the patient. This made coding for these themes redundant. In immersing myself in the transcripts and in the ritual of the hearings, it became clear that the interesting data existed in the questions the District Attorney and the Defense Attorney were asking of the clinician and 
other witnesses called. In order to address this coding category and the second research question I returned to the original transcripts and collected all questions asked by each perspective. The power held by these two perspectives lies in what questions they asked of the witnesses. These questions were posed in order to solicit arguments that could be used to bolster their side of the dispute. These questions were collated and used in later comparison analysis.

NVivo9 was further helpful in that each transcript uploaded could be categorized in several ways. In my analysis transcripts were split and categorized by perspective and by setting. While transcribing each hearing, the participants were identified by perspective rather than by individual attributes as there were times where different individuals represented a perspective, or several people were represented at once. These were District Attorney, Defense Attorney, clinician, PSRB, and Other. The setting category contained two selections--PSRB hearings and individual interviews. Though setting can be interpreted as location, I use it here to indicate the context in which the data was collected - a public hearing verses an individual interview. These categories allowed cross-role and cross-setting comparisons for the second research question. Are these risk narratives deployed differently in: the context of the public PSRB hearing as opposed to an individual interview? Across the actors that represent the perspectives of the patient, District Attorney, and the clinician? Comparisons were made across individual interviews and across roles, with an eye out for themes that arose in multiple data sets. Themes that arise from multiple sources are assumed to have higher levels of trustworthiness, credibility, transferability, and confirmability, which are often 
considered the counterparts to validity and reliability in qualitative research (Denzin \& Lincoln, 2005). This consideration did not discount themes that arose from a single source, however, particularly since themes that arose in the PSRB hearings were recurring.

The third and final tier of coding addressed how attributions were made when discussing or questioning patient behavior. Here I paid particular attention to the testimony given by the clinician in coding for individual level attributions, of within person traits or adaptive coping, and contextual attributions. Clinicians were the main source of testimony in the hearings. From them came longer narratives that interpreted and explained the behavior of the patients, and though both the District Attorney and the Defense Attorney had their own interpretations, clinicians are the carriers of expertise in the PSRB hearings. As such it is their testimony where the attributions of behavior are primarily found.

Once the PSRB hearings were coded I moved to examining the three individual interviews. These interviews were chosen to explicate the position of three perspectives in the PSRB hearings: the District Attorney, Defense Attorney, and the clinician. These were coded in similar manner to the hearings as described above. In brief, I began by coding each for prototypical narratives of risk followed by aspects of ongoing and cessation of risk. Finally I coded for behavior attributions. This last step was very important in that these individual interviews were a space where each perspective could expand upon their beliefs and assumptions surrounding GEI patients. 
Finally, the entirety of the data set was reviewed in relation to the final thematic pattern to pull back and make sure these themes worked with the data set (Braun \& Clarke, 2006). This overview satisfied me that the reconfiguration of the thematic structure and the emergent themes sufficiently captured the range and complexity of the data. In the next section I review the ritual structure of the hearings and the findings in relation to the three research questions, followed by an analysis of the themes informed by my literature review and illustrated with examples from the data. 


\section{Findings}

\section{Overview}

I begin with an overview of this thesis project and then address the findings related to each research question. The thesis grew out of a documentary project focused on the process patients undergo when admitted to the Oregon State Hospital (OSH) through the insanity plea. Approximately 80 percent of patients admitted for long-term care to OSH have enlisted the "guilty except for insanity" plea and are under the jurisdiction of the PSRB. Entering into analysis I made several assumptions that proved to be unsupported by the data. These included assumptions about how risk is debated, specifically that the District Attorney would argue that the patient is a risk to the community and the Defense Attorney would argue the patient is not. Instead, the point of contention is the mental illness of the patient, and its active or non-active status.

The difference between the original assumptions and the findings of my study form the basis of this analysis. Patients are held for far longer than is best for treatment of their mental illness (Lund Report, 2011; Statesman Journal, 2011). This is justified by use of prototypical narratives of risk that conform to community held fears of dangerousness and unpredictability; supporting the primary mandate of the PSRB board of community safety. This thesis analyzed data from a larger social action research project through a thematic content analysis in order to address the following research questions.

1. Are there identifiable prototypical narratives of risk that are constructed around evidence admitted to a hearing in addition to the three previously identified? 
2a. Are these risk narratives deployed differently in public PSRB hearing as opposed to an individual interview?

2b. Do the District Attorney, Defense Attorney, and clinician deploy risk narratives differently?

3. As professionals that create, administer, and interpret risk assessment instruments, how do these clinicians use these risk narratives to support or refute the arguments of each side?

Based on my literature review and initial observations at PSRB hearings, I reasoned that the focus of PSRB hearings would be on whether or not the patient in question posed a risk and that seeking evidence in support of this judgment would structure the board's decisions. I also assumed that the District Attorney would argue on the side of riskiness, and that the patient and their attorney would argue for non-risk. Once I began to analyze the hearings, I found these assumptions to be incorrect. Rather than arguing in relation to risk versus non-risk, all sides initially agreed to the inherent risk the patient poses as a person with mental illness. This initial finding had important implications for the structure of the coding scheme that had been developed and the subsequent analysis.

This opening finding of inherent risk shifted the argument. Rather than argue the risk posed by the patient, it became hidden or presupposed by its link with mental illness. The active presence of a mental illness became the focal question. Interestingly, similar themes were found around this discourse of mental illness that had been predicted when the focus was thought to be risk. This reflects the causal ties that are made between risk 
posed and the presence of mental illness. That this relationship is inferred is not entirely unreasonable. As discussed in greater detail later, the people who are the focus of these hearings have been convicted of a crime, which is the only form of entry into PSRB jurisdiction. However, that then brings up the question of the seriousness or type of crime committed and what affect that then has on the active mental illness and dangerousness link.

In answer to the first research question there was one overarching and four subordinate themes identified that represent the prototypical narratives deployed by participants; elopement, compliance, drug use, treatment, and the broader theme of insight (see table 2). Rather than call them prototypical narratives of risk, I identify them as prototypical narratives. They still address ideas of dangerousness and unpredictability that may be posed by the patient, but indirectly and through the mediating construct of active mental illness.

Table 4 - Prototypical Narratives

\begin{tabular}{|c|c|c|c|}
\hline \multicolumn{4}{|c|}{ Insight } \\
\hline \multirow{4}{*}{ 这冚 } & Elopement & \multirow{4}{*}{ 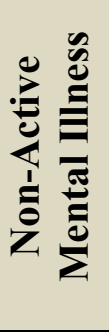 } & Non-elopement \\
\hline & Non-Compliance & & Compliance \\
\hline & $\begin{array}{l}\text { Unauthorized } \\
\text { Drug Use }\end{array}$ & & Authorized Drug Use \\
\hline & $\begin{array}{l}\text { Treatment } \\
\text { Adherence }\end{array}$ & & $\begin{array}{l}\text { Treatment Non- } \\
\text { Adherence }\end{array}$ \\
\hline
\end{tabular}

The second research question contained two aspects that addressed subject positions and contexts in which these narratives were deployed. The aspect of role or subject position confirmed my original supposition wherein the Defense Attorney argued that the patient's mental illness was non-active, and the District Attorney argued for 
active mental illness, by deploying the above themes. In practice, however, "opposing" participants sounded remarkably similar in the form and manner in which they made their cases. This is where the second aspect of the research question comes into play. It addressed the two contexts in which data was collected: the public PSRB hearings and the individual interviews. In the context of the hearing, the deployment of these themes was made clear in the form of questions asked by the District Attorney and Defense Attorney as they queried the witnesses. These lines of questioning were generally straightforward and adhered to the structure and ritual characteristic of PSRB hearings and as noted above, sounded much the same between these opposite subjects. The individual interviews highlight the differences, however, between the views and beliefs held by each subject position. The passion with which these individuals spoke of their beliefs illustrate the profound effect the procedures and ritual nature of the hearings had on their behavior. The procedures that comprise the PSRB hearings have been carefully constructed over time and through legislation as such, the behaviors and speech acts of each participant are highly scripted with little tolerance for deviation. Excessive speech or affect could negatively mar the case built. As such, the individual interviews were a place where each participant could better explain their opinions and convictions surrounding issues that were highly charged.

The final research question explored how clinicians use identified themes to support or refute the District Attorney and/or Defense Attorney's claims about mental illness status. Each subject perspective solicited testimony from the clinician to support their case. Overall, clinicians had a much more complex understanding of the patient and 
the patient's mental illness and of the patient's behavior and behavior attributions than the other participants in the hearings. Clinicians were more likely to use adaptive or coping narratives to describe patient's behavior than the District Attorney, but were divided in supporting conditional release.

\section{PSRB Ritual \& Structure}

Like many formal legal procedures, the PSRB hearings follow a closely prescribed pattern that has been worked out in theory and practice over time. It is so ingrained in the responses of participants that when anything happens that departs from the script, all sides, no matter the position, police, the offending party "Mr. [PSRB member], if you would District Attorney the obvious please...”. Here the Defense Attorney interrupted the PSRB member as he gave the final decision but did not follow the ritual pattern in the delivery. The District Attorney and the Defense Attorney as well as other members of the PSRB called each other to task on several occasions in addition to the example above. The seriousness with which these violations were taken as well as the immediacy of correction evinced how important the ritual pattern was to the parties involved. This emphasis on procedure is typical of hearings of this nature as an aspect of procedural fairness in legal proceedings of GEI cases (Rogers et al., 1986). In these and other criminal proceedings, judgments can be appealed or thrown out on the basis of procedural failings. In this process though, it seems as though attention to procedural detail goes beyond procedural justice and is over-determined by participant's needs' to experience the proceedings as rationale, and to avoid scrutiny of the premises of the hearings. 
The main attendees of each hearing were members of the PSRB, a representative from the District Attorney in the form of an assistant district attorney, the patient, accompanied by his/her attorney, and a clinician familiar with the case. Occasionally other individuals were present to support the District Attorney or patient or to add testimony to the case. Once all parties are present and seated, the spokesperson for the PSRB calls the meeting to order with the specifics of the case; always including the date, the type of hearing, who the focus of the hearing is on, naming all participants, and finally given the type of hearing, who the burden of proof is upon.

Good morning, let's see this is Wed Jan 30th, 2008. This is a hearing for the Oregon PSRB; this is a hearing on the matter of [Patient]. [Patient] is personally present here this morning represented by his attorney [Defense Attorney]. The state is represented by assistant attorney general [District Attorney]. Board members present this morning, [PSRB members]. This is a 2 year hearing and in this type of hearing the burden of proof is upon the state.

Once the specifics of the hearing have been established, the PSRB admits a number of exhibits, individual pieces of evidence, to the record. The type of hearing it is, two-year update or a request for hearing made by a patient, determines who has the burden of proof and also who has the right to speak first in opening statements. The hearing follows a "call and response" pattern which is a linguistic configuration of interaction between two or more individuals in which statements, calls, are punctuated by expressions or responses (Smitherman, 1977). This form of speech is described more often in music or informal settings and is also associated with Black culture; however it fits well here with an acknowledgement of the formality and entrenchment of the exact wording in procedure. Here the PSRB spokesperson makes the appropriate calls and is answered by the District Attorney or Defense Attorney. Following the admittance of 
exhibits the PSRB calls for any stipulations in the case. A stipulation under the law is to admit or agree to a fact rather than require the opposition to prove that fact. In these cases, the PSRB is asking the patient to stipulate to the fact that they have "a mental disease or defect that, when active, poses a substantial or significant danger to the community". The stipulation is important to the structure of the hearing, and is oft repeated with very little variation in wording. The repetition of stipulations suggested that this aspect of the proceedings carries a social symbolic loading, as well as legal significance. The stipulation is asked for at the beginning of the process, reiterated during testimony and statements, and finally at the conclusion of the hearing. In the final statements, the stipulation also is linked to jurisdiction of the PSRB over the patient, which in all cases used for this analysis was found to be appropriate. The introduction of the stipulation by the Defense Attorney is followed by opening statements from each side, followed by the calling of witnesses. The implication the stipulation has for the analysis is discussed further in the next section of the analysis.

In the hearings analyzed for this thesis, the main source of testimony is the treating clinician. Each witness is sworn in, and questioned first by the person who called the witness, then by the other side, and finally by the PSRB members. The opportunity for follow up questions is given, and the next witness (if any) is called. This pattern is followed for all witnesses as one side and then the other is given the opportunity to call testimony to support their case. In all cases used in this analysis, the primary witness was the treating clinician. When all witnesses have completed their testimony, the PSRB calls for closing statements, wherein stipulations are again made. 
The District Attorney and the Defense Attorney both speak to the stipulation, the District Attorney makes statements to reaffirm it, and the Defense Attorney reiterates that the stipulations were made. The room is then cleared for deliberation. Once the hearing is reconvened, the PSRB accepts the stipulations of the case and reaffirms the appropriateness of their jurisdiction over the client and delivers their decision. This is followed by a statement of the right of the patient to appeal the PSRB's decision. The hearing is then over.

Implications of the Stipulation. In situating the ritual of the hearings, it is important to return to key assumptions guiding my analysis. In creating the preliminary coding guide, my analysis was to be situated in individual roles and their functions in a PSRB hearing. Using initial perceptions and guided by the literature, the "job" of each role was defined as follows. The District Attorney represents the most conservative view and argues that the patient is an ongoing risk. The District Attorneys as representatives of the State are opposed by the patient and the Defense Attorney who argue that the patient does not pose a risk. This is reflected by the level 1 codes (see fig. 1) where these narratives of ongoing and cessation of risk codes were generated. It seemed that risk and non-risk were the central arguments. The PSRB sits as the ruling board with a primary mandate of public safety, and the arbiter of the final decision as to whether or not the patient poses a risk to the community. Given the extremely low recidivism rate, the PSRB seems to be quite conservative in their decisions around risk. The most recent recidivism rate for persons who have been released from the jurisdiction of the PSRB is $2.8 \%$ in 2008 (PSRB factsheet, 2008). These rates are calculated according to persons 
who commit a felony offense while on conditional release as granted by the board (PSRB, 2009). Mary Claire Buckley and Alex Bassos, professionals included in the documentary film for their expertise and experience in the criminal justice and mental health systems, cite the recidivism rate of people under the PSRB to hover around $2 \%$ (Haaken, 2010). Buckley, the current head of the PSRB board, indicates the PSRB is pleased with these rates and often references them in comparison with the larger CJS recidivism rates of approximately $32 \%$. These rates are based on felony offences committed while under the supervision of the board. They do not include persons who have been released from jurisdiction nor non-felony crimes and are geographically based in Oregon. The clinician was seen as the scientific arbiter between these narratives of risk and cessation of risk. However, given the low recidivism and release rate, we hypothesized that clinicians also erred on the side of caution and were reluctant to recommend release.

My analysis began with the idea that PSRB hearings were sites where the risk the patient posed was the focus of debate and where clinicians provided expert interpretation of the patient's circumstances and behavior. As I began to review the proceedings, the stipulations dramatically shifted my beginning assumptions. Rather than only the District Attorney and the Defense Attorney arguing that the patient was a risk, all sides initially agreed that in fact the patient was a danger.

At this time we are stipulating to the propriety of your jurisdiction over my client in that she does suffer from a mental disease or defect which, when active, can cause her to represent a substantial danger to others. - Defense Attorney 
There was no doubt or debate about this finding. Also important to the analysis is that danger is inextricably and causally linked with "active" mental illness. In all hearings except one, described below, the Defense Attorney gave this stipulation, which was then echoed throughout the hearing by the District Attorney and the PSRB and again at the very end, where all parties agreed and found that the evidence supported the stipulation, and the appropriateness of the PSRB's jurisdiction.

The repetitious reference to the stipulation throughout the hearing comes to fruition as the PSRB spokesperson delivers the verdict at the end of each proceeding while also revealing an underlying determination the board is required to make. "We do accept your stipulations to the presence of mental disease or defect and dangerousness when that disease is active. And we further find that you are properly placed under the board's jurisdiction" (emphasis added). Each hearing addresses the matter at hand which varies depending on the patient, but can be along a continuum from a simple status update to a request for release from jurisdiction of the PSRB. Each hearing also reaffirms the authority of the PSRB over the patient along the axis of mental illness and dangerousness to the community. Should the patient not meet those criteria, the board would not have legal grounds as to jurisdiction over the patient, thus it is reiterated at every hearing. In one case, the Defense Attorney stipulated to the mental illness of the patient, but not to the danger posed. As the patient requested the hearing, the burden of proof was upon him, and at the conclusion of the proceedings was found to not have met that burden of proof. In hearings that are held at the request of the patient, the burden of proof is upon the defense, meaning that the defense is first to give opening and closing 
statements, and the first to call witnesses. In two year hearings the burden of proof is upon the District Attorney, and they are the first to speak. In this specific case the patient did not prove that he was not a danger despite evidence and discussion of only one occurrence of "inappropriate touching" that was several months prior to the hearing. What was particularly interesting about how this hearing unfolded was that there were few references to violence or dangerousness to others, instead the focus was on proving that he had an active mental illness. Once that was established, the dangerous stipulation followed. With a causal link between active mental illness and dangerousness, the board need only prove the patient suffers from mental illness to confirm their authority. This is one area where the role of the clinician is central to the hearing process. They are the experts that confirm the correctness of the diagnosis of mental illness.

Medical Model. Another implication is that the stipulation, "The patient suffers from mental disease or defect," situates the PSRB squarely in the paradigm of the medical model and leaves no room for other ways of understanding the patient's condition. The locus of expertise then becomes medical clinicians rather than the patients themselves. It is the prerogative of the clinician to not only interpret the evidence for the District Attorney and Defense Attorney, but also to describe the patient's experience through the lens of their expertise in the mental health field. By filtering interpretations of patient behavior through a medical lens the clinician reinforces their place as interpreter and expert. In the hearings clinicians were protective of their interpretations and understanding of diagnosis and patient behavior. The attorneys would repeatedly push their interpretations of patient behavior onto the clinicians, seeming to press for a 
different response. In one case when the clinician's answers did not change after repeated questioning, she adopted an abrupt tone and began to preface her answers with, “Again..." or "As I said before...”. The clinician's defensiveness stirred a response from the DA who felt a need to justify his questions, reassuring the clinician, "I'm not trying to challenge your diagnosis, I'm just for me trying to understand how it fits..." These interactions suggest that the legal process did crucially depend on clinical discourses and the authority of clinical expertise.

Dangerousness. The link between mental illness and dangerousness has implications beyond establishing the authority of the PSRB. In all cases included in the analysis, the patient was placed under the jurisdiction of the PSRB after having pled "guilty except for insanity." As one Defense Attorney describes the plea, "a defendant who uses an insanity defense basically trades time for treatment. They get the maximum sentence allowed by law, but in return for that maximum sentence, they are, in theory, getting treatment at the State Hospital or in the community, to address their mental health problems." However, to remain under the jurisdiction of the PSRB the patient must continue to be found to pose a substantial danger to the community. According to this same attorney, this provision was built into the system to provide a "carrot" for people with mental illness to adhere to rules and work with care providers in order to get better. Once treated, they could be gradually released into community living or even completely released from jurisdiction. Given that this finding of mental illness and dangerousness is required in order to justify jurisdiction, it becomes important for each hearing to reiterate this link over and over until it becomes unquestioned. People with mental illness are 
dangerous to the community. A clinician experienced with the process explained it thusly, "when their psychosis is under good control and they're not feeling paranoid they tend not to be aggressive. Their risk goes greatly up when they're ill, and significantly down when they're not."

It is important to note that these patients were accused of committing crimes. The plea means relinquishing their right to a trial and effectively admitting to guilt, even though their mental state inevitably complicates the guilty plea. They must be both competent enough mentally to understand the charges and the proceedings, and mentally disturbed enough to establish that their mental state hindered their capacity to conform to the standards of the law. Their entry into the $\mathrm{OSH}$ and treatment was through the criminal justice system, so the label of "dangerous" is not completely unjustified. The question of whether this link is made in all cases or only in cases where a violent crime was committed is key here. Would the same stipulations and justification for PSRB jurisdiction exist in hearings where the patient committed a property or vandalism crime? This is a question that is not answered in this analysis as all patient participants were directly involved in harming another individual, though we can make some inferences by examining the crime of murder. A clinician specializing in risk assessment in an individual interview described that murder has a very low recidivism rate, "when you step back and look at the actual numbers, since we are talking about murder, you know, murder is statistically a very very low rate of re-offense. Most people who commit a murder don't go on to commit another murder, and it's not just because they are not, don't have opportunity". Particularly those who have little or no history of violence, this 
clinician goes on to describe how traumatizing murder can be. So even in cases that tend to incite a lot of media coverage, patients "are at a very very low risk for any kind of future violence".

Linking active mental illness with risk changes the basic structure of the hearings that was originally hypothesized. Rather than directly arguing whether or not the patient is dangerous, the District Attorney and Defense Attorney instead dispute the active or non-active state of the patient's mental illness. This had profound effects on the preliminary coding scheme developed for the project. The original hypotheses that guided the codes were that the District Attorney would argue the patient's risk was evident through incidents of elopement, non-compliance, or unauthorized drug use, while the Defense Attorney would argue that, through redemption, treatment, and aging out, the patient was no longer a risk. However, the Defense Attorney initially stipulates to the substantial risk that is present in conjunction with the patient's mental illness.

Rather than argue that the patient was not a risk, the District Attorney and Defense Attorney concentrate on "insight." As the key site for adjudicating the fate of patients, insight became the pathway through which causal connections between active versus non-active state of mental illness and dangerousness were debated. The concept of insight became an overarching theme as it was enlisted to demonstrate how a patient's behavior indicated adherence to the other four prototypical narrative themes; compliance, drug use, elopement, and treatment. Additionally, the Defense Attorney did not use narratives of redemption or aging out to demonstrate their client's lack of risk or the inactivity of their mental illness as originally hypothesized. These themes in the context 
of the PSRB hearings were the points of contention or conflict. For each theme, the District Attorney and Defense Attorney solicited arguments that supported their interpretation of each theme. For example, the District Attorney would argue that the patient did not have insight and as such was at risk of elopement, while the Defense Attorney would argue that the patient would not elope because he or she did have insight, and therefore knew that staying at the hospital or residential treatment facility was in their best interest. The figure below shows what the final coding guide looked like and initiates a discussion of the first research question.

Table 5 - Prototypical Narrative Themes

\begin{tabular}{|c|c|c|}
\hline \multicolumn{3}{|c|}{ Prototypical Narrative Themes } \\
\hline \multicolumn{2}{|l|}{ Insight } & $\begin{array}{l}\text { Whether or not the patient understands their mental } \\
\text { illness as defined by the CJS \& PSRB }\end{array}$ \\
\hline \multicolumn{2}{|l|}{ Elopement } & $\begin{array}{l}\text { Term used in indicate unauthorized leave from } \\
\text { supervision }\end{array}$ \\
\hline \multicolumn{2}{|l|}{ Compliance } & $\begin{array}{l}\text { Indicates to what extent the patient follows orders } \\
\text { and cues given by staff, how well patients obey the } \\
\text { rules }\end{array}$ \\
\hline \multirow[b]{2}{*}{ Drug-use } & Authorized & $\begin{array}{l}\text { Indicates how well or poorly the patient adheres to } \\
\text { the medication regimen prescribed by their treatment } \\
\text { team }\end{array}$ \\
\hline & Unauthorized & $\begin{array}{l}\text { Term used to address the use of illegal substances; } \\
\text { e.g. marijuana, cocaine, methamphetamines etc. } \\
\text { And/or use of legal substances in ways not approved } \\
\text { by treatment team; alcohol, prescription medication, } \\
\text { etc. }\end{array}$ \\
\hline \multicolumn{2}{|l|}{ Treatment } & $\begin{array}{l}\text { Indicates how well or poorly the patient participates } \\
\text { in group and individual treatment provided by the } \\
\text { OSH }\end{array}$ \\
\hline
\end{tabular}

\section{Prototypical Narratives}

The first research question asks if there are prototypical narratives of risk that are constructed around the evidence admitted at PSRB hearings in addition to elopement, 
non-compliance, unauthorized drug use and treatment, aging out, and redemption. As discussed previously, the structure of the hearing and stipulations required a reassessment and organization of these projected themes. Redemption and aging out were unsupported by the data and eliminated as themes while the other four themes, while evident, were found to be used by both the District Attorney and the Defense Attorney. These four with the addition of a fifth theme, insight, are the prototypical narratives by which the District Attorney and Defense Attorney argue their cases. This section defines and explores these themes as identified in the transcripts, beginning the theme of insight and followed by elopement, compliance, drug use, and treatment.

Insight. Insight was an overarching theme that affected the four other prototypical narratives as an avenue through which the subject participants spoke to the adherence or non-compliance of the patient along each thematic line. This section describes findings under the thematic code of insight and how this theme was used to illustrate where patients fell along the other four themes; for example compliance vs. non-compliance.

Insight was a code that emerged early in the proceedings as both the Defense Attorney and District Attorney began asking questions such as "what degree of awareness does [Patient] have about her mental illness", "Has the patient shown insight into her mental illness", "Has he admitted he has a mental illness". That the patient accepted a specific definition of mental illness was foundational to the understanding of insight for all involved. The PSRB needed to hear that the patient conceded that they had a mental illness and understood the conditions in terms of the medical model. This 
acceptance was necessary as a beginning point for further discussion about future possibilities of conditional release and moving forward in treatment into less secure settings. It spoke to the model by which treatment is expected to occur, in a linear stepwise fashion, "I read that as her progress has not been linear, there has been some back and forth movement" the District Attorney points out in questioning the recovery of a patient. The clinician then replies that in fact the patient has changed in a linear progression, which must perforce begin with an acceptance of the PSRB's believed definition of mental illness.

"To your knowledge has he admitted to you or your staff that he does have a mental illness?" - Defense Attorney "Um, when did [Patient] start admitting her diagnosis or her mental disease or defect?” - - District Attorney

"In the time that I have known her she has admitted that she has a mental illness since day one that I have known her, which is only the past couple of months." Clinician

"Ok, um do you believe that he has insight into what caused his crime, that mental illness caused his crime?" - Defense Attorney

In the context of these hearings, the concept of insight is comprised of two components that are attended to by the District Attorney and the Defense Attorney as they query witnesses. The first is that mental illness is a lifelong condition that must be managed medically. A patient's time in the hospital is seen as a time to gain full insight or understanding of all aspects of their mental illness. The second component refers to 
the level of understanding gained by the patient into the definition and interpretation of his or her mental illness. It speaks to the extent of the patient's awareness of his/her mental illness in regards to variables that trigger the activation of symptoms, "And did [the Patient] identify the triggers that would lead to a manic episode or a bi-polar problem?" the District Attorney asked or "what are your warning signs, warning that a relapse may occur" the Defense Attorney clarified. Once insight is gained, it is thought that the patient will be capable of avoiding triggers, and also of dealing appropriately with triggers that will occur in the world and cannot be avoided, reacting in such a way as to prevent a relapse.

Lack of insight is a strong argument against moving forward in the system or into conditional release. As the District Attorney notes in one case, "...the fact that he has not made the appropriate therapeutic steps in order to transition to a minimum security ward may be indicative of the fact that he still has therapy and, needs to develop better insight in order to be an appropriate candidate for conditional release". In another case, the DA offers similar commentary, suggesting the importance of insight as a signifier: "I was looking back through the records here and I saw that [residential treatment facility] had considered [the Patient] back in 2006, but uh they were concerned that he had a lack of insight."

This search for insight as it is operationalized within this setting, has the effect of introducing blind spots into the decision making process. The term implies a new way of looking at a psychological phenomenon, yet, in context it operates as self-confirming, implying that a greater level of knowledge and understanding of the patient's condition 
has been reached. Having such a complex concept defined so narrowly can blind participants in the system, from administrative members to the patients themselves, to alternative ways of understanding mental illness and recovery. Insight is a term that carries a heavy psychological load. It was first used psychologically in psychodynamic theory and refers to the process of interpretation or the assignment of underlying meaning and causality to emotions and behavior (Scaturo, 2002; Karasu, 1990). Gestalt psychology holds that insight is a key component to productive thinking and a product of unplanned responses to situation and environment (Sternberg, 2003). The incorporation of the word insight into the hearing and decision making process lends the weight of legitimacy to the way the subject participants discuss and use insight as a method of determining the active or non-active status of mental illness.

Elopement. To reiterate, elopement is the term used by the OSH to indicate an escape or risk of escape by a patient. This is a charged area of patient transgressions to explore in that it is the focus of the most intense media interest. News articles and stories tend to focus on the danger these escaped individuals pose to the community, and call "the mindset" of the OSH into question when supervising "people with violent histories" (Tilkin, 2012). This and other news stories tend to reiterate how often elopements occur, with a single article relating three different statistics spaced throughout; ten escapes over two years, 24 patients over the past five years, and three escapes in "2011 alone". This emphasis on the prevalence of elopements was not reflected in the data. Some of the patients that were the focus of the hearings have earned higher levels of privilege that allows them to move about the OSH campus with low or no supervision for jobs or to 
travel between buildings for treatment. However, elopement was addressed in all cases but one at least briefly,

"Defense Attorney: Have you ever tried to run away?"

"Patient: No."

Even in cases where there had been an elopement in the past, a short description of what was being done to discourage future elopements in conjunction with a patients current good behavior was sufficient for the participants in the hearing, "As far as steps we are taking to evaluate her risk of elopement, after um, you know on conditional release, basically we are discussing this with her in psychotherapy regularly".

Of the four themes, insight was least talked about in PSRB discussions of elopement. There were few mentions of insight, and all were connected to the patient having awareness of their mental illness. Patients were expected to hold insight that the appropriate place to receive treatment is the OSH and through the PSRB. Attempting to elope, then, could be an evidence of lack of insight. This has implications in selfknowledge that are important to point out. A patient, in their compliance with the authorized definition of mental illness must abandon their own experience and understanding. The source of treatment, the source of interpretation of how a patient is feeling, or what stage of recovery a patient is in comes from outside, an external perspective of expertise. Thus a patient cannot or should not trust their own interpretations of wellness, and should carry the knowledge that they need to be institutionalized, and should not try to elope in order to be a good patient. 
Compliance. In the context of the OSH and in outside residential facilities, a question that is often asked centers on the patient's capacity for self-control. How well a patient can control their emotions and behavior, and when that personal control slips, how well the person responds to staff or outside control—all of these questions are of vital importance. The District Attorney and Defense Attorney spend considerable time debating over how episodes of non-compliance should be interpreted, relying on the expertise of the clinician. A common question is, "In your experience is my client one who can generally be redirected by trained staff?" from a Defense Attorney. Or “And how much cuing does he generally require?" This ability to take direction or cues goes a long way towards proving to the PSRB that the patient has insight into their mental illness, which includes in this context an understanding of how their mental illness should work, and how it can be tamed, or brought under control, along with a willingness to surrender control if it cannot be achieved by the self, "I [District Attorney] have read many of these incident reports and in fact she willingly went, was escorted by staff to the side room in many of them".

A patient's behavior is scrutinized for most, if not all, hours of the day and night, with deviations from standards of conduct, broken rules, negative peer interactions, and other behaviors recorded in notes or incident reports and introduced at each hearing. These examples of poor behavior must be explained and this is often done by the clinician and in terms of mental illness as a driving factor, "overlying that is the PTSD, a lot of trauma, a significant trauma history, and so when [Patients] traumatic recollections are triggered she has a lot of the kind of instant fight or flight response that you see in 
people with a serious trauma history, that combination explains the significant amount of her extreme behaviors". In one hearing a patient's behavior on an outing was in question, though there was no evidence or indication the patient was eloping, there was a period of time, three to five minutes, wherein he could not be located. As a consequence for this violation some of the patients earned privileges were removed, "We may return that status [privilege] to him but we are trying to help [Patient] to understand the importance of cooperating with supervision" one clinician explained.

In addition to compliance within the hospital, patients who come before the PSRB to request evaluation for release or conditional release must prove that they are able to comply with the rules related to management of their mental illness outside of the institutional environment. The District Attorney often emphasizes the uncertainty associated with trying to predict a patients behavior, "with that record of behavior, it's difficult to find a place where you could say with certainty, she's gonna be ok in your setting". These rules are put in place by the hospital and the PSRB as a release plan in order to maintain control over the mental illness, preventing a relapse. The understanding is in place that, should a patient violate their release plan in any way they will be returned to the OSH. The following quote from a Defense Attorney describes the low levels of tolerance and consequences for any breach of the rules.

So it's a pretty stringent expectation. And a violation of any of those expectations - failing to show up for an appointment with a psychiatrist for example, stopping medications, stopping going to psychiatric groups which is required, refusing to provide a urinalysis, all of which are relatively minor potentially compared to things like leaving without authorization, or actually committing another crime - any of those things - documented recurrence of substance use - any of these things can result in the PSRB saying 'nope, you don't get to stay in the community anymore, you're going back to the hospital 
because we don't trust you to continue on the road of being safe in the community.

Insight interacts with compliance in a similar way as with elopement. A patient with insight will comply with the staff and rules because he or she knows that this is what is best for them and the treatment of their mental illness. It also overlaps with the other themes in that a patient can and should also comply with treatment and medication use.

Drug Use. Drug use is split into two sub-themes, authorized and unauthorized. These were disparate enough in the ways in which they were discussed and addressed by participants, that separate codes were justified, but at root are really discussing the same action, and in some cases the same substance. As such I did not create separate themes. The first is authorized drug use, and indicates how well if at all a patient adheres to the medications given as a part of treatment plan. The second is unauthorized drug use, and refers to the use of illegal substances, refraining from use of illegal substances, and/or authorized substances used in an unauthorized manner.

Authorized Drug Use. The use of medication was seen as a significant part of treatment, and adhering to the drug regimen was an important aspect of compliance. In every hearing authorized drug use was attended to. The clinician was often asked if the patent was taking medication, and if so what kind, "Is she, is she taking medication for her condition?". The lists of medications were given and in many cases involved at least two if not more different medications. There was also discussion of titrating to determine the levels of medication in the blood stream in addition to supervising patients as they ingest their prescriptions, "Every now and again we get blood levels just to see how everything is going, and I have no concerns regarding her blood levels of". 
One particular case demonstrated the importance of the patient adhering to medication recommendations when a patient who refused and continues to refuse antipsychotic drugs attended a hearing. This was such an issue that the Defense Attorney had to make clear that this refusal was allowable by asking the clinician "has he been deemed competent to... to um, for example to refuse medication if he so chose?" The answer was yes, but it required a special consultation on the part of the clinician, "I believe that he is competent and that question was also put to [Doctor] in his review and he agreed that [the Patient] was competent to refuse medicine". Even so, that he did not take medication put his future requests and his very ability to move through the system in doubt. This refusal to take medication had the clinician at a loss, and during the hearing he described his uncertainty, "and I was really unsure on how to proceed because overall the patient does very well in treatment, has not experience further psychotic symptoms during his this hospitalization. And a question comes up about what to do at this point, whether to proceed with a referral for placement or whether to wait him out until he agrees to take anti-psychotic medicine; which might not ever happen". The ambiguity pointed to an understanding of the theme of insight and how it informed this theme by posing the question; does this patient demonstrate lack of insight by refusing medication? Insight played a large role in this prototypical narrative. The selection of quotes below reveals how often the two are linked:

"In your opinion, what if any, insight does she have into her need for medication?" - Defense Attorney “OK, and does she take the medication voluntarily?" - Defense Attorney 
"Do you believe that he appreciates the importance of his medication?" - Defense Attorney

"And how long do you believe you will have to take those medications?

Patient - For the rest of my life."

"You indicated that if you stop taking your medications you'd become psychotic, you realize that your bi-polar condition may come back in the future?" - Defense Attorney

These quotes were taken from five of the hearings, and indicate that there is an understanding about what the appropriate treatment is for mental illness, and that treatment includes medication. By accepting this definition of mental illness again the patients understanding must be subsumed or dismissed. Their mental illness can be controlled by medication, it is a lifelong condition, and if the treatment plan is not obeyed the patient will relapse which in turn triggers a return to the hospital. Taking these medication voluntarily show the level of compliance a patient has, and demonstrates they are good patients.

It is important to note here that in this analysis I am not discounting that medication does help many people in symptom management and recovery from mental illness and is valuable in the treatment process. I am, however, critiquing the unquestioned acceptance of medication as an essential part of a treatment plan.

Unauthorized Drug Use. Rather than use legal and illegal drug use as subthemes, I chose the term unauthorized as it includes drugs that are legal, but are used in an unallowable manner. For example, Ambien became an example of non-compliance when 
a patient used it improperly, as a clinician explained "[patient] was taking Ambien but not intending to go to sleep, and we determined that he was using Ambien to basically alter his mental state rather than using it as a sleeping aid". Interesting to note was that it was not the taking of the drug that was a problem, but instead the behavior of not sleeping that followed. The patient had gotten the Ambien from the staff in a sanctioned transaction. This situation was an example used to show the patient had little insight and was part of the District Attorney's argument against granting the release requested.

The other major concern that emerged from analysis of the hearings was addiction and substance abuse. Many of the patients whose hearings are in the data set were diagnosed with substance abuse problems. These were often identified as triggers for activation of mental illness, and as such were of great concern when discussing the patient's conditional release into the community. A District Attorney asked, "If he was to use drugs or alcohol and if that disorder were to become active would he pose a substantial danger to others?"

"Clinician - Yes."

For each of these patients, a portion of their release plan as deliberated upon in the hearings was dedicated to how these addictions would be managed in the community. Regular drug tests were prescribed in all cases, and in one case the amount of tests given, on average ten to twelve per year. One such recommendation elicited concern on the part of the District Attorney that this frequency may not be sufficient: "Well let me ask you this, this is a big move into a community setting, albeit a secure one, they [residential treatment facility] is proposing a once a month random unannounced screens, do you 
think that's enough given the change that we are looking at?". In this case these tests were increased to twice a month at least, with an increase during targeted times, for example, when the patient returns from a family visit even though the patients "drug of choice" is alcohol, and that cannot be tested for in an urinalysis.

Insight was relevant here in that a patient must again construct their beliefs around mental illness and the consequences of using unauthorized substances. Capitulation to their addiction would cause activation of mental illness and thus create a danger to the community. "Well one of the most important things is that [the Patient] needs is to stay clean and sober. Free of substance abuse and he needs to demonstrate that he's willing to continue actively collaborating with the staff in his best interest". Clinician

Treatment. Treatment refers to how well or poorly the patient participates in group and individual treatment provided by the OSH or residential treatment facility. This prototypical narrative overlaps with several of the other themes. Treatment includes medication, and compliance with treatment is often spoken of in the context of the hearings. It is a separate theme however, because it is a separate concern and is the process by which patients gain insight.

"The legislature recognized that people can and do change with treatment. Even though they may have an illness, when they get to a point where they fully understand that illness and fully understand how to treat it and what they need to do to maintain themselves in good remission, that they can be discharged as no longer being a substantial danger to others."

- Defense Attorney

It is also another method by which insight may be demonstrated, the patients willing and active participation in all forms of treatment is a powerful indicator to the PSRB that the 
patient has gained acceptance of his or her mental illness and is following the path to recovery. The following quotes illustrate this theme.

"And I think you've also touched on this, but would it be fair to say that he is actively involved in treatment here at the hospital?" - Defense Attorney "Excellent, he attends all the groups that he is assigned to, and especially substance abuse groups off grounds, and uh, he helps, he is supportive of other patients, and he does his jobs without difficulty." - Clinician "He takes his treatment very seriously, he tries to get into psychotherapy and he tries to understand what the idea is." - Clinician

Summary. The overarching theme of insight informs and interacts with the four prototypical narratives in negotiating the fate of the patient under the PSRB. That the term insight is used is paradoxical in that it signifies that the patient has understood the concepts of mental illness in a very specific and uniform way, which gives precedence to an "outside" medical perspective. This deployment of the concept of insight then creates two blind spots - one in the patient, and one in the clinician. Patients are taught to turn to outside sources for understandings of the meaning of their behavior and to view their own personal interpretations as symptoms of illness rather than sources of insight or selfunderstanding. Any experiences that fall outside the framework of the medical model are disqualified. The practitioner develops a blind spot as well in accepting a limited and proscribed concept of mental illness and in pushing the idea of insight leads to compliance. In actuality, all participants must comply with the dominant narrative to operate within this system. 


\section{Cross-Role \& Cross-Setting Analysis}

Data used for this thesis were collected in two settings, public PSRB hearings and in individual interviews. Data were also collected from people who represent three roles, clinicians, the District Attorney, and Defense Attorneys. Given this structure it behooves me to take advantage of these various data sources in a comparison which findings are reported in the following section. In this section of analysis, the themes coded for were compared and the data was again revisited for clarity.

Settings. As discussed in the Ritual \& Structure section above, the PSRB hearings are a setting that through legislation and repetition has an exceedingly defined procedure that is followed meticulously by its participants. This ritual is a part of the legal systems endeavor to assure fairness, all patients or individuals who come before the board can be sure they will be subject to the same procedures. Speech acts under these circumstances from the District Attorney and Defense Attorney are, except for the opening and closing statements, limited to questioning of witnesses and brief responses to the board member running the hearing. Given the restrictions on speech and the formal nature of the hearings there was a professional courtesy between opposing sides and little outright contention. In many ways the questions asked by the District Attorney and the Defense Attorney were similar in style and substance, and in debating the prototypical narrative themes described in the previous section were very much arguing either side of the same coin.

The individual interviews were open and as such gave the participants much more freedom to express their beliefs and interpretations of the patients and the system. Group 
differences in the interviews were heightened and a more complex understanding of the issues emerged. The following section summarizes how risk was brought up and understood by each role.

Roles. This section of the analysis addresses risk. Risk is submerged into the concept of active and non-active mental illness; which is then the center of debate in the context of the hearings. Here I explore individuals in their role and how they defined risk. The individual interviews for this portion of the analysis were chosen as each represented a subject role important in the hearings. The State is represented by a District Attorney, a position that embodies the more conservative side of the proceedings. A DA who has long been involved with GEI cases and represents several of the patients in the hearings that comprise the data set was selected. Finally a clinician with many years of experience and who also represented two patients in the sample was chosen.

District Attorney. The District Attorney focused strongly on the concept of justice as it pertains to the victim of the crime, "it's the job of the prosecutor to represent justice. These folks who come to the PSRB are first in the system because they've committed a crime against someone". This focus on justice comes with some assumptions that are important to attend to. The first is that there is a victim in the crime. This brings the idea of dangerousness to the forefront; the presence of a victim implies physical harm. "They are patients, but they are also people who have done, in these cases, horrible things to somebody else, and that I tried to explain to them that the public safety system does best when people have confidence that just results happen". Risk for the state was decidedly one way; patients who are GEI are a danger to the community. In 
describing people who have committed crimes, it becomes clear that though this individual did acknowledge mental illness as a factor that deserves treatment, he also located the bad deed within the person. The crime was situated in the person, who then must be punished. Treatment is of secondary priority.

The District Attorney told several stories where a person who had committed a heinous crime was considered for conditional release as soon as the patient was at the appropriate place in their treatment. He was upset at this change "in philosophy" that he felt betrayed the trust of the "public safety and victims". He also spoke of risk in broader terms, moving out of the individual level and into a discussion about society and the implications of punishment. "People are punished as a proportional response to the seriousness of the crime. That is the first traditional reason why people are sentenced". Though he states that risk is not why we place people in secure facilities, he seems to be speaking of letting people free without an appropriate punishment time as a risk in and of itself. Without such an understanding and punishment we risk the public taking control, “The public has to have confidence in the public safety system. If it doesn't, they will take action through the initiative process to change it. We've seen that happen over and over in the last twenty years".

Defense Attorney. Perhaps unsurprisingly, the attorney whose interview was chosen to represent this role saw risk from the perspective of the patient and placed more emphasis on social contexts for the crime and for the process of recovery. The first key distinction between the DA and the Defense attorney was about the risk society posed to the patient. The Defense Attorney felt that the fears of the community towards people in 
the OSH could be quite damaging, particularly where these fears limit access to care and treatment outside of the institutional boundaries. "There used to be a cottage that was unfenced, where people who were doing very, very well could graduate to. There were essentially no problems with that system, but that was closed down for security reasons. And not because anyone had done anything but a determination was made. Because of fear, I think, more than anything else". Societal fears lead to policies and institutional practices that hide the problems that people with mental illness present. This concealment prevents issues from being "dealt with productively". This societal fear also affects placement of facilities that are needed in order to place people in the community when appropriate. This is directly linked with risk to the patient in that there are fewer and more crowded institutions, and fewer group homes to supply the needs of the patient.

In contrast to the District Attorney, this defense attorney categorized people who have pled GEI as, "people who have done nothing wrong themselves, but have a mental illness". He felt that, "the medical community is often trumped by the PSRB in making decisions about whether or not people should or should not remain at the hospital". This is a concern and can lead to frustration on all sides of the equation.

Clinicians. Even more than the defense attorney, the clinician used a large portion of the individual interview to discuss risks to the patient, focusing on risk in a mental health capacity. She characterized the job of the clinician as, "to find whatever medication and treatment regimen works for that particular person that keeps them well with the understanding that there's always a risk of relapse, and that schizophrenia, for example, and bipolar disorder are chronic illnesses that need ongoing management and 
that it is normal to expect relapse in symptoms - partial or complete — under periods of significant stress". This closely aligns with the idea expressed earlier that mental illness is a long term or lifelong struggle, and that the patient faces a risk in the possibility of a relapse. She links continued mental health with a reduced likelihood of recidivism or risk of future offence, particularly in major or violent crimes. Like the defense attorney the clinician recognizes that there is a discomfort or fear of people with mental illness. In a more complex analysis in addition to the Defense Attorney's breakdown of fear caused by risk of violence or harm, she adds that many are uncomfortable around people whose behavior is different, unpredictable, or "follows its own internal logic".

A region unexplored by either the Defense Attorney or the District Attorney is the risk posed to a patient with mental illness by being institutionalized, "psychiatric facilities like this one are not the ideal place for certain folks". The first area of risk to the patient she address as residents of an institution is the high level of activation and chaos on overcrowded units. There is little space to seek a calm or quiet corner. This lack of calm space and high level of drama on a ward leads to continuous high levels of stress, "and when you're chronically stressed-out, your resources are taxed. Your tolerance is lower and your ability to grit your teeth and keep your cool is lower". This can lead to direct risk, as one patient can harm another, or indirect when these high stress levels lead to a patients vulnerability to their own mental illness. Long-term exposure to these environments has detrimental effects that work to balance the effects of treatment. In PSRB hearings clinicians are the arbiters of insight. Their clinical expertise and personal experience with the patient contribute to their authority. The testimony of 
the clinician is generally the main component of the hearings. The questions asked by the District Attorney and the Defense Attorney are designed to solicit the appropriate support for their case. However, the clinician is the arbiter of insight. Should the clinician feel the patient has insight then their arguments are very supportive of the patient along the lines of the prototypical themes, "He's quite ah, mindful of his mental illness". If they feel the patient does not have insight or full insight, then their testimony will reflect that, and they demonstrate a reluctance to support the patient in a request for evaluation/release etc. "I do not believe, I don't have confidence that he is able to do that at this time [identify triggers of mental illness]".

Attributions. Clinicians were the source of all behavior attributions in the context of the hearings, though questioned by the District Attorney and the Defense Attorney, clinicians were the experts, and maintained that status. Thus, I focus here on how attributions were made in order to begin to explore the power and knowledge relationship inherent in the role of the expert. In this analysis attributions specifically refer to statements about the causes of the patient's behavior. There were three areas of attribution hypothesized for this analysis, contextual, adaptive coping, and within person traits. Within person traits indicates that the behavior is a result of the desire to perform behaviors that have a negative consequence for others. The patient wants to do bad things because they are a bad person. No clinician spoke to this attribute as a sole reason for behavior, though one did say that individual level traits (not necessarily negative ones) were part of a "combination of factors" that drive behavior. A solely contextual reason for behaviors, meaning that the patient's behavior is entirely caused by the context 
in which it occurred, was again not supported, though it could be seen as part of that combination of factors. The final attribution hypothesized, adaptive coping, was supported by the data.

Adaptive coping represents the idea that the patient's behavior is situational and, although on the surface may be negative; it is an adaptive reaction to a negative context. This became particularly relevant in one case where the patient in question had a rather large number of incident reports of poor behavior. The clinician explained these as an adaptive coping mechanism where the patient found a place of quiet and safety in a chaotic ward by getting sent to a seclusion and restraint room reserved for those who themselves are making a ruckus. These incident reports were evidence of time when she was feeling unsafe or triggered and anxious, "When she gets into verbal battles, she will escalate, she will often engineer a situation where she ends up in a side room because she needs to be in that protected environment to feel safe". This and other behaviors by patients were given a more complex interpretation from the clinician in the PSRB hearings. 


\section{Discussion}

\section{Risk Assessment}

The aim of this project was to examine how risk and risk assessment were discussed in the context of PSRB hearings and in interviews of people intimately involved in the hearings process. Interestingly, risk assessment was not generally discussed in the hearings, aside from a very brief mention in one hearing out of seven. In this instance the District Attorney references the assessment in his closing statement, "Given the recent risk assessment indicating the potential for high risk for violence if there is a community placement" as part of his argument against evaluation for conditional release. In addition to risk assessment instruments not being highly relevant in hearing discussions and testimony, the concept of risk itself is masked in the link made between mental illness and dangerousness inherent in the stipulations required of the patient. Risk is tied to active mental illness, and the state of active or not active mental illness becomes the point of contention by which the District Attorney and Defense Attorney argue their cases.

The first research question taken up by this project addresses how these arguments are made along five themes that are prototypical narratives of hidden risk. The first is Elopement, a term used to indicate a patient's unauthorized leave from supervision, or more simply, escape. Compliance indicates to what extent the patient follows orders and cues given by staff, how well patients obey the rules of the institution and ward. Drug-use is divided into two sub-categories, Authorized and Unauthorized. Authorized drug-use indicates how well or poorly the patient adheres to the medication 
regimen prescribed by their treatment team. Unauthorized is the term used to address the use of illegal substances; e.g. marijuana, cocaine, methamphetamines etc. It can also be used to indicate use of legal substances in ways not approved by treatment team; alcohol, prescription medication, etc. Treatment, the fourth theme, indicates how well or poorly the patient participates in group and individual treatment. These four prototypical narratives fell under an overarching theme labeled Insight. This larger theme informed how each of the preceding were debated, and was itself used to demonstrate the active or non-active status of the mental illness. For example, if a patient appreciated that they benefited from being in the hospital setting, they were unlikely to Elope, complied with staff, used Authorized Drugs appropriately, avoided Unauthorized Drugs and willingly participated in Treatment; then they could be said to have Insight. Which in turn indicated the patients mental illness was non-active, and under control.

That risk assessment was so rarely part of the discourse of the hearings, echoed the findings of Hilton \& Simmons in that risk assessment scores did not correlate significantly with decisions made by tribunal boards of maximum security forensic facilities (2001). Additionally, it was found that decisions correlated most strongly with testimony of senior clinicians. Though this project did not measure the correlation between the final decision and clinical testimony, it was noted in all hearings that clinicians were the primary and often only testimony in the case. Their expertise was appropriate particularly as the link between active mental illness and dangerousness made by the stipulation emphasized the medical model above and beyond other ways of understanding mental illness. 


\section{Clinical Expertise}

The expertise of the clinician reaffirmed Foucault's knowledge-power loop wherein knowledge is produced by experts immersed in a system which then supports that system. In this case, the understanding of mental illness reinforced by the clinicians in the context of the hearings has a profound effect on the patients as they navigate their way through the system. Jurisdiction under the PSRB is felt to benefit the patient, "The state would just note that as previously noted the board's jurisdiction is proper, that the board's jurisdiction has benefited [the Patient] and will continue to do so. That jurisdiction is not expired till 2020, so there is plenty of time left for [the Patient] to benefit from future treatment under the benefit of the boards jurisdiction". That this quote and others like it, "So it would be fair to say that the board's jurisdiction has benefited [the Patient] and will continue to do so", are unquestioned and accepted without objection from the Defense Attorney are indicative of how power effects the patient and their case. It becomes necessary for the patient to accept and adhere to an understanding of their mental illness imposed externally. They must, if they want to successfully navigate the system and achieve higher levels of privilege and one day conditional release not only "play the game" but truly believe in the entirety of the system.

Insight and the accompanying scrutiny required to determine its achievement necessitate a very high level of surrender. Mental health professionals, clinicians, and psychologists can both work to construct and perpetuate the system, particularly those who are embedded within it (Hook, 2007; Foucault, 1977). It is significant to be aware though that clinicians also play a middle role, as their treatment and recovery focus also 
allows them to concentrate on the patient's well-being, acknowledging that the hospital setting can also be harmful and working against the system to secure disposition for the patient in a setting more congenial to their recovery. Yet they gain significant prestige and remuneration in the continuation of the current system.

This is particularly interesting when viewing the role of the clinician through the lens provided by Mulvey \& Lidz in their critique of risk assessment in the CJS. As described above, Mulvey \& Lidz question the premise that dangerousness is a key concern for mental health professionals, saying that this practice has become courtmandated across much of the nation leaving risk assessment instruments and links between mental illness and dangerousness unquestioned (1995). This line of argument supports a point made by risk assessment specialist Alex Milkey, featured in the documentary film (Haaken, 2010). He argues that the risk of re-offense for people who commit murder is quite small, yet the system is reluctant to grant conditional release. In this instance risk measures alone do not support continued incarceration.

Linking active mental illness directly with dangerousness may also have an effect on stigma. As hypothesized by Link and Phelan (1998), the use of dangerous criterion in civil commitments introduced a powerful phrase; "dangerous to self or others" that could lead people to the logical conclusion that psychiatric patients must be dangerous. A similar connection is found in this project in the procedural introduction to the hearings: "At this time we are stipulating to the propriety of your jurisdiction over my client in that he does suffer from mental disease or defect which when active can cause him to represent a substantial danger to others." This explicitly links dangerousness and mental 
illness in a causal sequence and could perhaps be even more powerful in this context as the people under the jurisdiction of the PSRB have already committed a crime.

A courtroom workgroup, as addressed in the literature review, consists of individuals who share a common workspace, interact in the performance of their jobs, and have a collective purpose that includes disposition of cases (Eisenstein, Flemming, Nardulli, 1988; Eisenstein \& Jacob, 1977). As the PSRB is a decision-making board with adjudicative control over people who have been found GEI, its processes carry a number of parallels to traditional courtroom work groups. The GEI workgroup, made up of PSRB board members, an Assistant District Attorney and Defense Attorney, are familiar with each other, and work together on a regular basis. In their initial studies Eisenstein and colleagues (1988) found that differential patterns of sentencing occur because courtroom work groups perceive cases differently and that the structure of each workgroup explains much of the variance in sentencing outcomes. Later research focusing on the similarity, proximity and stability found these variables to be strong determinants in the resolution of cases. The board should be examined overall, in order to see if the same variables affect decision making in this context, i.e. perception of cases and structure of the group. The assumptions of the group as a whole can reflect the assumptions of the system and of the individuals that make up the workgroup, further helping to make explicit the underlying belief structures and ideology around important concepts such as the medical model and insight. Attending to these underlying ideologies at various levels of interaction will lead to a more thorough understanding of how they contribute to decisions made about the disposition of patients under PSRB jurisdiction. 
The factors that have been found to influence decision making in courtroom work groups, stability, proximity, and similarity, should also be examined in terms of the PSRB. The board meets twice a month, with membership in the PSRB being fairly stable in four year appointments. However, not all members of the board are present at every hearing. Generally, three out of five members are present, although at the hearings attended by the research team, different members were present at each hearing. Though membership in the board is stable, attendance of the hearings may not be. The position of district attorney is also subject to change, as the assistant DA who represents the state is part of a regular rotation. Stability of the workgroup has been associated with lower probability of fines and restitution (Haynes, Ruback \& Cusick, 2010). Proximity among the people who attend the PSRB is also low. All members travel to the physical location of the hearings in the OSH. No members work in close proximity of a regular basis. Proximity is associated with lower likelihood of incarceration (Haynes, Ruback \& Cusick, 2010). Lastly, similarity as measured by demographic variables, education level and institution, is also associated with lower probability of incarceration. This project did not collect such information on the individuals present at PSRB hearings, so cannot address similarity as a variable. However, we can presume that the stability and proximity of the members that attend each hearing is low. Extrapolating from previous research on courtroom work groups, these may be important as contributors to the conservative rates of release that has been a longtime critique of the board (Lund Report, 2011; Statesman Journal, 2011). 
As the GEI workgroup has come to an understanding of how mental illness works, it has also developed a specific way of managing that risk, which as stated in a previous section, has been called conservative in the press and by mental illness advocacy groups (Lund Report, 2011; Statesman Journal, 2011). The workgroup also may affect the ritual nature of the hearings as delineated in the results section above. As people gain familiarity with each other, patterns of behavior are established cementing the initial rituals imposed by the systems functioning, and decreasing possible flexibility as new cases occur. Though the effects of a workgroup on sentencing in these types of hearings can be speculated based on previous research, so far no analysis on a PSRB workgroup has been conducted. Research that addresses the effect of a "courtroom workgroup" on sentencing decisions would be a valuable direction to explore. 


\section{Conclusion}

The four themes and one overarching theme, Elopement, Compliance, Drug-use, Treatment and Insight were the prototypical narratives of the hearings. Though indirect, ultimately these themes were the way in which risk was discussed and debated in the PSRB hearings, and the answer to the first research question. The second question was constructed to explore the differences between the setting in which data was collected, a highly formalized and legal proceeding, versus a more informal individual interview; and the differences between the subject roles represented in the hearings and interviews, District Attorney, Defense Attorney, and clinician. In comparing settings, I found that the interviews contained a much more complex understanding of the issues. There were no differences in the content and opinions about matters discussed in both settings, but the individual interviews allowed more freedom to explore and expand than the formal ritual of the hearings. The differences between roles were to be expected. The District Attorney clearly defined his role as being protective of greater society and emphasized punishment as an aspect of incarceration that was of primary concern to the state as a whole and his office in particular. The Defense Attorney was much concerned with the legalities of jurisdiction, and strongly emphasized the mental illness aspect of using a GEI plea. He in addition to the clinician had a more contextual view when making attributions of patient behavior. Finally, the clinician was the expert in mental illness, diagnosis, treatment, and attribution of patient behavior. In hearings they were the primary testimony and source of information on the status of a patient's mental illness. As the carriers of the greatest amount of specific patient information, the clinicians were 
very much the individuals who had the most influence on the case in question. The above prototypical narratives were used by the clinicians to convey their opinion on the active or non-active state of mental illness. In answer to the final research question, clinicians used Insight as a way to recommend or not the issue in question in each case according to their own clinical decision and interaction with the patient. In some cases this meant going against the Defense Attorney and in some the District Attorney.

\section{Applications}

This study thoroughly examines the setting of the PSRB hearings and supported a previous study in the importance of clinical narratives in decision making processes. As each state has a different system in place to adjudicate persons who use a GBMI or GEI verdict it is important to comprehend the similarities across systems. Oregon is one of the two states that use a PSRB system, a separate board to manage such cases. In this circumstance the clinician's testimony and interpretation is of primary importance, which echoes the only two other studies of this nature and brings into question the role of risk assessment instruments. A more thorough examination of how risk assessment instruments specifically are used is necessary. A primary factor in the use of risk assessment instruments is the standardization of how patient risk is measured and used in making decisions about directions for future treatment and incarceration. The existing literature makes it clear that mental health professionals themselves are not immune to stereotypes and prejudices that surround this group. However, my immersion in the data has proved how disparate each case can be, even if the diagnosis and/or index crime is similar. Particularly where mental illness is an issue, the addition of clinical experience 
with the patient is vital. The START used by the OSH and other structured clinical judgments are moving in the right direction by incorporating actuarial measures and clinical opinion. Yet in this study the risk assessment instruments themselves were very rarely mentioned. Conversely, risk assessment instruments also have their blind spots. They are just beginning to appreciate that there is risk to the patient as well. This is an area that the clinician has much greater insight than the assessments.

In previous research, risk assessments have been found to have a higher level of predictive validity than clinical judgment alone, yet this thesis and previous research has found that clinical judgment and demographic variables such as gender, race, and level of education profoundly affect sentencing and release decisions for people who have used a GEI plea. Structured risk assessment instruments seem to incorporate the flexibility of clinical judgments with the greater predictive validity of actuarial assessments as part of a greater risk management paradigm (Webster et al. 2006). It may be that the results of risk assessment instruments need to have a larger role in decision-making processes to eliminate the stigma mental health practitioners can be subject to (Schulze, 2007; Wahl \& Aroesty-Cohen 2010). Given the amount of time, funding and resources that go into development and implementation of these tools, it was a surprise that the risk assessments were not discussed explicitly in the PSRB hearings or used in making decisions about the disposition of patients. Further examination as to why this is the case is needed. As the newer risk assessment instruments, like the START used by the OSH, incorporate both actuarial and clinical methods I would recommend that the results of these assessments take a more prominent place in how decisions are made. 
Examining the legal proceedings in their structure and content in addition to examining the perspectives of those involved can give a unique perspective that is especially valuable in examining and expanding researcher's comprehension of this intersection of the CJS and mental health system. In attempting to understand a system community psychology underlines the importance of the experience of those within said system as those who can have needed perspective for what is working, what needs changing, and how that change can happen.

\section{Limitations}

This analysis of actual recordings of the PSRB hearings and interviews based on actual professional decision-making lends verisimilitude to the data, as does the random nature of how these hearings were chosen. Of the 16 patients approached during hearings and invited to participate in the project, 10 agreed to participate. Of the ten, six agreed to continue after consultations with their attorneys and therapists. Four patients were selected on the basis of their representativeness of the larger hospital population and their capacities to understand the project and withstand the process of participating over time. Consents included signatures by patients and their legal representatives. As filming progresses, other participants were added, including the additional female patient included in the findings here.

There are significant limitations to this study, however. First, the sample size is small. Second, there are seven hearings and three individual interviews analyzed for this project. This limits generalizability as does the structure of the CJS and mental health system here in Oregon. Oregon is one of only two states that have a PSRB board 
governing the adjudication of people who have plead GEI. Interestingly, though the ruling body that makes the decisions differs from state to state, the importance of clinician testimony was clear in the three studies on the topic, including this one.

A third limitation of the study is that the data in the individual interviews was originally collected for another project. This means that the structure of those interviews was not specifically designed to address risk and risk assessment. Though these are important topics in the system, they were not the only avenue of inquiry and were one among a range of issues discussed in the interview context. As they were not the sole focus, there could be aspects of either topic that may not have been a part of the discourse simply because of the time limitations and number of topics covered.

Further limitations of the study are related to the shifting political context of the PSRB and the state hospital. Changes in the structure of the hospital, its policies, state legislation, and the composition and role of the PSRB could affect the findings reported here. New legislation, federal investigations, and siting groups are and have been involved in making extensive changes to both the physical structure of the hospital and the ways in which the PSRB adjudicate persons. These continuing changes could affect who is under the jurisdiction of the PSRB and how decisions are made. On a positive note, the underlying assumptions and ideologies that this thesis describes could be used as a basis for examining changes over time.

The patients included in the study are also a source of limitations. Though there was an element of randomness in the inclusion of some of the participants, it happened that all patients were under the jurisdiction of the PSRB for major crimes that involved a 
significant amount of harm to another person. This may have had an effect of the decision making process around evaluation and possible conditional release. Perhaps our data would have been different if our participants had committed property offences or vandalism. Given the violent nature of the crimes of the participants, the themes identified in this study may be limited to this group of individuals. The focus on gaining insight and its masking of the level of compliance required could be affected by this previous violent behavior. The high level of monitoring on a physical and mental level of the patients could be an extension of the level of risk they are perceived to pose. There is more public pressure around violent offenders, even when they are statistically at a very low risk of reoffending, a statistic oft repeated by the participants in the documentary film (Haaken, 2010). This perceived risk may also explain the focus on compliance. The board responds to increased anxiety and pressure the public places on them in these cases. Future studies should ensure that various levels and types of index crimes be included in the analysis to determine if the same themes would apply to people who have used the GEI plea in non-violent or property crimes. The level of compliance required for the cases where violence was a factor in the index crime may not be the same for a person who did not commit a violent crime. The link between insight and compliance should be examined to see if level of violence affects the level of compliance required. It was also the case that our participants had been in the system for a fairly long time, most of them for several years if not more. They have had time to become accustomed to the system and earn privileges that people admitted more recently to the hospital. This may have changed the tenor of the discussions in the hearings. Further, patients included in 
this study were of necessity fairly high functioning for inclusion in the documentary film. Their experience may not reflect that of people who would be categorized as low functioning.

Finally, it is important to note that people who have used the GEI plea have already acknowledged that mental illness is a factor in committing their index crime. Persons who make use of the GEI plea have enlisted the medical model in advancing that plea. That's a rule of entry into this form of plea bargaining, even if it turns out to be a costly defense. In endorsing this causal explanation for their crime, they may be inadvertently participating in a system that reinforces stereotypes. At the same time they don't have a lot of choices, particularly if they want access to treatment. Alex Bassos, a defense attorney included for his expertise in mental illness and the law, emphasizes the brutality of the system and points out that the GEI plea is an alternative to increasingly punitive laws that enforce mandatory severe sentencing (Haaken, 2010). However, by linking mental illness with dangerousness and adhering strictly to the medical model, some of the problems of reentry to the community may be exacerbated. The association between mental illness and violence or dangerousness is strengthened, thereby reifying stereotypes associated with people who have mental illness rather than the small portion of those who do commit violent crimes. Also, the link between mental illness and future risk of violence is not strongly supported by previous research. As described in the literature review, people with mental illness have a modest level of increased risk of violence, as comparable to adolescents, men, and grade school graduates (Watson, Ottati \& Corrigan, 2003). The PSRB has the unenviable task of weighing the safety of the 
public and the public's perception of safety against the needs of the patient. As previous research has shown, mental health professionals are just as likely as others to hold and adhere to stereotypes of dangerousness and unpredictability, it is not surprising then, that the PSRB hearings show a strict adherence to the medical model and beliefs about mental illness and future violence, erring on the side of caution as they come to decisions about patients.

\section{Future Research}

In order to broaden and deepen the findings of this study, future research should more specifically take up the subject of risk and risk assessment in individual interviews with a more comprehensive range of participants including multiple Assistant District Attorneys, clinicians, and patients. It would also add immensely to the generalizability of the findings to have patient participants who have committed a range of index crimes for which they use a GEI plea. This study, though it did speak to several questions, brought up new ones as well. Specifically, whether hearings for patients who have committed index crimes that are not directly involved with harm to another would have the same stipulation and connection made between active mental illness and dangerousness for the community.

Preferably, future projects will be more participatory in nature, directly soliciting the input of patients in the focus of inquiry and how that inquiry would best be made. Though the documentary was completed in a collaborative way with the participants throughout the documentary filming and post-production process, the analysis for the thesis was done without input from the patients or board. Though current patients are a 
vulnerable and protected population, that marginalized position makes it even more important to include them. Another group that would be wise to include are patient's rights and advocacy groups. These groups would be ideal settings to present the findings of the thesis, in addition to academic conferences. Increasing knowledge of the system from a variety of perspectives and incorporating the voices and experiences of people with marginalized status on the basis of psychiatric diagnoses will result in findings that have greater validity which in turn can facilitate incorporation of more extensive knowledge of systems. These multiple perspectives and deeper understanding of the system will hopefully aid progressive change over time. An incorporation of alternative forms of data dissemination by researchers, for example, the documentary format, can facilitate public awareness around GEI patients and perhaps contribute to programs that work to lessen stigma. Advocacy group's avenues of information sharing; newsletters, websites, etc. that could be made available to researchers through partnerships in future research are another way that more accurate conversations around mental illness could occur.

Throughout the analysis process, many data points returned to the concept of insight. Debates by the District Attorney and Defense Attorney centered on this concept, the clinicians gave information to prove or disprove insight, and it became the richest site for production of meaning and understanding. Future research might actively pursue this line of analysis on insight, specifically alternative ways of thinking about insight.

The stated goal of a range of participants in this project is to enable persons with mental illness to live within the community surrounded by as little fear and stigma as 
possible. Community psychology plays a key role in realizing this aim, and in identifying support at a community level that can contribute to avoidance of situations where the CJS must step in as either a source of punishment or treatment. Future research might examine barriers both within the criminal justice/mental health systems and within communities. Including public perspectives and advocacy groups, both for and against inclusion of persons with mental illness into communities, in the analysis would be an important addition. The PSRB board responds in many ways to public perceptions of people with mental illness. Bringing people diagnosed with mental illness and members of the community into regular interaction may well be one of the first steps in addressing the social madness in the management of the "criminally insane." A collaborative research program could well be the ideal site for these initial interactions. 


\section{References}

Aegisdottir, S., White, M., Spengler, P., Maugherman, A., Anderson, L., Cook, R., Nichols, C., et al. (2006). The Meta-Analysis of Clinical Judgment Project: FiftySix Years of Accumulated Research on Clinical Versus Statistical Prediction. Counseling Psychologist, 34(3), 341-382.

Arens, R. (1967). The Durham Rule in Action: Judicial Psychiatry and Psychiatric Justice. Law \& Society Review, 1(2), 41-80.

Baillargeon, J., Hoge, S. K., \& Penn, J. V. (2010). Addressing the Challenge of Community Reentry Among Released Inmates with Serious Mental Illness. American Journal of Community Psychology, 46(3-4), 361-375.

Banks, S., Pandiani, J., \& Boyd, M. (2009). Measuring Criminalization/Diversion of Adults with Serious Mental Illness. Best Practices in Mental Health, 5(2), 62-70.

Banks, S., Robbins, P., Silver, E., Vesselinov, R., Steadman, H., Monahan, J., Mulvey, E. P., et al. (2004). A Multiple-Models Approach to Violence Risk Assessment Among People with Mental Disorder. Criminal Justice and Behavior, 31(3), 324340.

Bettelheim, B., \& Janowitz, M. (1964). Social change and prejudice, including Dynamics of prejudice. New York: Free Press of Glencoe.

Bloom, J., Rogers, J., \& Manson, S. (1982). After Oregon's insanity defense: a comparison of conditional release and hospitalization. International journal of law and psychiatry, 5(3-4), 391-402. 
Borum, R. (1999). Empirical research on the insanity defense and attempted reforms: evidence toward informed policy. Law and human behavior, 23(1), 117-135.

Braithwaite, E., Charette, Y., Crocker, A. G., \& Reyes, A. (2010). The predictive validity of clinical ratings of the short-term assessment of risk and treatability (START). International Journal of Forensic Mental Health, 9(4), 271-281.

Braun, V., \& Clarke, V. (2006). Using thematic analysis in psychology. Qualitative Research in Psychology, 3(2), 77-101.

Callahan, L., \& Silver, E. (1998). Factors Associated with the Conditional Release of Persons Acquitted by Reason of Insanity: A Decision Tree Approach. Law and Human Behavior, 22(2), 147 - 163.

Coid, J., Yang, M., Ullrich, S., Zhang, T., Sizmur, S., Farrington, D., \& Rogers, R. (2011). Most Items in Structured Risk Assessment do not Predict Violence. The Journal of Forensic Psychiatry \& Psychology, 22(1), 3-21.

Cooke, D., \& Michie, C. (2010). Limitations of diagnostic precision and predictive utility in the individual case: a challenge for forensic practice. Law and human behavior, 34(4), 259-274.

Corrigan, P. (2000). Mental Health Stigma as Social Attribution: Implications for Research Methods and Attitude Change. Clinical Psychology, 7(1), 48-67.

Corrigan, P. W, Larson, J. E., \& Kuwabara, S. A. (2007). Mental illness stigma and the fundamental components of supported employment. Rehabilitation Psychology, $52(4), 451-457$. 
Corrigan, P. W, Rowan, D., Green, A., Lundin, R., River, P., Uphoff-Wasowski, K., White, K., et al. (2002). Challenging two mental illness stigmas: Personal responsibility and dangerousness. Schizophrenia Bulletin, 28(2), $293-309$.

Corrigan, P. W, Watson, A. C., Gracia, G., Slopen, N., Rasinski, K., \& Hall, L. L. (2005). Newspaper stories as measures of structural stigma. Psychiatric Services, 56(5), $551-556$.

Corrigan, P. W, Watson, A. C., Heyrman, M. L., Warpinski, A., Gracia, G., Slopen, N., \& Hall, L. L. (2005). Structural stigma in state legislation. Psychiatric Services, $56(5), 557-563$.

Corrigan, P. W, Watson, A. C., Warpinski, A. C., \& Gracia, G. (2004). Implications of educating the public on mental illness, violence, and stigma. Psychiatric Services, $55(5), 577-580$.

Corrigan, P. W. (2007). How Clinical Diagnosis Might Exacerbate the Stigma of Mental Illness. Social Work, 52(1), 31-39.

Corrigan, Patrick W., Morris, S., Larson, J., Rafacz, J., Wassel, A., Michaels, P., Wilkniss, S., et al. (2010). Self-stigma and coming out about one's mental illness. Journal of Community Psychology, 38(3), 259-275.

Corrigan, Patrick, Watson, A. C., Byrne, P., \& Davis, K. (2005). Mental illness stigma: Problem of public health or social justice? National Association of Social Workers, 50(4), 363-368. 
Cutcliffe, J. R., \& Hannigan, B. (2001). Mass media,“monsters” and mental health clients: the need for increased lobbying. Journal of Psychiatric and Mental Health Nursing, 8(4), 315-321.

Dear, M. (1992). Understanding and overcoming the NIMBY syndrome. Journal of the American Planning Association, 58(3), 288-300.

Eisenstein, J., Flemming, R. B., \& Nardulli, P. F. (1988). The contours of justice: Communities and their courts. Boston: Little, Brown.

Eisenstein, J., \& Jacob, H. (1977). Felony justice: An organizational analysis of criminal courts. Boston: Little, Brown.

Faulkner, G., Irving, H., Paglia-Boak, A., \& Adlaf, E. (2010). Adolescent knowledge of schizophrenia and social distancing: a province-wide survey. Journal of Community Psychology, 38(8), 933-942.

Fine, M. and Vanderslice, V. Reflections on qualitative activist research: Politics and methods. In E. Posavac (Ed.) Methodological Issues in Applied Social Psychology. NY: Plenum, 1992.

Foucault, M. (1995). Discipline and punish : the birth of the prison (2nd ed.). New York: Vintage Books.

Freud, A. (1946). The ego and the mechanisms of defence. New York N.Y.: International Universities Press.

Goffman, E. (1963). Asylums: essays on the social situation of mental patients and other inmates. Chicago: Aldine Pub. Co. 
Grann, Martin, \& Långström, N. (2007). Actuarial Assessment of Violence Risk. Criminal Justice and Behavior, 34(1), 22-36.

Gray, G. (2002). Integrated medical care in a mental health clinic improved quality of care and outcomes in serious mental disorders. Evidence-based mental health, $5(2), 46-47$.

Grove, W., Zald, D., Lebow, B., Snitz, B., \& Nelson, C. (2000). Clinical versus mechanical prediction: A meta-analysis. Psychological Assessment, 12(1), 19-30.

Gustafson, A. (2011, April, 24). Bill might prompt earlier releases at Oregon State Hospital. The Statesman Journal. Retrieved from http://pqasb.pqarchiver.com/statesmanjournal/access/2327899301.html?FMT=AB $\underline{\text { S\&date }=\mathrm{Apr}+24 \% 2 \mathrm{C}+2011}$

Haaken, J. \& Portland State University in association with Herzog and Company (Producer), Haaken, J. (Director). (2010). Guilty Except for Insanity: Maddening Journeys Through an American Asylum [Motion Picture]. United States.

Hart, SD, Michie, C., \& Cooke, D. (2007). Precision of actuarial risk assessment instruments: evaluating the "margins of error" of group v. individual predictions of violence. The British Journal of Psychiatry. Supplement, 49, 60-65.

Haynes, S. H., Ruback, B., \& Cusick, G. R. (2010). Courtroom Workgroups and Sentencing The Effects of Similarity, Proximity, and Stability. Crime \& Delinquency, 56(1), 126-161.

Hayward, P., \& Bright, J. A. (1997). Stigma and mental illness: A review and critique. Journal of Mental Health, 6(4), 345 - 354. 
Heilburn, K., Dvoskin, J., Hart, S., \& McNeil, D. (1999). Violence risk communication: implications for research, policy, and practice. Health, Risk \& Society, 1(1), 91-106.

Hilton, N., \& Simmons, J. (2001). The Influence of Actuarial Risk Assessment in Clinical Judgments and Tribunal Decisions about Mentally Disordered Offenders in Maximum Security. Law and Human Behavior, 25(4), 393 - 408.

Hinshaw, S., \& Dante, C. (2000). Stigma and mental disorder: Conceptions of illness, public attitudes, personal disclosure, and social policy. Development and Psychopathology, 12(4), 555-598.

Holt, R. (1986). Clinical and statistical prediction: a retrospective and would-be integrative perspective. Journal of personality assessment, 50(3), 376-386.

Hook, D. (2005). Genealogy, discourse,"effective history”: Foucault and the work of critique. Qualitative research in psychology, 2(1), 3-31.

Johnson, P. (1985). The Turnabout in the Insanity Defense. Crime and Justice, 6, 221 236.

Jost, J., \& Banaji, M. R. (1994). The role of stereotyping in system-justification and the production of false consciousness. British Journal of Social Psychology, 33(1), 127.

Karasu, T. B. (1990). Psychotherapy for depression. Northvale, NJ: Jason Aronson, Inc.

Kessler, R., Berglund, P., Bruce, M., Koch, J., Laska, E., Leaf, P., Manderscheid, R., et al. (2001). The prevalence and correlates of untreated serious mental illness. Health services research, 36(6), 987-1007. 
Konrad, N. (2010). Ethical Issues in Forensic and Prison Psychiatry. International Library of Ethics Law and the New Medicine, 45, 363-380.

Lee, S. (2009). The criminalization of mental illness: How theoretical failures create real problems in the criminal justice system. Vanderbilt Law Review, 62(3), 10531083.

Linhorst, D., \& Dirks-Linhorst, P. A. (1997). The impact of insanity acquittees on Missouri's public mental health system. Law and human behavior, 21(3), 327338.

Link, B. G., Yang, L. H., Phelan, J. C., \& Collins, P. Y. (2004). Measuring mental illness stigma. Schizophrenia Bulletin, 30(3), 511-541.

Link, B., Phelan, J., Bresnahan, M., Stueve, A., \& Pescosolido, B. (1999). Public conceptions of mental illness: labels, causes, dangerousness, and social distance. American journal of public health, 89(9), 1328-1333.

Livingston, J., \& Boyd, J. (2010). Correlates and consequences of internalized stigma for people living with mental illness: A systematic review and meta-analysis. Social Science and Medicine, 71(12), 2150-2161.

Lunde, D. (1976). Murder and madness. San Francisco: San Francisco Book Co. Manguno-Mire, G., Thompson, J., Bertman-Pate, L., Burnett, D., \& Thompson, H. W. (2007). Are release recommendations for NGRI acquittees informed by relevant data? Behavioral Sciences \& the Law, 25(1), 43-55.

Mankowski, E., \& Rappaport, J. (2000). Special Section: Qualitative Research on the Narratives of Spiritually-Based Communities - Narrative Concepts and Analysis 
in Spiritually-Based Communities. Journal of community psychology, 28(5), 479494.

Monahan, J. (1984). The prediction of violent behavior: toward a second generation of theory and policy. The American journal of psychiatry, 141(1), 10-15.

Monahan, J. (1992). Mental Disorder and Violent Behavior: Perceptions and Evidence. American Psychologist, 47(4), 511-521.

Muir, K. (2008). Challenging the exclusion of people with mental illness: The Mental Health Housing and Accommodation Support Initiative (HASI). Australian Journal of Social Issues, 43(2), 271-290.

Mulvey, E. (1994). Assessing the evidence of a link between mental illness and violence. Hospital \& community psychiatry, 45(7), 663-668.

Mulvey, E. P., \& Lidz, C. W. (1995). Conditional prediction : A model for research on dangerousness to others in a new era. International Journal of Law and Psychiatry, 18(2), 129-143.

Nairn, R. G. (2007). Media portrayals of mental illness, or is it madness? A review. Australian Psychologist, 42(2), 138-146.

Nelson, G., \& Prilleltensky, I. (2010). Community psychology : in pursuit of liberation and well-being (2nd ed.). Basingstoke UK ;;New York: Palgrave Macmillan.

Nicholls, T. L., Brink, J., Desmarais, S. L., Webster, C. D., \& Martin, M.-L. (2006). The Short-Term Assessment of Risk and Treatability (START): A Prospective Validation Study in a Forensic Psychiatric Sample. Assessment, 13(3), 313-327. 
Nightingale, D. (1999). Social constructionist psychology : a critical analysis of theory and practice. Buckingham [England] Philadelphia: Open University Press.

Nonstad, K., Nesset, M. B., Kroppan, E., Pedersen, T. W., Nottested, J., Almvik, R., \& Palmstierna, T. (2010). Predictive validity and other psychometricproperties of the short-term assessment of risk and treatability (START) in a Norwegian high secure hospital. International Journal of Forensic Mental Health, 9(4), 294-299.

Oregon Revised Statutes. ORS 4(161). ORS §§ 161.295, 2009.

Oregon Revised Statutes. ORS 4(161). ORS §§ 161.336(10)), 2009.

Oregon Revised Statutes. ORS 4(161). ORS §§ 161.346 (1), 2009.

Oregon Revised Statutes. ORS 4(161). ORS §§ 161.346 (6)(b); (11)), 2009.

Oregon Revised Statutes. ORS 4(161). ORS §§ 161.346(6)(a)), 2009.

Oregon Revised Statutes. ORS 4(161). ORS 161.336(1)(a), 2009.

Oregon Revised Statutes. ORS 4(161). ORS 161.346(1)(b), 2009.

Penn, D. L., \& Martin, J. (1998). The stigma of severe mental illness: Some potential solutions for a recalcitrant problem. Psychiatric Quarterly, 69(3), 235-247.

Perez, A., Leifman, S., \& Estrada, A. (2003). Reversing the Criminalization of Mental Illness. Crime \& Delinquency, 49(1), 62-78.

Peterson, J., Skeem, J. L., Hart, E., Vidal, S., \& Keith, F. (2010). Analyzing offense patterns as a function of mental illness to test the criminalization hypothesis. Psychiatric Services, 61(12), 1217-1222. 
Phelan, J. C., \& Link, B. G. (1998). The growing belief that people with mental illnesses are violent: the role of the dangerousness criterion for civil commitment. Social Psychiatry and Psychiatric Epidemiology, 33(13), 7-12.

Psychiatric Security Review Board (2008). PSRB Factsheet. Retrieved from http://www.leg.state.or.us/tomei/special_topics/psrb_factsheet_070208.pdf

Psychiatric Security Review Board (2009). Annual Performance Progress Report (APPR) for Fiscal Year (2007-2008) Proposed KPM's for Biennium (2009-2011). Retrieved from http://cms.oregon.gov/DAS/OPB/docs/appr08/psychsec.pdf

Robin, G. (1997). The evolution of the insanity defense: Welcome to the twilight zone of mental illness, psychiatry, and the law. Journal of Contemporary Criminal Justice, 13(3), 224-235.

Robinson, D. (1996). Wild Beasts and Idle Humors: The Insanity Defense from Antiquity to the Present. Harvard University Press.

Rogers, JL, Bloom, J., \& Manson, S. (1986). Oregon's Psychiatric Security Review Board: a comprehension system for managing insanity acquittees. The Annals of the American Academy of Political and Social Science, (484), 86-99.

Rogers, Richard. (2000). The Uncritical Acceptance of Risk Assessment in Forensic Practice. Law and Human Behavior, 24(5), 595-605.

Scaturo, D. (2002). Fundamental Dilemmas in Contemporary Psychodynamic and Insight-Oriented Psychotherapy. Journal of Contemporary Psychotherapy, 32(23), 145-165. 
Schulze, B. (2007). Stigma and mental health professionals: a review of the evidence on an intricate relationship. International review of psychiatry (Abingdon, England), 19(2), 137-155.

Sims-Schouten, W., Riley, S. C. E., \& Willig, C. (2007). Critical Realism in Discourse Analysis. Theory \& Psychology, 17(1), $101-124$.

Singh, J., Grann, M., \& Fazel, S. (2011). A comparative study of violence risk assessment tools: A systematic review and metaregression analysis of 68 studies involving 25,980 participants. Clinical Psychology Review, 31(3), 499-513.

Sirey, J., Bruce, M. L., Alexopoulos, G., Perlick, D. A., Raue, P., Friedman, S., \& Meyers, B. (2001). Perceived stigma as a predictor of treatment discontinuation in young and older outpatients with depression. The American journal of psychiatry, $158(3), 479-481$.

Skeem, J. L., \& Monahan, J. (2011). Current Directions in Violence Risk Assessment. Current Directions in Psychological Science, 20(1), 38-42.

Skeem, J.L., Mulvey, E. P., \& Lidz, C. W. (2000). Building mental health professionals' decisional models into tests of predictive validity: the accuracy of contextualized predictions of violence. Law and human behavior, 24(6), 607-628.

Slate, R. N., \& Johnson, W. W. (2008). The criminalization of mental illness: crisis \& opportunity for the justice system. Carolina Academic Press.

Slovenko, R. (2009). Psychiatry in law/law in psychiatry (Second.). New York, NY: CRC Press. 
Smitherman, G. (1977). Talkin and testifyin: The language of Black America. Detroit: Wayne State University Press.

Spohn, C. (2002). How do judges decide?: the search for fairness and justice in punishment. Thousand Oaks, Calif.: Sage Publications.

Steadman, H, Monahan, J., Appelbaum, P., Grisso, T., Mulvey, E., Roth, L. H., Robbins, P., et al. (1994). Designing a New Generation of Risk Assessment Research. United States.

Sternberg, R. J. (1982). Handbook of Human Intelligence. CUP Archive.

Stier, A., \& Hinshaw, S. P. (2007). Explicit and implicit stigma against individuals with mental illness. Australian Psychologist, 42(2), 106-117.

Tajfel, H., \& Turner, J. (1986). The Social identity Theory of Intergroup Behavior. Nelson-Hall.

Tarasoff v. Regents of the University of California. 551 P.2d 334 (1976).

Tilken, D., (2012). After many escapes, state promises changes at Oregon State Hospital. KATU On Your Side Investigator. Retrieved from: www.katu.com/news/specialreports.State-promises-security-changes-at-hospitalfor-mentally-ill-138971539.html

Wahl, O., \& Aroesty-Cohen, E. (2010). Attitudes of mental health professionals about mental illness: a review of the recent literature. Journal of Community Psychology, 38(1), 49-62.

Waldroupe, A. (2011). Drastic Changes Needed at Oregon State Hospital. The Lund Report. Retrieved from: 
http://www.lundreport.org/resource/drastic_changes_needed_at_oregon_state_hos pital

Watson, Amy C., Ottati, V., \& Corrigan, P. (2003). From Whence Comes Mental Illness Stigma? International Journal of Social Psychiatry, 49(2), 142-157.

Webster, C. D., Nicholls, T. L., Martin, M.-L., Desmarais, S. L., \& Brink, J. (2006). Short-Term Assessment of Risk and Treatability (START): the case for a new structured professional judgment scheme. Behavioral Sciences \& the Law, 24(6), 747-766.

Weihofen, H. (1967). Capacity to Appreciate "Wrongfulness" or "Criminality" under the A. L. I-Model Penal Code Test of Mental Responsibility. The Journal of Criminal Law, Criminology, and Police Science, 58(1), 27-31.

Zeifert, M. (1957). Psychiatry and the Law. California Medicine, 86(1), 11-15. 


\section{Appendix A - Transcript of PSRB Hearing}

\section{PSRB}

Ok. Good morning everyone, this is a hearing of the Oregon Psychiatric Security Review Board. Today is February $20^{\text {th }} 2008$. This is the time set aside in the matter of [Patient], who is here with his attorney Jim Hughes, and representing the state is assistant attorney general Kristine Boyd. And for the board we have [PSRB Member], [PSRB Member], and myself [PSRB Member]. Before we proceed in the details of the hearing, there are a number of people here today, and it has been our custom to have people introduce themselves if they choose to do so. So, and we include hospital staff cause I don't know whom is whom here. Would you please identify yourself?

Other: My name is [Other], I'm [Patient]'s uncle.

Other: I'm [Other] and I'm his dad.

PSRB

Welcome.

Other: I'm [Other]; I'm [Patient]'s prior probation officer in X County.

Other: we are doing an educational documentary in bringing out the human side of this process, to bring more nuance and complex view of the issues than the public generally sees.

PSRB

Thank you, welcome to the hearing. We'll proceed then, [Patient] you have made a request for this hearing, and therefore during the hearing today the burden of proof will rest with you and your attorney going forward. With the additional exhibit we have 59 exhibits to go into the record today unless there is objection?

\section{DEFENSE ATTORNEY}

No objection.

DISTRICT ATTORNEY

No objection

PSRB

Are there any stipulations today?

DEFENSE ATTORNEY

Um, I spoke with [Patient], met with him last week, and he indicates that he does have a mental illness, however, he is not more dangerous if the mental illness is active so, one stipulation.

PSRB

Let's proceed with opening statements. [Defense Attorney]?

DEFENSE ATTORNEY

Yes, in meeting with [Patient], the file clearly demonstrates, and [Patient] will readily tell you that the issues that bring him here are due in part largely to trauma that he has experienced as a result of car, I believe multiple car accidents, vehicle accidents. And his treatment is um, here is, he has done what he needs to do and he is ready to get out. And so today he is asking for a full discharge, and if it is not within your good graces, I guess, to allow that full discharge he would consider conditional release as he wants to start working towards life on the outside. 
PSRB

[District Attorney]?

DISTRICT ATTORNEY

Thank you the state would waive opening.

PSRB

Thank you, then [Defense Attorney] you have witnesses to call?

DEFENSE ATTORNEY

I do have witnesses today. First I would like to call [Clinician], his treating

psychologist.

PSRB

[Clinician], please raise your right hand. Do you solemnly swear or affirm that the testimony you are about to give will be the truth?

CLINICIAN

Yes.

PSRB

Please state your full name and your relationship with um, [Patient].

CLINICIAN

Dr. Michael Robinson, I am the treating psychologist for [Patient] on ward 50F.

PSRB

Thank you. [Defense Attorney] will ask you some questions, the state will ask you some questions and likely the board will as well. Pease proceed.

DEFENSE ATTORNEY

Mr. Robinson, are you the treating psychologist for [Patient]?

CLINICIAN

Uh, yes I am.

DEFENSE ATTORNEY

And how long have you treated him?

CLINICIAN

Um, he has been on ward 50F for several months. I don't know the exact length of time. DEFENSE ATTORNEY

$\mathrm{Ok}$, and did you prepare the progress note update that I believe is dated February $13^{\text {th }}$ ?

CLINICIAN

Yes.

DEFENSE ATTORNEY

Exhibit number 58 in the file. Great. What is your diagnosis of [Patient]'s mental illness?

CLINICIAN

[Patient] has an axis I diagnosis of Bi-polar disorder and also a diagnosis of cannabis abuse, alcohol abuse, uh recent cocaine abuse and also cognitive disorder not otherwise specified. There is an, also an axis I listing of recent methamphetamine abuse which may not be the case. He had a test for methamphetamine recently, uh, it tested positive initially, but it was retested and the confirmation indicated that the test was actually negative. So I have reason to believe that that may not be the case.

DEFENSE ATTORNEY 
And, as a result of being his treating psychiatrist, you are on his treatment team?

\section{CLINICIAN}

Yes.

\section{DEFENSE ATTORNEY}

Has the treatment team reached a conclusion about what they are recommending for [Patient]?

\section{CLINICIAN}

Um, at this time we are not recommending conditional release. He, there is a consensus that he has a mental disorder.

DEFENSE ATTORNEY

Has what?

\section{CLINICIAN}

A mental disorder. And there was evidence for this mental disorder being active immediately prior to the revocation of his conditional release the last time. In which he had symptoms of mania. In addition he has um, problems maintaining, being clean and sober. Even in the controlled hospital environment.

DEFENSE ATTORNEY

Have you prescribed medication for [Patient]?

CLINICIAN

Yes.

DEFENSE ATTORNEY

What type of medication is he on?

\section{CLINICIAN}

He is currently on Abilify, Clonapin, and Depacote.

DEFENSE ATTORNEY

Ok, do you believe that he has insight into his mental illness? The bi-polar issues that you speak of, as well as the other various issues?

CLINICIAN

As a degree of awareness his mental illness and his cognitive limitations, insight would be possibly too strong of a word. [Patient] has difficulty understanding how the diagnosis and the problems that they present for him would affect his ability to function safely in the community. And also impact on his decisions about where he should live in the community; the degree of supervision that is required to um, be safe in the community.

DEFENSE ATTORNEY

Do you believe that he appreciates the importance of his medication?

\section{CLINICIAN}

Um, I think he does appreciate that to some extent.

DEFENSE ATTORNEY

Does he take the medication voluntarily?

CLINICIAN

Yes.

DEFENSE ATTORNEY

And do you believe that the medication has had a positive effect on [Patient]? 


\section{CLINICIAN}

Yes.

DEFENSE ATTORNEY

Ok, um do you believe that he has insight into what caused his crime, that mental illness caused his crime?

CLINICIAN

Um, I think he has some degree of insight, but again I think that the level of understanding that he has regarding it is limited in scope.

DEFENSE ATTORNEY

Ok, does he attend classes er, any classes or group discussions?

CLINICIAN

Yes.

DEFENSE ATTORNEY

And what type of classes or group is he in?

CLINICIAN

$\mathrm{He}$ is involved with a number of different classes. He has been involved with the matrix class, which has to do with substance abuse issues. He attends self-help groups, among other groups.

DEFENSE ATTORNEY

And are these classes targeted toward his diagnosis, his illness?

CLINICIAN

Yes.

DEFENSE ATTORNEY

And are they also, they are also targeted like the matrix class toward his drug and alcohol issues?

CLINICIAN

Yes

DEFENSE ATTORNEY

Ok, is his attendance good at these classes?

CLINICIAN

I do not actually have a list of the classes that he has attended.

DEFENSE ATTORNEY

Ok

CLINICIAN

So I can't respond to how reliably he has attended the class at this time.

DEFENSE ATTORNEY

Not even, do you have any information as to the classes he has attended on your ward?

CLINICIAN

That's what I'm talking about.

DEFENSE ATTORNEY

Oh ok, ok, I thought you meant other wards. Um, do you find that he is cooperative?

CLINICIAN

Uh

DEFENSE ATTORNEY 
With respect to scheduling classes and things like that?

\section{CLINICIAN}

Um, yes.

\section{DEFENSE ATTORNEY}

And do you find him to be a person who is engaged, you know, interacts, is involved in asking questions discussing issues with you.

\section{CLINICIAN}

Yes.

\section{DEFENSE ATTORNEY}

Ok, and could you describe his progress I guess in the time that he has been here at the hospital, do you have a feel for how he is progressing in being able to, in the treatment I guess, for his mental illness.

CLINICIAN

Well [Patient] does not have any active symptoms of bi-polar illness at this time. His cognitive limitations are fairly stationary, and could be considered at baseline. It's an ongoing limitation in terms of his function. The issue, one of the main issues right now has to do with [Patient] not fully appreciating the need for structure and supervision when he gets out of the hospital.

DEFENSE ATTORNEY

Ok. And is [Patient] working?

\section{CLINICIAN}

Um, at this time I'm not aware of his status with regard to employment.

DEFENSE ATTORNEY

Ok, and are you aware of whether he has worked in the past?

CLINICIAN

I don't have that history.

DEFENSE ATTORNEY

Do you find that [Patient] gets along well with the residents on the ward?

CLINICIAN

I believe that he does.

DEFENSE ATTORNEY

Ok and does he get along well with the staff?

\section{CLINICIAN}

Yes.

\section{DEFENSE ATTORNEY}

OK, does he have, do you guys, I don't know if you have write ups, or formal disciplinary proceedings or anything like that, but does he have any glitches I guess with respect to write ups or disciplinary proceedings?

\section{CLINICIAN}

Yes um, he has had difficulty staying clean and sober, and he did abuse cocaine recently, and that prompted a transfer from minimum security ward to maximum security and later back to the 50 building toward 50F.

DEFENSE ATTORNEY

And uh, does [Patient] have any passes right now that you are aware of? 


\section{CLINICIAN}

I am not aware that he has any. To my knowledge, he doesn't have privileges so he is not available for passes at this time. I can confirm that if you'd like.

DEFENSE ATTORNEY

Sure.

(Shuffling)

CLINICIAN

He did have privileges but, my understanding is because he was transferred to ward 48B, maximum security, in that process a person will lose their privileges and they will have to reapply for them.

DEFENSE ATTORNEY

Are you aware if [Patient] has prepared a relapse prevention plan?

CLINICIAN

At this time I am not aware of a relapse prevention plan that has been completed.

DEFENSE ATTORNEY

Ok, do you believe [Patient] has changed since he came to the hospital?

CLINICIAN

He has changed with respect to the bi-polar illness. He doesn't have active symptoms of mania at this time.

DEFENSE ATTORNEY

Ok. So with respect to the bi-polar treatment, could it get any better? Could his response be any better or basically we have reached the limit of what we can expect on the bi-polar treatment?

CLINICIAN

Well one way of looking at it is that you're, when you're treating an axis I mental disorder you treat the target symptoms, and that is obviously very important aspect of treatment, but you are also treating other aspects of illness that have to do with the person degree of awareness understanding and acceptance of the nature of their condition, and what needs to be done to remain symptoms free or to address symptoms is they emerge. And that is really the area in which [Patient] has difficulties.

DEFENSE ATTORNEY

Ok. So you are saying that if he has a, kind of has a realistic relapse prevention plan and appreciates the need for I think you said structure and supervision, those are the kinds of things that would allow him to evolve and possibly move out toward conditional release? CLINICIAN

Yeah.

DEFENSE ATTORNEY

Ok, ok. Do you believe [Patient] is supervisable in the community?

CLINICIAN

Yes.

DEFENSE ATTORNEY

If he was granted conditional release do you believe he would earnestly attempt to work with the people that he assigned to work with?

CLINICIAN 
At this time I think that there is some degree of uncertainty with that because he has made statements that he feels that he should be simply released from under the jurisdiction of the PSRB, he has stated that he doesn't believe that he has a mental disorder and that his problems are due to brain injury alone. This is problematic.

DEFENSE ATTORNEY

Ok, no further questions. Thank you.

DISTRICT ATTORNEY

Thank you, good morning Doctor. Are you familiar with the reasons for why the revocation occurred from the most recent conditional release?

CLINICIAN

Yes I am.

\section{DISTRICT ATTORNEY}

Can you tell us why he was revoked back in October of 2006 ?

CLINICIAN

Yes, he developed prominent manic symptoms after only a very brief period of time out of the hospital. It was a matter of days, and he also was not compliant with his medications at that time.

DISTRICT ATTORNEY

Was there any conflict with other peers or members of the house that we was conditionally released to?

CLINICIAN

Yes.

DISTRICT ATTORNEY

Do you recall the nature of that conflict?

CLINICIAN

Um, not specifically.

DISTRICT ATTORNEY

Now was he following staff, uh, at the conditional release placement in their requests?

CLINICIAN

Oh, was he following staff directives?

DISTRICT ATTORNEY

Yes.

CLINICIAN

Um, not completely or consistently. He also was approaching female staff and inappropriately touching them. In addition from my chart review, in reviewing my notes um he was threatening other residents of the group home.

DISTRICT ATTORNEY

And this was [Patient]'s second conditional release placement at X County correct?

CLINICIAN

Yes.

DISTRICT ATTORNEY

Do you recall the nature of the reason for the revocation from the initial conditional release placement?

CLINICIAN 
Uh, not at this time.

DISTRICT ATTORNEY

You indicated that there has been some substance abuse problems continuing with

[Patient] while he is on the wards at the hospital is that right?

CLINICIAN

That's correct.

DISTRICT ATTORNEY

I think you testified specifically that there was a positive test for cocaine, is that right?

CLINICIAN

Yes.

DISTRICT ATTORNEY

Also I believe this is in exhibit 58, in December of 2007 the hospital staff was concerned of Ambien abuse is that correct?

CLINICIAN

Um, yes. I was the treating physician at that time. So I have firsthand knowledge of that.

$17: 57$

DISTRICT ATTORNEY

And what was of concern?

CLINICIAN

[Patient] was taking Ambien but not intending to go to sleep, and we determined that he was using Ambien to basically alter his mental state rather than using it as a sleeping aid. DISTRICT ATTORNEY

And has [Patient] been honest with the treatment team about his substance abuse use while in the hospital?

\section{CLINICIAN}

Um, his degree of honesty and openness are in question. I guess that's the best way of putting it. It's something that we are evaluating.

DISTRICT ATTORNEY

You communicated that [Patient] has a, I believe you said degree of awareness about his mental disorder, but then I think I also heard you say he at times has often stated that he did not have a mental disorder. Is it a fluctuating response? Could you clarify?

CLINICIAN

Well I think partly it could be related to his cognitive disorder from his prior brain damage. He has a, a, behavior in terms of what he verbalizes that suggests that there is some damage to his frontal lobes such that he tends to perseverate and partly I think he has been perseverating on wanting to get out of the hospital using a particular strategy, and he has had difficulty looking at all of the different ramifications of that, whether or not it's even feasible. So he has pursued that line of reasoning the idea being that if he doesn't have an axis I mental disorder he should be released from the hospital. And he has stated his belief or his intention to be released from under the jurisdiction of the PSRB because he can state that his problem is only due to brain injury and therefore there is no mental illness.

DISTRICT ATTORNEY 
How is his insight into the nature and causes for his revocation?

\section{CLINICIAN}

Um, we have not talked a great deal about the specifics of that since he has been on ward $50 \mathrm{~F}$. I can say though that he does acknowledge, despite the fact that he disavows having a mental illness sometimes, there are other times when he does acknowledge having a mental illness. Including a bi-polar illness and he has some degree of awareness of what symptoms there are in having the bi-polar illness.

DISTRICT ATTORNEY

the fact that he sometimes disavows having a mental disorder does that cause you concern that he may not be compliant with any medication of treatment if he was to be conditionally released or discharged?

\section{CLINICIAN}

Yes.

\section{DISTRICT ATTORNEY}

And I believe I just want to clarify; at this point the risk board has not approved [Patient] for privileges is that right?

\section{CLINICIAN}

That's correct.

\section{DISTRICT ATTORNEY}

And at this point the risk board is not approved [Patient] for conditional, I'm sorry they have not; the treatment team is not recommending conditional release or discharge. Is that right?

\section{CLINICIAN}

That's correct, and that's also the position of the risk board as well. DISTRICT ATTORNEY

And has [Patient] been recommended for an evaluation? Has there been a placement identified for [Patient]?

\section{CLINICIAN}

I'm not aware of any at this time.

DISTRICT ATTORNEY

You indicated I believe at this time there is not a relapse prevention plan at this time, is that correct?

\section{CLINICIAN}

I am not aware of a relapse prevention plan at this time that has been completed. DISTRICT ATTORNEY

And did [Patient] identify the triggers that would lead to a manic episode or a bi-polar problem?

\section{CLINICIAN}

I do not believe, I don't have confidence that he is able to do that at this time.

DISTRICT ATTORNEY

As part of, do you know [Patient]'s plan if he was to be discharged, what where he believes he would live and seek treatment.

CLINICIAN

He has indicated that he wants to live with family. 


\section{DISTRICT ATTORNEY}

And are you aware of any difficulties that surround his contact with his family?

\section{CLINICIAN}

There are some difficulties, um, I'm sure there are a lot of things that I'm not aware of but in particular, his sister was the person who brought cocaine to the hospital and gave it to him; in a rolled up dollar bill.

\section{DISTRICT ATTORNEY}

So would that be a concern for [Patient] maintaining his sobriety?

\section{CLINICIAN}

Yes.

DISTRICT ATTORNEY

Thank you I have no additional questions.

PSRB

Members of the board?

PSRB

No questions.

PSRB

[Clinician], how frequently are you titrating [Patient]'s medication?

CLINICIAN

At this time there is not any active titration involved. Basically, it seems like the Abilify and the Depocote are fairly good medications for him. I believe that they are at therapeutic levels. The blood level for the Depocote is therapeutic, and the Abilify is certainly within the dose range that should be considered therapeutic. The Clonapin is something that, in the long run it would be worth considering tapering him off of. $\mathrm{He}$ was on Clonapin when he came to $50 \mathrm{~F}$, and that has not been fully addressed yet. Certainly that is something that we could take a look at and work on.

PSRB

Is that the kind of medication adjustment that could be accomplished with a less frequent medical service for example? What might be found in a secure residential treatment facility?

CLINICIAN

Yes it could be done there.

PSRB

Ok. Thank you.

PSRB

Follow-up on any of the questions that [PSRB Member] asked?

DEFENSE ATTORNEY

No further questions from me.

DISTRICT ATTORNEY

No further questions thank you.

PSRB

Thank you [Clinician]. Do you have any other witnesses?

DEFENSE ATTORNEY

I do, [Patient] himself. 
PSRB

[Patient], would you raise your right hand please? Do you solemnly swear or affirm that the testimony you are about to give is true?

\section{PATIENT}

Yes I do.

PSRB

Your attorney is going to ask you some questions, and then [District Attorney] will ask you some questions, and I think it's highly likely that we'll want to ask you some, that we'll want to talk with you too.

\section{PATIENT}

OK.

\section{DEFENSE ATTORNEY}

Great, [Patient], I'd like to go over some issues that we chatted about last week when we met. First of all, there is some discussion about whether you have a mental illness or not. Could you please clarify your position on your medical situation here?

\section{PATIENT}

Yes I am, I do have bi-polar illness that was activated when I got in my motorcycle accident before I got into a car accident 11 months later that gave me traumatic brain injury. So I actually had 2 traumatic brain injuries a year apart from each other. So um, DEFENSE ATTORNEY

No that's great. And you have heard [Clinician]'s testimony, so I'd just like to go through a few preliminary issues and then ask you some I guess more in depth questions. First of all, was his recitation of your medications accurate?

PATIENT

Did I take Clonapan, Depocote, and er not Zyprexa, Abilify? Yes. That's accurate. DEFENSE ATTORNEY

Ok, and do you take those medications voluntarily?

PATIENT

Yes I do. DEFENSE ATTORNEY

And how long do you believe you will have to take those medications?

PATIENT

For the rest of my life.

DEFENSE ATTORNEY

Ok and what would happen if you stopped taking those medications?

PATIENT

I would go psychotic.

DEFENSE ATTORNEY

Ok, and have you prepared a relapse prevention plan?

PATIENT

Yes I have, it's right here.

DEFENSE ATTORNEY

And what are your warning signs, warning that a relapse may occur.

PATIENT 
Um, drinking too much coffee gets me stimulated to where I'm unable to function correctly. I get really anxious and really anxiety, full of anxiety and stuff like that, so... DEFENSE ATTORNEY

Go ahead, I'm sorry.

PATIENT

I do believe that a PRN of Visterol that was added to my list, I used to take Visterol and that worked well for me. On days that I feel anxious I feel that should be added to my PRN list; cause that's some of the medication that I need.

DEFENSE ATTORNEY

Ok, if you were out in the community and you started feeling these feelings that you are just describing now what would you do?

PATIENT

I would contact my doctor, DEFENSE ATTORNEY

Ok, that's great.

PATIENT

Go to the ER

DEFENSE ATTORNEY

OK

PATIENT

If I have to.

DEFENSE ATTORNEY

Ok that's excellent, is that what your relapse prevention plan indicates to?

PATIENT

Yeah I believe so.

DEFENSE ATTORNEY

Ok, and do you believe that you have a substance abuse problem?

PATIENT

I know I do, I know I made a mistake on 35A, and I know I set myself back a long time. DEFENSE ATTORNEY

OK

PATIENT

And I believe that um, it was the total wrong thing to do. It was totally the wrong thing to do. I just went on a whim and I did it cause it was in front of me when I found, I unrolled a twenty dollar bill and I found this cocaine inside of it, and I decided to use it just on the spur of the moment, and I should have flushed it down the toilet, it's what I should have done but I didn't.

DEFENSE ATTORNEY

Are you in groups or classes here that address substance abuse issues?

\section{PATIENT}

Yes I am.

J What types of groups and classes are you in?

PATIENT 
I'm in matrix, I'm in, I take relapse prevention still, I go to DDA, Dually diagnosed anonymous, I go to NA, and I go to a lot of church and that's good for me.

DEFENSE ATTORNEY

Ok and do you feel like you benefit from these groups?

PATIENT

Yes I do, and do you, how do you benefit from the groups what...

PATIENT

Well they teach me about, I mean, yesterday I had a matrix class and it just teaches you more, it opens you up to more of a, the issues of substance abuse problems and what can occur on the outside you know? Going to a wedding you're gonna be influenced by alcohol or you know just separate things that are really opens you mind up to different aspects cause we got a really good teacher and he does a really good job in the matrix group.

\section{DEFENSE ATTORNEY}

Ok, and when you are in these groups do you personally express yourself, do you actively involve yourself in the discussions?

\section{PATIENT}

Yes I do.

\section{DEFENSE ATTORNEY}

Ok, you talk through your problems in there?

\section{PATIENT}

Yes I do.

\section{DEFENSE ATTORNEY}

Ok, what, how long will you need to stay in groups whether in the hospital or out on the streets?

\section{PATIENT}

Oh I always, I'll always stay in groups. I plan on being a, actually a person that will help the mentally ill when I get out, whether it's on a conditional release or on a full discharge. Someday you know.

DEFENSE ATTORNEY

Ok, what do you need to do, if you were let out, what do you need to do to stay sober? What things do you need to avoid or do or take, how would you change your...

\section{PATIENT}

I need to avoid my sister. I need to avoid stressful situations. I need to avoid bars. I need to avoid people that are going to into bars a lot you know? And being around that environment, and avoid all people using drugs or alcohol.

DEFENSE ATTORNEY

There's been some I guess discussion or inference that if you went back to your family or you were living to your family there may be some exposure there possibly to your sister or to some other influences. Would you be open to placement in say a group home or someplace like that as opposed to your family?

\section{PATIENT}

I would be open.

DEFENSE ATTORNEY 
Ok,

\section{PATIENT}

And let me state this, um, its, it sounds kind of funny but um, the group home would gladly take me back where I was at before. I've talked to them and talked to my case manager in X county and he said he'd gladly take me back, I was a really good person for them to have at $\mathrm{X}$ county. I did have issues with my brain damage and my mental illness um, sometimes it came, the two combined are really hard to get your head straight, and get things focused and stuff. Like I try to take college courses and stuff like that, but it didn't work out for me, you know what I'm saying? It's like really hard on me. So I think that I'm getting a lot more focused nowadays and um, I'm just getting closer to where I need to be.

\section{DEFENSE ATTORNEY}

So you believe you've completed all the classes you need to here at the hospital to allow you to kind of be prepared for the outside.

\section{PATIENT}

Yes, I , this is actually a book I did over in 35A, and it's called Social Independent Living Skills, it's a management module and I completed about half that book before I got transferred to 45B, a little over half of it actually. And I did my relapse prevention plan for the $4^{\text {th }}$ time I believe, and um, I've tooken classes on $41 \mathrm{~A}$ and $35 \mathrm{~A}$, I've tooken classes in 50F prior um, over a year ago, when I was on 50F. You know I've done, a lot of stuff at this hospital, and it comes through groups and stuff like that. I know what I need to do. I'm aware of my mental illness, um, you know I'm, I know the medications are working for me, so I don't' want to change them. I I just don't, I want to stay straight and sober as I can be you know? And um,

DEFENSE ATTORNEY

Are you working now in the hospital?

PATIENT

No I'm on the March list I guess I'll be brought up.

DEFENSE ATTORNEY

Ok, have you worked here in the past?

PATIENT

Yes I have.

DEFENSE ATTORNEY

And where'd you work?

PATIENT

Um 93 bench work.

DEFENSE ATTORNEY

And what was your work schedule like on atypical week when you were working?

PATIENT

It's just two hours a day, we only worked like an hour and half and it takes 15 minutes to get there and 15 minutes to get back.

\section{DEFENSE ATTORNEY}

Ok, Ok, and do you get along well with the residents in your ward?

PATIENT 
Yes I do.

DEFENSE ATTORNEY

Ok and any problems with them at all?

PATIENT

No.

DEFENSE ATTORNEY

Ok, you get along well with the staff?

PATIENT

Yes I do.

DEFENSE ATTORNEY

Ok, any problems at all? Write ups or?

PATIENT

No

DEFENSE ATTORNEY

Ok,

PATIENT

Not that I'm aware of

DEFENSE ATTORNEY

Ok, would you

PATIENT

I wasn't aware of the Ambien problem that [Clinician] was talking about.

DEFENSE ATTORNEY

Ok

PATIENT

I still take Ambien on a regular, not on a regular basis, but when I need it, for sleep.

DEFENSE ATTORNEY

Ok, I appreciate that you've gone, you went to 40A briefly, and now you are back, did you have privileges on $40 \mathrm{~A}$ ?

PATIENT

I had I think about all the privileges you can get. Um, unescorted on grounds, peer to peer, the only thing I didn't have was unescorted by yourself on and off grounds.

DEFENSE ATTORNEY

And are you working back towards regaining those privileges now?

PATIENT

Yes, but the treatment team told me that they would wait till my hearing before they would put me in front of the risk review board.

DEFENSE ATTORNEY

Ok, ok, now there has been some discussion that you may need more structure and more supervision on the outside so to speak. Would you be open to having a kind of a group home that has rules and structure and expectations?

PATIENT

I would, but on the other hand I want to say something on my dad's behalf. I was once in mental health court and he took me to NA and AA like five days a week and he, he was really good about it. And he didn't wasn't mad at me or nuthin. He just, I said “it's time 
to go" and he said "ok", or he'd say "it's time to go" and I say "ok". You know, we go like 5 days a week; we'd even go from Sandy to Gresham and different meetings there. DEFENSE ATTORNEY

Now, you, right now [Clinician] says your bi-polar condition your mental illness is not active. You indicated that if you stop taking your medications you'd become psychotic, you realize that your bi-polar condition may come back in the future.

\section{PATIENT}

Yes, I am aware of that.

DEFENSE ATTORNEY

Ok, and what would happen if you went on the, flip back to the sobriety issue, the clean and sober issue, because that seems to be a recurring theme here. What do you believe would happen if you start drinking or taking drugs again, how would that impact your life?

\section{PATIENT}

Well that would turn my life around, you know? It'd take me backwards, it would back step me and I don't wanna move backwards anymore want to move forward. It's time for me to grow up and take responsibility for my own actions. And um, just not use and help other people out.

\section{DEFENSE ATTORNEY}

Do you believe you have changed since you have entered the hospital here?

\section{PATIENT}

Yes I know I have.

\section{DEFENSE ATTORNEY}

You've been out on conditional release once and there were some problems almost immediately and you came back, do you believe that if they released you a second time that those problems would re-occur?

\section{PATIENT}

No I don't think they would.

\section{DEFENSE ATTORNEY}

And what would you do to make sure they don't re-occur?

\section{PATIENT}

I would take medication I would make sure I'm not, I'd listen to staff and take cues from staff that's cueing me. And I'd do everything as asked to do on conditional release.

DEFENSE ATTORNEY

Do you believe you; you now understand your mental illness better than you did when you enter the hospital and when you came back under conditional release.

\section{PATIENT}

Yes I do, exactly; I'd do a lot more.

DEFENSE ATTORNEY

And finally I guess question I asked previously, if they did grant you conditional release would you agree to follow all rules?

PATIENT

I would.

DEFENSE ATTORNEY 
Ok, no further questions for [Patient].

PSRB

[District Attorney]?

DISTRICT ATTORNEY

Thank you. [Patient], you indicated in your relapse prevention plan you have some triggers you've identified. I think you said coffee was one of them. What are some of your other warning signs?

PATIENT

Going into a bar, and being around alcohol or just, I can be around alcohol and not drink it. I haven't dranken for a long long time. So it's not, it hasn't been a problem for me. DISTRICT ATTORNEY

You can be around alcohol and not drink it is that what you just said?

PATIENT

Yes I can.

DISTRICT ATTORNEY

And what are, I guess I'm specifically asking your warning signs for you mental illness. What are those warning signs?

\section{PATIENT}

My warning signs for mental illness are, um, let's see, if I quit taking my meds, those are like, a sleep deprivation, um, food stop eating my food. Not as much food. There's a few of 'em um, let's see... ()

DISTRICT ATTORNEY

And are those listed in your relapse prevention plan?

PATIENT

Yes.

DISTRICT ATTORNEY

And your substance abuse warning signs what are those? You have identified not going into a bar...

PATIENT

Yeah and not going around people who are smoking or using drugs.

DISTRICT ATTORNEY

Ok, you indicated that was your sister, is that right?

PATIENT

Yes

DISTRICT ATTORNEY

How did you get the cocaine in October?

PATIENT

How'd I get it?

DISTRICT ATTORNEY

Yes.

PATIENT

Well she gave me a 20 dollar bill wadded up and said here I hope this helps you out.

And I got back to my room in $35 \mathrm{~A}$ and opening it up and there was a bag of cocaine in it. And that's when a friend of mine, a fellow person in the hospital was in the room with 
me, came in and said, what do you got there, and I said a bag of cocaine, and he said can I have some of it? And I said sure, and we both used a line of it and he got the UA the next day and they then UA'ed the whole unit and I came up positive the next day. DISTRICT ATTORNEY

And you've heard [Clinician] talk about Ambien in December, and that you indicated that you were unaware that the treatment team thought that you were seeking Ambien to alter your mental state. Is this the first time you are hearing this?

PATIENT

Right right. Yes it is.

DISTRICT ATTORNEY

And so are you denying that that's accurate?

PATIENT

Yeah I'm denying that for sure I didn't know anything about that.

DISTRICT ATTORNEY

And you never talked to [Clinician] or anyone else in the hospital about that issue?

PATIENT

Not that I remember, not that I recall.

DISTRICT ATTORNEY

What is you plan if you should be discharged, where would you live?

PATIENT

I would live with my dad, and um I have a job already at [resort], and they have a bus at the top of our hill. We live in the country a couple miles from [Town], and there is a bus at the top of the hill that takes us to [resort], my dad says he'd be glad to wake up early in the morning and take me to work.

DISTRICT ATTORNEY

So you have a job at [resort] doing what? What's your job?

\section{PATIENT}

Um, being a lift operator.

DISTRICT ATTORNEY

And how about treatment and medication and maintaining your sobriety, what are your plans?

PATIENT

My plans are to keep going to X county mental health and um, my treatment in and um what else?

DISTRICT ATTORNEY

Your mental health treatment, you said X county mental health...

PATIENT

Yes

DISTRICT ATTORNEY

And how about Substance abuse treatment?

PATIENT

I plan on going to a lot of AA classes and DDA classes, they just started DDA, I just started going to them like a year and half ago and it's a really god class cause it focuses on both your mental illness and your drug addictions and alcohol use. And um, so it's all, 
it's like a package deal, and I want to actually work for DDA or do um, what's that called? When you just volunteer, I just want to volunteer for them cause it's a really good group.

\section{DISTRICT ATTORNEY}

Is gambling an addiction for you?

PATIENT

Yes it is.

DISTRICT ATTORNEY

And do you go to treatment for that?

PATIENT

Um I went to 6 months of it I believe.

DISTRICT ATTORNEY

And would you do treatment for it if you were to be discharged?

PATIENT

Um, yes I would. I would go back for another 3-6 months and take it and do that too. DISTRICT ATTORNEY

It's not something you think you need to do always?

\section{PATIENT}

Um treatment? No, I think the gambling anonymous is something I need to do always, but I don't think gambling therapy... I mean it's a totally different group. Gambling anonymous I like AA or DDA or NA, it's something that GA is a really good group. I like it cause people, you're aware of what, people are aware of what you're like, and you're aware of what they are like, and it's a really good group.

DISTRICT ATTORNEY

And if you are living at your Dad's house how would you avoid having contact with your sister? What's your relapse prevention plan for that?

\section{PATIENT}

She doesn't come out to [town], she lives in [town] or [town] or somewhere.

DISTRICT ATTORNEY

So if she contacted you what's your plan for avoiding contact?

\section{PATIENT}

Just tell her that I can't be around her. My focus is all on recovery and um, not, I can't be around her right now. Or in the future I can maybe you know, but she needs to get herself straight first. I've had my time of, I've learned my lessons you know? I've had my lessons to learn over the years and um it, it's been a hard road to travel you know? I'm 30 years old and I have addiction problems, I'm not gonna lie you know? But I can't face them, and I realize that I do have addiction problems and I do need to go to groups and treatment groups and stuff. Like I would even enter into alcohol and drug therapy where they give you UA's in there too.

DISTRICT ATTORNEY

You were placed under conditional release to X County twice right?

PATIENT

Yes, the second time was only for 4 days.

DISTRICT ATTORNEY 
And I think you in answering a question of your attorney I think you said that you are of the opinion that they would accept you back for their group home is that right?

PATIENT

Yes, they said that they would.

DISTRICT ATTORNEY

Have you been evaluated recently by them?

PATIENT

No I haven't.

DISTRICT ATTORNEY

Ok, Thank you I have no additional questions.

PSRB

Members of the board?

PSRB

I just have a quick question.

PSRB

Please.

PSRB

I'm concerned about your last time you went out on conditional release, how quickly things fell apart for you, what happened? What is your understanding of what happened? PATIENT

I, I my understanding was, I wasn't ready to be discharged from the hospital. I was only sleeping two hours a night at the hospital. And I was drinking too much caffeine, cause in $35 \mathrm{~A}$ you are allowed coffee and I wasn't aware of my coffee issue at that time. Um that I had issues with drinking too much, er, even though just, four cups of coffee will put me over the edge, a regular person can drink 4 cups of coffee a day. But I, being bi-polar and having brain damage I can't do that to myself. Cause I had Starbucks coffee, I had the good stuff (giggling but unclear) coffee and I was like, man this is too much. And I was, they were fully aware cause they had staff at the hospital, and I guess half the staff said I could go and half the staff said I couldn't go. And they went with the staff that said I could go and um, I think they were really worried about me losing my bed at X county cause I was out only at the hospital for like 2 months before they sent me back out again. And see I was, I was at

PSRB

You really just think that you weren't ready.

PATIENT

I wasn't ready to go back and told them back and told them I didn't want to go back to X county at the time that I wasn't ready.

PSRB

So you are ready at this time?

PATIENT

Yeah I feel ready, I feel like I'm ready.

PSRB

All right thank you.

PSRB 
I'm just curious because, you convey such a sincere desire to succeed, but you talked earlier about the fact that sometimes something happens on impulse. You just, why is that?

\section{PATIENT}

That's cause my frontal lobe is um, pushed back from the car accident, and I have a impulse control problem. But I have been working sincerely on that problem. And um PSRB

If it's a problem with your brain how can you control it? What are your plans for avoiding impulsive behavior?

\section{PATIENT}

I think that thinking about it puts, it's like looking at the computer screen and taking in the information, thinking about things before you do them you know? I think I've been doing that a lot more, I know I have you know? I have been inputting stuff into my brain before I do them and it's been working for me so

PSRB

Even if this board doesn't grant your request today and we haven't, we'll deliberate in a few minutes and let you know. In 25 months you are not gonna be under our jurisdiction any longer.

\section{PATIENT}

That's what I'm saying, I want to get out and get help, I want to get out and get there PSRB

Is your plan to move back with your family then? One way or the other?

\section{PATIENT}

Not really, my plan is to stay with my Dad for a couple to a few months, save up money for my own house, see I was the best resident at this house. When they had people come from X County or the state or the cops come, they would talk to me, and I would tell them about mental illness. What, what to look for the cops to look for and a person that might be showing signs of mental illness before they have to be, be brought to violence or...

\section{PSRB}

Let me interrupt cause I'm getting a little lost. You want to live with your Dad for a while and then move out on your own?

\section{PATIENT}

Yes, I was very good, I cooked independently, I had my own garden at this house that I was at for a year and 3 months. I did a lot of stuff on my own, you know I went to college on my own, I can ride the mass transit system, you don't have to worry about me getting in a car and turning the key and trying to take off any more. I've grown past that. I've learned my lesson.

PSRB

Did you hear [Clinician] said, the two things he thought were most important were a solid relapse plan and a structured environment? What do you think he meant by a structured environment?

\section{PATIENT}


Well, he meant somebody to watch over me, and make sure I'm doing, taking my medications I guess.

PSRB

Would you agree with that assessment?

PATIENT

Well I think I can take my medications on my own you know?

PSRB

About the structured environment I mean.

PATIENT

Yes I do. I think my dad has a structured environment for me, but I think a group home would work just as well.

PSRB

Any follow up on anything the board has pursued?

DEFENSE ATTORNEY

Not from me.

DISTRICT ATTORNEY

No additional questions.

PSRB

[Patient], thank you very much, you did a good job. [Defense Attorney] other...?

DEFENSE ATTORNEY

I would like to have [Patient]'s father, [Other].

PSRB

[Other], can you come to the table where [Clinician] is and we'll do a little swap so you can be heard on the recording that we make of this hearing? Will you raise your right hand? Do you solemnly swear or affirm that the testimony you are about to give is the truth?

OTHER

I do.

PSRB

Please state your full name and your relationship with [Patient].

OTHER

[Other] and I am [Patient]'s father.

PSRB

Thank you. Proceed with your questions, the state will then ask some questions and then we'll have some questions for you sure.

DEFENSE ATTORNEY

[Other] you have heard all the testimony at this point, I'd just like to ask you a few questions to see how you can kind of fit into his whole thing and maybe kind of solve some of the problems or the the shortcomings of some of the plans that might come up here. Help me understand your involvement with [Patient] when he has been, had to go, I think he mentioned that you took him when he has had to go to NA class and AA class and stuff like that.

OTHER

Well I've been involved with him since the second accident 


\section{DEFENSE ATTORNEY}

Involved?

(Chuckling)

OTHER

Well since day one, but since the second accident where the most of the damage came from. The first accident, the motorcycle accident he had Doctor at [Hospital], who is a wonderful surgeon and even the bi-polar thing manifested gradually went away. And, as a matter of fact he had a job that he was going to start the day before this drunk driver put him into this tree, he, no it was two days later, he was going to start a job over in central Oregon. So you know things were going well. And then this second, this second wreck, after that the bi-polar came back and it never has went away. But his brain was damaged; he was basically in a coma for almost a month.

DEFENSE ATTORNEY

Wow

OTHER

The medical bills were 400 and some thousand dollars, he had a lot of damage, I think he even actually had a stroke during it, during this accident, his life (flooded?). It was very traumatic but I have been with him through thick and thin, we have been through a lot together, I say he should make a movie about it, you wouldn't believe some of the stories I could tell you. And as a parent, I been worried a lot that, first off I'd like to say that the state hospital has been the only place that has given my son any help. You know X county mental health was pretty good. [Other] has been a saint! He still, he's taken a day off work to come down here and be with my son. You, he, you know, he probably won't like me saying this but the guys been a saint to my son. He's been like a second father, but my point is that; it's like, [PSRB Member] ?

\section{DEFENSE ATTORNEY}

Yes

OTHER

[PSRB Member] is kind of like thinking like I am, I'm worried about the next 25 months it's gonna go away and I'm concerned that he's gonna have to go from this controlled structured environment into the free world and then, it's not, and there is not going to be this support anymore, he's not going to have this PSRB board over his head anymore. And what I'd really hope for him is that he could have some kind of a transition like he had before. Because like he said, he, for 13 months at this group home in, before he had the relapse, and then the 4 day thing where he shouldn't have really left the hospital. That's the only thing about the hospital that I would say. And I don't think it was really the hospital, for two months they were holding his bed at the group home where he had had success for over a year, he'd been there for over a year, being a successful, off of drugs, and he went to college classes, which were, he went to a full credit. He went from, you know, he's got a GED but he never even hardly went to high school. I think freshman year that's all. So anyway he went to a full load in college and he couldn't he couldn't cope with it. It was just too much stress, but. I'm with [PSRB Member]; I'm worried that, what I'm hoping is that he can have some kind of a transition where he goes from here, maybe to a more structured environment perhaps than he was at the other 
house. But I know the other house was a good house, except they needed to have more people that could identify, because I called this house, and I told them, 5 days before he ended up being taken back here, I said he, cause I know the signs, cause I've lived with him for enough years that I know. When he starts staring at the sun, or when he starts turning the music up way loud, I know all the symptoms of when he's gonna go manic. And I warned the house and they just, they just, they didn't take me seriously and it, you know in going from being stable to manic its happens so quickly. And especially if you are not taking your meds, I mean it happens just like that (finger snap). So I guess what I'm trying you know, I know my son wants to live with me, and I wouldn't have a problem of that, but in the next two year period I would like to see him be successful perhaps in a controlled environment for a little while. Maybe where he gets some serious drug and alcohol treatment, and then the house like he was at before, and maybe prove himself for 6 months there, like say maybe 3 moths at the drug treatment, and then maybe 6 months with me, and then, you know all this with conditions, and then by that time we are almost done with the two years that he's got left. Because he is gonna have to know in two years how to take care of himself, and I think he's gonna be capable of doing that. But till he actually gets out, you know, it's like sink or swim almost. I'm sorry to say that, you know? But you know he needs to get out somehow and get a little more responsibility, this deal with his sister you know, as a parent what can you say? Here's, here's, I love both my children, but when one of your children does something like that to another one of your child, she knows that he has brain damage; she knows that she has drug addiction. But you know people that such as her, that have drug addictive personalities they feel like if you're not all in the same boat with us then you're not normal, which is totally abnormal, I mean it's totally opposite of what. But you know, I know, I don't expect the board to give him his unconditional release today, and I don't really think [Patient] does, but you can see from listening to him, he is on the road to recovery, and he is gonna be ready in a month or two I think, or at the most 3 months, to be in a group home like he was before and be successful. And But then on the other hand I would like to be able to have him sent to a, or maybe if he goes on his own as a volunteer...

End of A

OTHER

...to [Hospital] and maybe they can help him understand with his brain damage how he is going to be able to ah, control his drug addictions. Because that's the only thing that sets him back. With him, it's one beer, on line one toke, you know? That's all it takes for him and he's off. And he knows that, but it's just so tempting. And in our society you know, most people that don't have brain damage, and don't have mental illness have a tough time avoiding these pitfalls. So then, you know? You give him one, you know. I'm just saying what I would like to see is what I just talked about. And I think, I think that maybe [Patient]s gonna be md at me for saying this I don't know. I don't think he will because I... He wants to get out of the hospital so bad, I think that's what the doctor was saying I think he kind of just trying to say ok I'll play the game, and he knows he can't do that. And he knows that this is the only place that's given him any kind of help at all other than like I said before, [Other] is a Saint. That's all I have to say. 


\section{DEFENSE ATTORNEY}

You've heard the two kind of big concerns or that he have what they call a relapse prevention plan and a structured environment. How do you think you could help him address those two concerns? Or how, what's you recommendation for him to address? You know him better than anybody in the room right now...

OTHER

You know that's, he's got his own demons, and he's got to fight them on his own. You know, he said, when he turned thirty in January; I think he realized that he wasn't a kid any more. He realized that I'm not gonna be around anymore, or I'm not gonna be around forever. And I think he's you know? And it's tough, you've got again what he's went through, you know, it's tough to be out there. I'm I'm totally confident that he is gonna be capable of getting it, and I think everyone here today just listening to him, can tell that he's you know... If you would have seen him after the accident you would not even believe how much he has recovered. I mean he's got a rod in the side of his leg, and the whole side of his face drooped, his lungs were collapsed, or one lung was collapsed. He was so beat up it was pathetic you know, but now he's... I'm real proud of him, I'm proud of what he's, I'm proud of my son and I know that he wants to make me proud and that's... I I I will do whatever I can in support

DEFENSE ATTORNEY

Ok. No further questions.

PSRB

[District Attorney]?

DISTRICT ATTORNEY

Just a couple... I just want to make sure... it sounds like what you are saying that the best plan at this point is a transition to a perhaps more structured environment than the previous conditional release, that he had. Is that accurate?

OTHER

Well I would either say that or a treatment, drug and alcohol treatment, and intensive course where he. I don't really know, I'm not an expert. But I think he could handle the house that he was in before, and if he says that they will take him back, he doesn't lie. And that's one thing about [Patient], matter of fact, he can't lie. I mean he can try but he's not very good at it. I'm sure that he's talked to him and they said they would take him back. But I would like to see, he needs to have some kind of more than NA I think and more than alcoholics anonymous () because, frankly that's why we travel so far. Sometimes we even go into [City]. Just because the meetings kind of get boring because it's the same people telling the same stories so you've got to go to different meeting to get different stories to make it more exciting to the persons, people that are there you know?

DISTRICT ATTORNEY

The, when he was on the first conditional release, this would be in August 2006, it looks like the two of you had a trip that you took together right before he was revoked the first time.

OTHER 
We, we have done all kinds of stuff. We went to Missouri, we took a trip to ah I don't know if that was Hawaii, Maui, but we weren't under the PSRB then. That wouldn't have been legal anyway. But we did go to central Oregon, went fishing for a week.

DISTRICT ATTORNEY

My questions deals with, in looking at the report from X county they indicate that before he was revoked the first time in August of 2006 you have taken a trip together and that, during that period of time you had observed but didn't comment to them that you saw some of the warning signs had developed, and also that he had been smoking marijuana. Do you recall that trip?

OTHER

I do.

DISTRICT ATTORNEY

And is it accurate that you observed those warning signs and saw that he was using marijuana?

OTHER

No. What happened though, what is accurate about that trip is that. Well I'll tell you the honest truth was, I thought that a friend of mine that was at, we were at lost lake resort and I thought a friend of mine had given him some marijuana, and I didn't find out about this till after he had been revoked, but I found out later it was the other way around.

[Patient] had given a friend of mine some marijuana. So you know, and I did not know about this during the trip at all.

DISTRICT ATTORNEY

So you didn't observe any signs during the trip?

OTHER

No

DISTRICT ATTORNEY

And you didn't observe any warning signs during the trip of a reemergence of his mental illness?

OTHER

He was doing some howling during that time, but he does that all the time.

PATIENT

No I, uh huh (agreement)

OTHER

He does that all the time, but I know the signs now. He turns the music up loud, if he looks at the sun, it's a sure sign that within an hour or two he's gonna go manic.

DISTRICT ATTORNEY

Do you think that at your house you can provide a sufficiently structured environment for [Patient] to be released to immediately?

OTHER

No I don't think so at this time. I would like to have him prove himself in a group home for I would be able to, but I would be able to after 6 months.

DISTRICT ATTORNEY

$\mathrm{Ok}$

OTHER 
He was doing so well and I don't know what happened at the time, but I know the pressures, they the pressures in X county; they were paying the rent in that expensive group home and then he was in the hospital and the hospital, and so that there the group home was saying we gotta either have him back or we gotta give up his bed, and I think was kinda what happened at that time. He should have stayed probably in the hospital after that first relapse a little bit longer. And if he had maybe he would have been able to, but I wouldn't want to have to make that decision, I know how much that costs, its expensive.

\section{DISTRICT ATTORNEY}

Thank you, no further questions.

PSRB

Board members? Nothing? No questions? Thank you for your testimony. Do you have any other witnesses?

\section{DEFENSE ATTORNEY}

Yes, [Other].

PSRB

Right hand please? You're not alone, do you solemnly swear affirm, er, I'm sorry, do you solemnly swear and affirm that the testimony you are about to give is the truth? OTHER

I do.

PSRB

Please state your full name and your relationship with the...

OTHER

[Other], [Patient]'s uncle. I noticed in the last twelve...

PSRB

Just, just a moment, because you are being called as a witness, let's let [Defense Attorney] do his job.

OTHER

Oh, I was just making a statement on his behalf.

PSRB

I understand that, [Defense Attorney] how would you like to proceed?

DEFENSE ATTORNEY

[Patient], what have you noticed recently?

(Laughter)

OTHER

I've just noticed, I've talked to [Patient] probably three to four times a week, maybe more cause he'd call a lot, he gets bored, and I've noticed in the last two to three months definitely way better improvement on conversation and decision making you know? Just talking with hi knowing that he's making the right choices and decisions and I think if he gets a, I don't think he's ready to be out to his house right away. Even though it's a good environment now with his sister gone. I think that a transitional state would be a lot better. You know? To, cause it would just be too quick of a transition, but I've noticed and I think what he really needs to is some physical therapy to where I think that mentally I think that would help a lot to be able to go golf, go fishing, be able to do 
things, cause when you try to be sober, I been sober since 1992, and I noticed that when you did go sober you definitely gotta have some type of activities, things to keep yourself occupied. And I think that would really help [Patient] out a lot, is to physically get better, and then prolly what would help a lot to is to get a part time job. Definitely help out, I mean that would help him out immensely, and if he ever needs a sponsor, any one to call, I will definitely be a sponsor for him, to call me if he ever gets in a bad environment, a situation, just give me a call, I have my cell phone usually on me at all time, I will come pick him up, I will take him to any meetings, I will do whatever it takes. I think the problem is, it always seems to be alcohol and drugs brings him back steadily to the point, so if he can keep, like I think, that I've talked to him over the last couple months he seems to be way more stable in his decision making and I really noticed that current events he talks with me about political things, and I think wow he's really you know, focusing on life. So I just thought I'd say that. Thank you.

DEFENSE ATTORNEY

Thank you, no further questions.

PSRB

Thank you, [District Attorney]?

DISTRICT ATTORNEY

No questions.

PSRB

Any questions from the board?

PSRB

Well, it might be difficult...

PSRB

I'd like just to ask you, where do you live?

OTHER

I am at probably 4 or five miles from his house.

PSRB

Thank you, thank you for your testimony. [Defense Attorney]?

(Shuffling)

DEFENSE ATTORNEY

No further witnesses

PSRB

Further witnesses? Ok, you rest then. [District Attorney]?

DISTRICT ATTORNEY

I'd actually like to call [Clinician] very briefly.

PSRB

[Clinician], I believe we can say that you are still under oath sir.

CLINICIAN

Yes.

DISTRICT ATTORNEY

Thank you. Ah, [Clinician], just a couple additional questions, I just want to make sure I'm clear that [Patient]'s still currently on medium security ward 50F right?

CLINICIAN 
That's correct

\section{DISTRICT ATTORNEY}

And is there a current transition plan in place to transition him back to a minimum security ward?

\section{CLINICIAN}

Um, we have been discussing that possibility. I don't believe that they are in a position to take him now.

\section{DISTRICT ATTORNEY}

Are there any additional classes or treatment aspects that [Patient] needs to complete before [Patient] needs to complete before he would be ready or appropriate for a transition?

\section{CLINICIAN}

Um there's no specific class that he needs to have fully completed before he transition, transition to minimum security. It has more to do with um, their assessment of his readiness for that level of treatment.

\section{DISTRICT ATTORNEY}

And is there a specific area that you have identified, or they have identified for [Patient] that he needs to work on in order to be ready?

\section{CLINICIAN}

Well one of the most important things is that [Patient] needs to stay clean and sober. Free of substance abuse and he needs to um, demonstrate that he's willing to continue actively collaborating with the staff in his best interest.

DISTRICT ATTORNEY

And ah, at this time does [Patient] pose a substantial danger to others?

CLINICIAN

In the hospital environment danger is mitigated. Outside the hospital environment, there is a high likely hood that his mental disorder would be reactivated and that could pose a danger to him or others.

DISTRICT ATTORNEY

So if he was to be off his medication and his illness were to become active you feel that he could pose a risk to others?

\section{CLINICIAN}

Yes, it really has to do with the specifics of his living situation. If there is enough structure and supervision that would mitigate much of that risk.

\section{DISTRICT ATTORNEY}

If he was to use drugs or alcohol and if that disorder were to become active would he pose a substantial danger to others?

\section{CLINICIAN}

Yes.

\section{DISTRICT ATTORNEY}

Thank you I have no additional questions.

PSRB

[Defense Attorney]?

DEFENSE ATTORNEY 
No further questions.

PSRB

Anything from the board?

PSRB

No questions.

PSRB

No questions.

PSRB

[District Attorney]?

DISTRICT ATTORNEY

No additional witnesses.

PSRB

Ok, I wanted to ask [Clinician], just very briefly, um, there seems to be consensus among everyone except your patient that a transition plan is needed and that time is of the essence, what how much time do you think the hospital would need to complete a relapse plan, prepare a transition plan for [Patient]?

CLINICIAN

Well, the hospital may need a few months, but it has, it has to do not just with how much time the hospital might need, but how much, the degree of readiness that [Patient] has to really genuinely accept the plan for going to a supervised living situation.

PSRB

Is it necessary for him to pass through the transitional wards in the 41 building or the 35 building before he can be conditionally released or evaluated for conditional release?

CLINICIAN

Uh, no it isn't.

PSRB

Follow up? Any follow up? No additional witnesses? Than we can proceed to closing. Thank you [Clinician].

DEFENSE ATTORNEY

In sum, [Patient] has been here at the state hospital for a couple of years, and for better or for worse he has been out on a couple of conditional releases and I think that it is accurate to say that his mental illness is not active any more, that he realizes that it may become active in the future but that this is a good point. He is not a violent or a dangerous person at all and ah, everyone I guess talks about his improvement and how things are getting better for him. He's learning better how to cope with his brain damage situation. It's encouraging that he's, it's both encouraging and discouraging that I can say he's been out on conditional release before. But what's encouraging is that it sounds as though even that facility, if deemed appropriate would take him back. It speaks volumes as to what the problems are and what type of person he is on the outside. There's no questions as to what the issues are, a solid relapse prevention plan, a structured environment including a focused attention to drugs and alcohol treatment and I, if anything has come of this it's that [Patient] has a pretty good insight into what is going on, he has tremendous and insightful support, and proven support. It's not just verbal support from his dad and his uncle and his family who really know his problems, his 
warning signs his. And they have his best interests at heart. And with any conditional release plan I think that should add just a tremendous amount of comfort that the eyes and the ears of the people around him that will be seeing him on a regular basis will be trying to accomplish the same goals as the hospital would want. I think all these factors considered I whole heartedly, for on [Patient]'s behalf I will ask for a full discharge, but in truth I would ask that you seriously seriously seriously consider a conditional release plan that has as many protections built into he front end of it as possible so that we can transition into life after the PSRB jurisdiction expires. Thanks.

PSRB

You [District Attorney]. DISTRICT ATTORNEY

Thank you. My understanding is that the hearing today [Patient] was asking for a discharge, a complete discharge, I think based on the testimony even of his family and certainly of [Clinician] that a full discharge is not appropriate at this time. The state would also oppose a conditional release or evaluation at this time. Our position is based on in part, [Patient]'s recent drug use. He was conditionally released in august of 2006 and had a manic episode I believe marijuana was involved in that instance. He was rereleased to the same program, was again revoked within a matter of about 4 days, after going off his medication experiencing manic symptoms threatening or at least harassing female staff and becoming oppositional with other peers within the house during that period of time he was violating the rules with having contact with his sister. He, this is October of 2006, we have a full year and then he again uses cocaine in October of 2007 approximately 4 months ago. Then we have testimony from [Clinician] today as well as exhibit 58 which discusses the fact that [Patient] was attempting to use Ambien to alter his mental state as recently as two months ago. The hospital is not in support at this time of his request for a discharge or conditional release, there has not been planning in place for a conditional release. It is my understanding he has not been re-evaluated. X County has provided two letters to the board those are boards exhibits 37 and I believe board exhibit 50, its from [Other] who is the PSRB X county coordinator. Those letters both indicate that at, at least as of this more recent one, exhibit 50, that at that point X County was not willing to take [Patient] back, they would be willing to reevaluate him however I'm not aware that that re-evaluation has occurred. The, [Patient]'s own testimony today was that he felt that he could be around alcohol, that he felt that that wasn't an issue. And that was concerning in light of his substance abuse issues. There is also within exhibit 37 which again is the letter from [Other] from X County, there is mention of concern about the ability of family members to identify his triggers when his mental illness becomes active. Specifically on page 1 of 4 on exhibit 37 as well as concern about [Patient]'s disinclination to follow a conditional release plan. His impulsive behaviors that included lying and compulsive gambling um and as well as using smoking marijuana around family members. As the board has recognized, [Patient] has, the board has jurisdiction over [Patient] for approximately 25 months, and the hospital has tried to place him under conditional release on two prior occasions, it sounds, based upon the testimony of everyone today, family members specifically, that they believe a transition um, would be the best approach to [Patient]'s treatment and that immediate discharge at any time, either 
today or at the end of the boards jurisdiction would not be helpful for [Patient], however at this time he has not made the steps necessary within the hospital to transition, and while he certainly could as [Clinician]s testimony indicated he could transfer off the medium security ward the fact that he has not made the appropriate therapeutic steps in order to transition to a minimum security ward may be indicative of the fact that he still has therapy and um, needs to develop better insight in order to be an appropriate candidate for conditional release. But at this time the state would oppose any evaluation of conditional release or discharge um, and I would just encourage [Patient] to continue thinking along the lines that he has expressed today and work with the hospital to eventually be conditionally released. Thank you.

PSRB

[Patient], the way this works is that we need to deliberate for a bit to decide what to find here and when we do that we do it in private, so we ask everyone, including the documentation people to leave the room while we have, while we deliberate. Thank you. PSRB

We are back and we have deliberated. [Patient], first for the formal aspects of this. We do accept your stipulation for the presence of a mental disorder and we find ample evidence in the record from your history, from the testimony that has been given today that that disorder when active, you do represent a significant danger to others. And there have been, you've led a busy life for a man of 30 years of age. And because those two criteria are met you are properly placed under the jurisdiction of this board. Um, the burden of proof when you make a request like yours is a preponderance of the evidence. And that means it's more likely than not that you are right in your assertion, or that you've proven, that that you, your request has merit. We don't find that that burden of proof has been met, that is to say that a full discharge would be appropriate at this time. And I think I heard someone say perhaps it was your father that, or your attorney that maybe that wasn't really a realistic request. But we are concerned about your ultimate discharge form the board's jurisdiction 25 months, and we want to see a successful transition to the community so that we don't see you back in front of this board again in the next iteration. So, let me tell you what our findings are with respect to your treatment and the transition plan. First, we accept that your sincere in your commitment to do well on the outside as [Defense Attorney] said, to succeed and get a job and all of these things. But if you, we've gone back and looked at Doctor's repost on the assessment of your cognitive functioning, and in a the case of a person with the kinds of disabilities that you have, you need a lot of support to be successful, and those supports need to be planned for and put in place so, as much as you think you can just use your mind to make everything ok, you're gonna need help from other people. And maybe even most of your success will depend on other people helping you in the future, and not just the near term, but for a good long time. So we are going to say today that we want to have you stay here at the hospital but we are going to order an evaluation for secure residential be initiated at a time when the hospital feels that they have and you feel together, that you have gotten the benefit you need here with more intensive, more intensive attention to your addictive disorders, not just substance addictions but, the kinds of addictions, gambling and so forth that reflect some of the impulsivity that you described when you 
were testifying. And at the time when the hospital thinks it is appropriate to make a request that you be evaluated by a secure residential program and then that plan that's developed form that can be brought back administratively before the board or we can have another hearing is the hospital requests that. And to take a look at that and if that's successful you move into a secure facility, then if you make progress there you can move into a less restrictive setting sort of to ease you into a community environment, where those kinds of supports are in place and they have been built in a natural way not just ah to have you leave the hospital as you did before. And the reason that we are concerned about this transitional process is that all of the good intentions aside we want a, before your term under the board is finished, we want you to be able to leave the hospital without failing. I think it would be more destructive to have you in the community and fail again rather than to take a little more time and finish the treatment process and put a solid plan together that reflects the reality of both your mental, your bi-polar disorder and your cognitive problems from the brain injury you suffered. But you've done a good job here today on your own behalf. I think you've got a caring family and a lot of people who really want you to succeed and among those you can count on us too; we want you to succeed as well. So that's our decision for today and uh, you can appeal these decisions, [Defense Attorney] has some information for you and a form to sign that acknowledges that you have been informed of your rights. And we wish you well in the next few months of your course of your treatment, and we hope that you find the right placement. PATIENT

Can I ask a question?

PSRB

Very briefly, cause we have a big schedule for today. PATIENT

I'm sorry. Do you know where the secure residential treatment is?

PSRB

Well you know, let me say something about that. There was a point during this hearing where I thought we were trying to arrange a treatment plan for you, and that's really not our job; our job is to review a treatment plan that is brought before us, that's something that [Clinician] and your treatment team need to work out. There are social workers on that team that know every resource in the state and what is available in $\mathrm{X}$ and $\mathrm{Y}$ counties, the metropolitan areas etc. so you work with them and they will be able to answer that question.

PATIENT

Thank you.

PSRB

You're welcome. And thank you to the families as well. 


\section{Appendix B - Transcript of Individual Interview: Clinician}

CLINICIAN: Okay. Forensic psychiatry is the intersection of psychiatry and the law. Every state handles these sorts of cases a little bit differently, but in terms of the recidivism rate, you're right, there's actually a lower likelihood of recidivism for the major crimes, particularly murder, always assuming that the person that you're talking about maintains psychiatric wellness. So that's the primary job of the psychiatrist in terms of clinical perspective - is to find whatever medication and treatment regimen works for that particular person that keeps them well with the understanding that there's always a risk of relapse, and that schizophrenia, for example, and bipolar disorder are chronic illnesses that need ongoing management and that it is normal to expect relapse in symptoms - partial or complete - under periods of significant stress. Sometimes medications just don't seem to work as well anymore. These are brain diseases, and in many cases are progressive brain diseases and so what you see over the course of time is that you have to make adjustments in a regimen that might have previously been working well because something else comes up. It can be any number of factors. So, as long as the person is doing well, their likelihood of recidivism is actually quite low, particularly for the major crimes. The petty theft and minor assault - that sort of stuff is actually more likely to recur.

INTERVEIWER: Isn't the issue partly how much we should expect society to tolerate in terms of risk? It sounds like you're saying 'there's no $100 \%$ guarantee.'

CLINICIAN: There's not a $100 \%$ guarantee, but society tends to not want to tolerate an enormous amount of risk, particularly out of somebody who did something horrific or that would be viewed as horrific, like murder or an arson or a serious assault. The average layperson is going to assume that the appropriate reaction to that sort of an event is punishment. They will want to see that that person is appropriately punished, and that's what the justice system is really about - is making sure that that person is out of society and not likely to do it again, and the assumption being that the way to do that is to get them out of society.

INTERVEIWER: And this society has prison terms that are off the charts, even escalating over time. So it's a question of - not all societies deal with troubled people-

CLINICIAN: ( ) American society "(laughter)". In my observation just as a citizen of the US is that the average layperson does not have a clear understand of what mental illness is, how it affects decision-making, how it affects the brain, what you can reasonable expect from somebody who is mentally ill in terms of their behavior, and how that person should therefore be treated. So in most states it's actually very difficult from someone who is mentally ill and commits a crime to be placed under the forensic system. In Oregon, my personal observations is that it seems to be easier for that to occur for a variety of reasons. 
00:03:26

INTERVEIWER: ( ) label of dangerousness. The 'dangerous' label is the pass into the system.

CLINICIAN: It's not just the 'dangerous' label because to be in the system in Oregon you need to meet two criterion and there's a causal relationship between the two. The first criterion is that you were mentally ill at the time of the crime, and that because you were mentally ill you committed a crime. And any crime falls under the 'dangerous' label. So, again, stealing a ten-dollar roll of quarters is considered dangerous because it's a crime in terms of how it's functionally used in the language. But the idea is there is a causal relationship between the two, and the assumption that is made, and this is usually valid when the system is working properly, is that if that person were not actively mentally ill, if their illness wasn't active at the time, they wouldn't have done it. Now the reality is that there are plenty of people walking around who have mental illness who also commit criminal behaviors whether or not their mental illness is active. There are plenty of people walking around who have significant drug problems who seem mentally ill because their drugs make them look mentally ill.

INTERVEIWER: There are plenty of people who do dangerous things.

CLINICIAN: And there are plenty of people walking around who do dangerous things who would not be termed 'mentally ill' under the system, and a lot of those folks end up in prison. So there's a lot of... what's the word I'm looking for? Diagnostic considerations are important. It's more than just 'what's your diagnosis'? But, 'is it this particular diagnosis, is it this particular mental illness that led to this behavior?' And sometimes it's hard to sort out.

INTERVEIWER: There's a particular fear or perception that people who have come out of the Oregon State Hospital under any circumstances are dangerous. The 'dangerous' label seems to be combined with mental illness as a very lasting, deep marker.

CLINICIAN: I think people are nervous around folks with mental illness anyway. Humans in general tend to be uncomfortable around people who behave differently than you would expect - whose behavior is unpredictable because it follows its own internal logic. In conjunction with someone who is known to have committed a crime and therefore they went to the Oregon State Hospital under PSRB, I think that does make people very nervous. And sometimes those people are just normal community people. Sometimes those people are attorneys. It's usually the clinicians who are the least nervous. But the PSRB's job is to have some understanding of what this relationship is. When we're doing our job right and the PSRB system is working properly, the people who are released to the community are doing as well as could reasonably be expected of them and are placed into a setting that is designed to maximize safety with as much supervision as is deemed necessary for that person, which is sometimes quite a lot. Frankly, my observation of the way PSRB supervision happens in the community is the 
average parolee is not as closely supervised as the average PSRB client on conditional release, which is why the recidivism rate is so low. Partly it's because of the extreme caution of letting people out of the hospital, and partly it's because it's fairly easy to have your conditional release revoked.

00:07:14

INTERVEIWER: Can you explain why that is?

CLINICIAN: If someone is under PSRB jurisdiction and they're living in the community, they're still under PSRB jurisdiction. So the PSRB is still responsible for monitoring them. And that's what I mean when I say that they are under supervision. Frankly, it is in most cases more strict than the average parolee would get: more frequent contact with the case manager, more frequent contact with the mental health system, monthly reports to the PSRB, usually with anyone with a history of substance abuse there's at least a monthly requirement for urinalysis to make sure that they're still clean and sober. So it's a pretty stringent expectation. And a violation of any of those expectations - failing to show up for an appointment with a psychiatrist for example, stopping medications, stopping going to psychiatric groups which is required, refusing to provide a urinalysis, all of which are relatively minor potentially compared to things like leaving without authorization, or actually committing another crime - any of those things - documented recurrence of substance use - any of these things can result in the PSRB saying 'nope, you don't get to stay in the community anymore, you're going back to the hospital because we don't trust you to continue on the road of being safe in the community.'

INTERVEIWER: So ideally what works well is kind of a progressive step-by-step process with consequences?

\section{CLINICIAN: Right.}

INTERVEIWER: But many people describe taking a step forward and then being yanked back. So there's like a lockdown - not a lockdown - kind of a restriction of privileges, where people take steps and then it seems that there are a lot of aspects of the hospital that can exacerbate the conditions. You were talking about some of that the day of the PSRB - institutions can themselves be part of the difficulty.

CLINICIAN: Psychiatric facilities like this one are not the ideal place for certain folks. One of the things that does occur is that if you collect enough people in a small environment who are there for a long period of time who are highly emotionally disregulated and prone to being aggressive, they tend to bounce off of each other quite a lot. They tend to aggravate each other, they tend to create just in-and-of-themselves an environment that is less-safe for everyone around them. And when that is prolonged, and by prolonged I mean more than a few days, but especially if it goes into the weeks and months, it creates what we call a 'high ward,' which means the acuity on the unit is high. You can walk on any unit in this hospital and if you've got kind of your radar on, you can 
tell pretty quickly just walking down the hallway how things are going that day because when the stress level on the unit is high, you can feel it because you yourself will get more tense. Humans are pretty good at sensing what's going on around them and physiologically reacting to that. Your bodies' fight or flight mechanism is pretty effective in identifying a high-risk situation before even anything else has really occurred. So, my unit in particular has had a significant problem with this over the course of the last I'd say year and half.

00:10:53

INTERVEIWER: Can you describe your unit?

CLINICIAN: My unit is, until recently, all female - about 30 patients and a mixed group. We have some people who are developmentally disabled primarily. We have quite a few people who have major mental illnesses - schizophrenia, schizo-effective disorder, biopolar disorder. And then we have a smaller handful of people who - the primary issue that they struggle with on a daily basis is severe PTSD, personality disorder, emotional dis-regulation, and these are folks whose fight or flight mechanisms are hair-trigger. Anything and everything sets it off. They're much more likely to go into full-on aggressive mode, and make the place unsafe for everybody else. The problem is when one person is yelling and screaming and completely dis-regulated it tends to cause other people around them to do the same thing. So it's usually not just one person having a problem. It's usually one or two or three, or sometimes four or five having a problem at the same time.

INTERVEIWER: ( ) There's a psychologist who does research on what's called a 'contagion effect,' that we all as humans-

CLINICIAN: There's only so much chaos and noise that the average person can tolerate. Some people's tolerance levels are higher than others. But most of us, in a really loud uncomfortable chaotic situation, will actively seek a place of calm and quiet to help us regulate ourselves. People who don't have much skill in terms of regulating themselves might not think to do that. They might not have the time. Their fight or flight mechanism might get activated so quickly that they're already in full-out...it's a vernacular term but freaking out, almost immediately. They don't have five minutes to go find some place to calm down because all it takes is 30 seconds in their case. When that happens a lot, it feeds on itself like I was saying before. When the stress level chronically gets more elevated, people are more likely to be short-tempered, and this is true of everyone. When my unit is like this, it's hard for the staff to keep their cool as well as they could because we're all human beings, and when you're chronically stressed-out, your resources are taxed. Your tolerance is lower and your ability to grit your teeth and keep your cool is lower. This is true for patients. This is true for staff. This is true for humans. What we see in wards where that's a problem is that if something isn't done to change the situation, it just feeds on itself for a very long period of time. And sometimes what needs to be done is patient movement, which is much more difficult with the female population because there are fewer places for them to go in the hospital. In our case, what needed to 
happen - we needed to have more people. We just needed to have more staff available to put out the fires before they became conflagrations that engulfed the unit. But it took a lot of re-allocation of resources and creation of new programs that didn't used to exist.

00:14:07

INTERVEIWER: What percentage of women are in the hospital versus men-can you explain that?

CLINICIAN: You know I don't actually know the numbers. I know that in the forensic program there are...two co-education units. One's mine which is technically a mediumsecurity unit, and one is a community transition unit. There is one unit that is designed for folks who have been referred to the hospital to be restored to competency that's co-ed. There's a newly created and soon to open women's intensive treatment that would be equivalent to the men's maximum security ward. That's brand spanking new-we've never done it in the hospital before, and it's going to have a population maximum of five.

INTERVEIWER: People generally assume that 'violent' ( ) is a stereotype.

CLINICIAN: There are quite a few of those folks in the hospital as well. My experience with the women, having worked on that unit for about two and a half years, is that a small handful of them and probably about the same proportion, maybe a little bit higher, have just as much difficulty. When you look at total number of aggressive incidents, the proportion of women on my unit who have difficulty with that is in the neighborhood of $30-40 \%$. The proportion of men who have difficulty with that in the same forensic program is more on the order of $10-15 \%$, which is what you would expect.

INTERVEIWER: Why? Why would you expect-

CLINICIAN: In aggregate, when you do studies in forensics hospitals, the number of highly aggressive patients, meaning people who are aggressive more than a couple times a month, on the average is about $10-15 \%$ in a forensic hospital. My unit, it's more like 30 , and sometimes a little bit higher than that. And most people wouldn't think of a female patient as being particularly dangerous, but I can tell you from experience that when your pre-frontal cortex is not online and the only thing driving your behavior is that fight or flight reflex and there's nothing in your brain that's inhibiting those impulses, women are very strong and can do some very serious damage to property and to people. Which is why we've moved towards the creation of a higher-acuity unit for people who need more attention toward managing those particular difficulties.

INTERVEIWER: Some of it then may be understanding violence and why-

00:16:42

CLINICIAN: Some of it has to do with understanding why people are violent, and it's not uncommon but the assumption is made, and this is sometimes a valid assumption and 
sometimes not, that men are aggressive for different reasons than women. I think I see two types of primary aggression in my population which is female. One is extremely psychotic: 'I'm defending myself or defending someone else.' For completely delusional reasons this is a justified act. That tends to resolve when the psychosis resolves.

INTERVEIWER: So something's being fought for or protected?

CLINICIAN: That's usually the reason that is given by the person that is aggressive is, 'I'm protecting myself or I am protecting someone else.'

INTERVEIWER: Can you give an example of a delusional situation similar to that?

CLINICIAN: Most people who are actively psychotic — paranoia is a very common delusion. Just the sense that 'I am unsafe, someone is going to hurt me, someone is going to hurt my child, someone is going to hurt someone that I care about and it's my job to protect myself or this other person.' And, 'aggression is something that I am willing to do to be protective.' Some people are never aggressive even when they're very paranoid and psychotic. Some people are aggressive whenever they are paranoid or psychotic. And it's recognizing that this is part of the typical pattern for someone who is psychotic. Keeping them non-psychotic as much as possible - that's the primary treatment goal. And that's a very different kind of aggression because usually those folks are not aggressive when they are well. When their psychosis is under good control and they're not feeling paranoid they tend not to be aggressive. Their risk goes greatly up when they're ill, and significantly down when they're not. The other pattern that I see - and I see this quite a lot - is a young woman, usually, who has a substantial history of trauma in childhood, she's either been physically or sexually abused or both, and her environment normalized violence. It was acceptable, reasonable, and that's what you do in a position of power. In those folks what happens when you're repeatedly exposed to violence and trauma is, what I was saying before, that fight or flight mechanism in your brain which is a normal functional mechanism, you do need it to be able to survive as a human, becomes so conditioned that very small things trigger it. Some women who have that fight or flight response, they flee. That's their - what happens to them is they flee. They run away, they dissociate, they do something that removes them from whatever the threat is.

\section{0:19:35}

INTERVEIWER: Can you just say what dissociate means?

CLINICIAN: Dissociate is sort of when you're walking and talking and interacting but your brain really isn't fully there. You're not fully conscious of what's going on. We definitely do see it. People will describe a sense of feeling like they're out of their body, or losing time - not remember what was going on at the time even though they were there and interacting. In severe cases it can look almost like a seizure because the activity is just so sort of disorganized and the person is not responding to what's going on around them. It's distinguishable from a seizure in a lot of different ways, but sometimes it's so 
severe that the person that you're talking to is just not responding to you at all. Eventually when they calm down, then they kind of come back to you and they feel like what they'll describe when waking up, coming to. And that's a flight mechanism. The alternative is the fight mechanism. So in those cases, women who are having difficulty with what's going on in their environment or already angry about something else will choose an aggressive response because that's worked for people in their past, and in many cases it worked for them. Sometimes they'll get what they want that way and the more ingrained that becomes, the harder it is to change that pattern because the first step is actually to prevent the fight or flight response from kicking in. That's hard.

INTERVEIWER: ( ) Wouldn't some of those same dynamics include trauma-leading to-

CLINICIAN: Completely. Absolutely, and I think it's probably under-recognized in that.

INTERVEIWER: Can you say something about—you said that there is perhaps a gendered pattern but not absolutely. But can you say anything about how that pattern of what you noticed in women that's different from men?

CLINICIAN: I think that women are somewhat less likely to have the pattern of choosing violence very deliberately and, in a very aware way, as a tool because it's effective and it gets you what you want. The bullying or sociopathic use of violence as a specific way of getting what you want when you want it without fail. I see that less often in my female clients than you see that in male clients.

INTERVEIWER: That behavior is less rewarded overall-

CLINICIAN: That behavior tends to not be rewarded at all in women. It's particularly unattractive in general in my opinion, but it tends to not be rewarded in girls. I do see every now and again - I've got-I've known a few people just in the last couple of years who've used that pattern, and it is historically very effective for them. That's a difficult one to convince someone to give up because it is so effective. But it tends to not be driven very strongly by emotion, other than 'I want.' It's not really about anger necessarily. It's not really about fear. It's not really about any of those really strong emotions that drive the fight or flight reflex. It's really about, 'this is a good tool.' I don't tend to see that as much in women. And I think that's the primary difference, but I do think that the trauma response happens in men, certainly, and I do think the aggression for psychotic reasons happens in men, certainly, if they happen to have a mental illness that pushes them in that direction.

00:23:19

INTERVEIWER: In some ways it's harder to understand that people are dangerous or aggressive because of mental illness. In another way it's a redeeming explanation. So you have people in prison who've had very hard lives, and are diagnosed with anti-social 
personality or something like that, who are seen as just real bullies. So you get this-one thing that I'm kind of working with in this documentary is the distinction between kind of the 'good patient,' versus these 'bad guys that should all be in jail, that we should ship out.'

CLINICIAN: Generally speaking, people are more willing to forgive a patient who is psychotic, clearly not in their right mind and being aggressive on those grounds. We are, as a rule, more forgiving of that because it really feels like this is outside of the person's control. I think that's really where that feeling comes from is, 'is this in your control or not? Did you choose this or not?' And the people who use aggression as a tool in a very calculated way, it's completely within their control and I think that's where a lot of that, 'this is not the right person for this person they need to be in prison'- that's I think where that attitude comes from. The difficulty we have is in the behavior of people who have the significant trauma history and whose fight or flight reflex is really strong and active because they can look very much like that population who's using aggression as a tool, and it's difficult to distinguish, because one of the classic symptoms of PTSD is 'I don't want to talk about it-I don't want to talk about what happened to me. That's too much for me to deal with, I refuse to talk about it.' So maybe it's in there and we don't know about it. But that type of aggression can and often does look like the very deliberate aggression. So that tends to get lumped together in the same group. In addition, people who have serious emotional dis-regulation problems are frankly, because they're highly emotionally dis-regulated, difficult to be around. They have a harder time keeping themselves cool. They have a hard time keeping themselves calm. They often seem to make irrational demands. They're emotionally up and down, all over the place. That's exhausting to be around regardless of who your are, whether you're their parent or their sister or their spouse or their child or their care-provider. Ultimately, people who have that level of emotional dis-regulation exhaust the people around them.

INTERVEIWER: And the borderline- - you mentioned people with borderline-

CLINICIAN: Borderline personality disorder is one of the classic diagnoses that goes with it.

00:26:00

INTERVEIWER: And women tend to be diagnosed much more with that than men or with anti-social-

CLINICIAN: Correct. Correct.

INTERVEIWER: You introduced that at that PSRB hearing. Maybe could you start with your, with something you did explain?

CLINICIAN: When we see someone who is engaging in outrageous behavior, the usual layperson's response is to label it 'crazy.' I don't mean to denigrate the average person 
without the clinical training but my experience is that the average person that does not have clinical training in diagnoses in mental illness is going to assume that any behavior that is completely outrageous that I can't imagine participating in, I'm going to think of as 'crazy.' The clinicians' stance is they're going to look at that behavior pattern and they're looking for different things. 'Crazy,' to me is psychosis - is complete break from reality - hearing voices, having delusional beliefs, and by delusion I mean a belief that is absolutely non-sensical but is so strong it cannot be argued out of. You can convince people of almost anything and under the right circumstances. You can convince people to give up beliefs that you would think would be unshakeable - the average human being. A delusion is an absolutely unshakeable belief under any circumstances it's just not going to change. That's an enormous level of conviction for a specific belief and I think it really does require a certain non-functional or differently functional process within the brain to sustain it.

INTERVEIWER: I tell my students that delusion is a belief that you hold that you cannot convince other people to follow that you cannot find-

CLINICIAN: That's not true. That's not true. There's a diagnosis called ( ) where the second person is not psychotic but believes the delusion of the first person - usually it's a dominant-submission partnership that's pretty much excluded from the outside world. So the other person doesn't have anybody else to bounce that off of and hear 'that doesn't make any sense.' But that's not entirely true. You can convince somebody of your delusional belief.

INTERVEIWER: What if you get a congregation "(laughter)."

CLINICIAN: That's-I mean we see that in cults.

INTERVEIWER: But that becomes sort of a value judgment - whether a religious system is a fixed delusion.

CLINICIAN: True. Fixed delusion has that- - the difference is that truly fixed quality. That the person who holds it just cannot be argued out of it. And sometimes it's something that on the surface would make sense. So-and-so is my-my husband is sleeping with someone else. Could be true. It doesn't necessarily have to be bizarre to be a delusion.

00:29:00

INTERVEIWER: So how do you establish the delusional part of it?

CLINICIAN: A big part of is if you can get anybody else's input into whether this actually makes any sense - if there's any evidence to support that particular belief. Sometimes we think that something is a delusion when in fact it's not. I've had patients, for example, who tell me that they have enormous amounts of money squirreled away in 
the bank and they're disheveled and they appear to be mentally ill. It turns out that that's true - they do indeed have that kind of money. So every now and again something that we think is a delusion turns out to be legitimate and we get surprised by it. But part of it is the more bizarre the delusion, the easier it is to identify: 'I have a micro-chip implanted in my head that when it's activated it will make me become violent' - unlikely.

INTERVEIWER: So the demand for evidence becomes higher the more probable-

CLINICIAN: The more likely it could be true, the more evidence we need to make sure that it's not. But also it has to do with how strong is this conviction and what are the other symptoms, because when we're looking at someone who is expressing what we think is potentially a psychotic symptom, there's usually other symptoms that go along with it.

INTERVEIWER: You were making a distinction between a bipolar disorder and-

CLINICIAN: In terms of that patient I was talking about the difference between mania and personality disorder/PTSD.

INTERVEIWER: How did you-we'll see some of that from the hearing itself, but can you describe what happens when ( ) into the chart and it get passed along in someway and each psychiatrist makes their own—how do you revisit their diagnosis?

CLINICIAN: Well the thing about psychiatric diagnoses, and I think this is why psychiatry is still looked askance at by some degree even by some physicians, is that I can't do a brain scan. I can't do a blood test. I can't do something that seems really definitive and say okay that's the diagnosis. I'd like to think that we'll get there. Maybe not in my lifetime. But I'd like to think that eventually it will be easier to nail it down. But frankly, most of our diagnoses are really collections of things that tend to go together-we'll call that a diagnosis because we see it together more frequently than we see it with other things. I think as we learn more about the brain we're probably going to figure out that it's such a complex system - it's not as clean as we'd like to make it. But it helps us in terms of thinking about what to expect from this person's behavior, and what treatments might be effective for them. It helps us to do the categorization system. So when someone's diagnosis is assigned, particularly in adolescence, what often happens is it gets continued over time... because you'd like to assume that the person who was taking care of that person before you was a thoughtful clinician and really thought about is this the right diagnosis, and made a diagnosis based on reasonable evidence. At the same time, people do, especially as they come out of adolescence into adulthood, they do tend to show you what's going on. Something that might have looked like bipolar disorder in adolescence, particularly when that person is too young to make a diagnosis of a personality disorder by the criteria, proves itself in later years to not be. And so it's incumbent upon every new clinician to get to know the person, to review the records, and it's part of being a good psychiatrist to look at it with fresh eyes and say, 'do I have enough evidence to support this diagnosis?' And if not, what am I really dealing with? In 
any case where your treatment program isn't working, your medications aren't doing squat, it's always important to go back and say, 'am I treating the right thing? Am I treating what I think I'm treating?' Because if I'm not treating the right thing, that would explain potentially why my treatment isn't working. In that particular case, and this happens a lot, emotional extremes, particularly significant problems with depression, self-harm behavior, suicidal behavior, outrageous behavior in terms of angers and acting out that can look like a bipolar disorder and often gets called that. There's a variety of reasons for that, one of which... is that in an adolescent you don't make a diagnosis of borderline personality disorder.

$00: 33: 46$

INTERVEIWER: Why is that? Why has that been stricter over the years?

CLINICIAN: Personality disorder diagnoses are generally assigned in adulthood, the idea being that adolescents in particular tend to be emotional and somewhat unpredictable. You don't necessarily want to say, 'oh yeah, definitely personality disorder,' when somebody is 16 because ten years from now they might settle out and have no personality disorder at all. They just had a really difficult period in adolescence where they were highly emotional. They may have had a legitimate depressive disorder, for example.

INTERVEIWER: Does it also say something about the power of the highly stigmatizing predictive label?

CLINICIAN: There is also that. Borderline personality disorder in particular has a strong social stigma that goes with it. Most clinicians, when they see that diagnosis, think 'oh boy.' There's an emotional reaction that goes with seeing a patient who already carries that diagnosis because there's a certain number of things that you expect from someone who legitimately has the diagnosis. You expect a lot of emotionality. You expect a lot of emotional labiality. Ups and downs, ups and downs. You expect to be- one day you're the best doctor they've ever seen. Ten minutes later you could be filth, and there's a lot of emotionally dis-regulation and how that impacts the provider is it creates some chaos in that provider relationship. So I think that because there is that expectation of somebody who has a borderline personality disorder, that's not an unreasonable expectation. It's not necessarily a label you want to saddle somebody with if that's not true, if that's not really what's going on.

INTERVEIWER: In the hospital though the bipolar disorder is less stigmatized than schizophrenia. It's also a basis for being treated here. The law precludes Axis-2 personality disorder categories. Could you say something about maybe how a clinician might have been using a diagnosis because of the context there?

CLINICIAN: Well it's not even the context here to be honest when it comes to treating somebody. Just the way our reimbursement system is set up - if I'm seeing a patient in my office and their only diagnosis is borderline personality disorder, I sincerely hope 
they're paying me out of pocket because their insurance company won't be. If they have an Axis-1 diagnosis, considered a major mental illness like depression or bipolar disorder, then I can expect to get paid.

$00: 36: 23$

INTERVEIWER: So can you also describe how it works here? It's here under legal-

CLINICIAN: Under the PSRB, personality disorders and substance abuse disorders don't qualify as a mental illness. Any doctor will tell you that personality disorders in particular create an enormous amount of difficulty with functioning in society and usual misery on the part of the patient. I've yet to meet someone who has a severe personality disorder who was a happy, well-adjusted person. They wouldn't have that diagnosis if they were.

\section{INTERVEIWER: ( )}

CLINICIAN: Or you were saying who chose to be-

INTERVEIWER: Who chose to be willfully oppositional.

CLINICIAN: No, I don't think that most people want to grow up the way they did if they end up with a personality disorder. Most people would not choose that life history for themselves or for someone they love. That being said it is not considered a major mental illness in that regard. And that's from a legal standpoint. My experience is that most people who have a borderline personality disorder also have something going on-a diagnosable illness on Axis-1 - either a depressive disorder or a PTSD.

INTERVEIWER: So did you know when you were ( ) for the PSRB that the Axis-2 borderline personality disorder is precluded by the PSRB?

\section{CLINICIAN: Yes.}

INTERVEIWER: So how did you think about your clinical strategy then?

CLINICIAN: To be honest I don't...I don't create an Axis-1 diagnosis just to keep someone under jurisdiction. That's not the way I personally work. In this particular case, she legitimately does have PTSD. She also, because of her life history, has not developed a functional adult personality. She has what you would expect of someone with borderline personality disorder: difficulty with self-concept, she has difficulty with emotion-regulation, she has difficulty with maintaining a stable sense of who other people are in relation to her, she tends to over-value or under-value people depending on how she feels about them at the moment. She doesn't tolerate ambiguity particularly well. Her emotions are extremely strong, and usually it's one pure emotion being experienced. At the same time more than one is almost impossible to tolerate. I have yet to meet someone with a severe borderline personality disorder who can fundamentally feel and 
understand the concept that you can love someone and not like them at the time. You can not like their behavior but still love them. The average person with borderline personality disorder is not capable of feeling both of those emotions at the same time- it's too distressing. And that's where that extreme, 'you're all good or you're all,' bad comes from.

00:39:17

INTERVEIWER: So what were you trying to make the DA understand?

CLINICIAN: So what I was trying to make the assistant attorney general understand is that that is fundamentally different from a manic bipolar disorder. A bipolar disorder is a cycling mood disorder. What you would expect in someone with bipolar disorder is that yes, their moods cycle, but not two and three and four times a day. The average person with bipolar disorder is going to have the occasional major depressive episode, which is going to last for weeks to months usually. They're going to have periods where they're completely fine and look no different than any other person walking around on the street who doesn't have a mental illness of any sort. They're going to be periods, usually less frequently but not always, where they're manic and those are usually days to weeks, rarely months in length. A manic episode is hugely different from the person's normal level of functioning and is characterized by decreased need for sleep, lots of energy, hyper talkativity, often hyper-sexuality, hyper-religiosity, grandiosity. There's a series of symptoms that go with a manic episode that can look very very psychotic, and sometimes are, but it's very very different than the normal functioning. It's sustained for a period of time and then eventually it wears itself out because the body cannot maintain not sleeping and go go go go indefinitely. It just can't be done.

INTERVEIWER: So the whole society should learn that.

CLINICIAN: Eventually the person will crash and what you usually see in someone who has a bipolar disorder is either they get on medications that get some traction and then they slowly come down for it. And occasionally you'll see someone who finally just crashes. They sleep for 16 hours and they wake up completely different-much calmer. Not necessarily completely back to normal but much calmer. The average person with bipolar disorder is going to have this long course and so their moods are going to change but it's going to be big chunks of time in one mood state, depressed or manic, and then big chunks of time hopefully in normal mood state.

INTERVEIWER: Why do you think earlier psychiatrists misdiagnosed ( )? That doesn't sound so hard, the differential diagnosis there. Why do you think she had this bipolar label for so many years?

CLINICIAN: I think what happens in children and adolescents, and this is increasingly common actually, is that the highly shifting very rapidly changing mood states are increasingly identified as bipolar disorder. Particularly we're seeing this more and more 
in very young children. That kids as young as three, four, and five years old are getting identified as having bipolar disorder and what's usually described in men is the extremely rapidly shifting mood state, which in an adult we would say that's probably a personality disorder, that's not a bipolar disorder. So I don't think the field has quite figured out what happens with these kids if they really have bipolar disorder what they look like when they grow up.

00:42:28

INTERVEIWER: Is some of this driven by the pharmaceutical companies? We were talking earlier - are quite aggressive these days, and some of them have been the most powerful factor in prescribing habits, practices of psychiatrist, are the drug companies?

CLINICIAN: Doctors like to think that they're immune to that sort of thing, but the reality is that we're just as human as the next person. You're more likely to think about and to prescribe something that you hear about a lot. The pharmaceutical industry would not be as invested in sending representatives to provide information and samples to clinicians if it wasn't an effective strategy for them. They're in the business to make money, let's be honest "(laughter)."

INTERVEIWER: So they're going to pitch Axis-1?

CLINICIAN: Of course they're going to pitch Axis-1. The reality is, and this is an unfortunate truth, is that one of the things that distinguishes an Axis-1 mental illness from an Axis-2 illness is that an Axis-1 illness is more treatable with medications. The person with bipolar disorder is much more likely to stabilize and stay well on a mood-stabilizer than the person who has a personality disorder.

INTERVEIWER: So some of the diagnosis is made based on how-

CLINICIAN: To some degree there is some sort of post-hoc diagnosis. You validate 'okay, I think I'm treating the right thing partly because this seems to have worked.' Because what drives a personality in my view, and again you can take a whole semester of classes about personality theory and what creates a personality disorder, I subscribe to the theory that it's a combination of factors. That when you're born you have a certain set of inheritable personality traits, and some kids are more excitable than others. Some kids are more emotional than others. Some kids have more frustration tolerance than others, and some kids have just more extreme emotional expression than others from a very very young age - under the age of one. In an environment of healthy caretakers who understand what's going on and who can help that child learn to regulate those emotions and that impulsivity, and to help increase their frustration tolerance over time, that child is going to grow up to be someone who probably has a pretty strong personality because they were born with these traits. It's not like they're going to become shy wallflower kids. 
INTERVEIWER: It could work in a certain-

CLINICIAN: It can develop into a functional adult personality where a lot of that intensity can be used as strengths. This is a kid who's likely to be very driven, who's likely to be persuasive perhaps, or be able to really be successful and go-getter kind of types - type A personalities. In a setting in which mom and/or dad - caretakers are themselves highly emotionally dis-regulated, prone to punishment, prone to seemingly irrational or unpredictable fits of anger, physical or sexual abuse, any of those types of things, and I'm not even going to talk about the impact of drugs later in life but that also does impact it, a kid with that extreme personality in childhood is not going to learn the emotional regulation skills that they need to have those traits form into an adult functional personality. What you're going to see in adulthood, and this is especially common in people who have been abused, is an emotional regulation pattern and an emotional response pattern that is completely normal for a three or four-year old child in the body of a 20 -something year old adult. That's what I see. That's how I think about it. And part of the reason that works for me as a clinician is that it takes a lot of that pejorative attitude out of the equation. When I think to myself, how old is so-and-so feeling right now? How old are they acting right now? What's their capability? The average two-year old kid throwing a temper tantrum is - there's a certain number of things you expect them to be able to do and you expect them to not be able to do. You're not going to be able to sit down and have a nice long conversation about what led to this, what are the consequences, and what could you have done differently, you're not going to do that in the moment. What you're going to do in the moment is you're going to make sure that they're not hurting themselves or other people and more often then not you're going to let them have their tantrum until they can calm down enough that you can interact with them again.

00:47:07

INTERVEIWER: So you try to provide a holding environment?

CLINICIAN: So my job at those times when I see someone who is 25 -years old who is that dis-regulated, my job is to create an environment right then that is safe. And sometimes that involves restraint or seclusion, because otherwise this is someone who would be punching people, throwing chairs, breaking objects and trying to cut herself with it, you name it - putting a fist through a window. All of this stuff I have seen, it's been done, and a 25 -year old is a heck of a lot stronger than a two-year old. A two-year old you can physically contain by yourself, a 25 -year old, not so much. And at the same time recognizing this is where this person is. They're two-years old right now. And we have to treat them in a way that is sensitive to the fact that their capabilities are not any greater than a two-year olds' are right now. And if you can do that successfully, if you have some understanding of child development, child emotional development, I think it really helps in treating people with this-with these diagnoses. 
INTERVEIWER: But with the two-year old you wouldn't put them on a ward that's frightening or just totally seize control from them. So what are the issues with hospital care? Hospitals have been criticized for often jumping to too much control.

CLINICIAN: That's a really delicate balance. That's a really delicate balance.

INTERVEIWER: Can you say what the balance is?

CLINICIAN: Particularly in people who are highly dis-regulated and prone to going down that path very quickly and potentially becoming very unsafe very quickly, on the one hand, you want people to learn the skills to self-regulate. You want them to be able to learn how to calm themselves down without you having to intervene. On the other hand, you want to keep everybody safe, and not just them because there are 29 other people living on the unit who have to experience whatever it is that this person's behavior creates in terms of how the environment is. If it's loud, if it's unsafe, if there are things flying, you have everybody else who lives there to think about, and you have the staff to think about and their safety. And you have this person's individual safety to thing about. So on the one hand, what we try to teach is self-regulation skills so that they can calm themselves down without getting to he point where we have to intervene physically. On the other hand, you have to recognize the pattern and the better we know the patient the better we can identify 'okay, we've reached the point of no return here.' This person is not going to be able to calm themselves down from this point forward, so we're going to have to do something.

00:50:01

INTERVEIWER: Is 12 to, and I would like to have a few more minutes with you- ( ) if you were hospitalized in your unit?

CLINICIAN: I - to be perfectly honest, I have an enormous amount of compassion for my patients because I find it very hard to work there sometimes, so do my staff. And we have homes and families and cars, keys. I get to unlock the door anytime I need to and leave the unit for five minutes or ten minutes or half the day if I have a bunch of meetings to go to. I get to leave at five o'clock and go home and come back the following morning. And I'm there usually no more than — on a bad day I'm on the unit from 8 o'clock in the morning until 6 o'clock a night and I never leave it. That's a bad day for me. They do occur "(laughter)" usually on the days where there's a lot going on.

INTERVEIWER: But you're saying you feel that?

CLINICIAN: I feel it, and I don't have to live there. So I have an enormous amount of compassion or the people who have to live there, particularly those who are not really having the trouble at that point, because it does affect them just as much as it affects me in terms of their stress level, their likelihood to have symptoms. 


\section{INTERVEIWER: To act out?}

CLINICIAN: I mean ultimately they do themselves act out. But a lot of what we see in terms of other people on the unit is when one particular person is really dis-regulated a lot, frequently, or a few people are frequently dis-regulated, what we see in people who don't have that particular trouble themselves, is they might become more psychotic, for example, they might become more depressed, more anxious, more likely to become manic. The stress affects them and how their mental health is able to be maintained, or not. And there are some people that are far more susceptible to that than others. I've got a couple of patients who I can tell how my unit's doing just by how their symptoms are that day because they're so reactive to the whole feel of the unit and how high the stress level is for everybody that-

\section{INTERVEIWER: Can you-}

CLINICIAN: Honestly that's not therapeutic for anyone, and that is the justification for the women's high-acuity unit is that...mixing the populations and not taking into consideration anything other than gender in putting together this group of people does not do anyone any favors. We don't do as good a job as we could of treating the people who have the enormous difficulty with emotional regulation because we're so busy focusing on safety and having to worry about everybody else as well that we don't really pull our resources together as effectively as we could to treat those particular people. They have a higher need for treatment. They have a higher need for resources, they just do. And a separate environment is probably going to meet their needs in a better way. We also end up not being able to pay as much attention and give as much care as we should to the other people who are not causing all of the dis-regulation on the unit. So nobody really gets what they need. It's difficult for everyone involved—staff and patients.

00:53:13

INTERVEIWER: I just want to ask you one more point in the last few minutes. Explain what-( )

CLINICIAN: It seems counter-intuitive to think that someone who is acting out a lot and ending up in seclusion and restraints frequently should be out of the hospital. It seems counter-intuitive but in fact it is not because when you realize-when you think about what a highly chaotic and stressful environment does, stress in general dis-regulates people. For example, anybody who's watching this film who has ever gotten a new job, gotten married, gotten divorced, bought their first house, moved to a new state, had a baby, anything that is a major life stress or represents a major change in their life, they're going to have symptoms. People get anxious. They can get briefly depressed. They can have difficulty sleeping at night. They may get more irritable. All of these things are symptoms. They don't necessarily mean a mental illness, but it just means that your coping mechanisms are stretched a little bit beyond their normal capacity and something's got to give. Well, if your coping mechanisms don't have- you don't have 
much in the way of coping mechanisms to begin with, and the capacity for that is not really great, you put someone in a highly stressful environment that's making —well you know what's a highly stressful environment because the staff who don't live in that environment are showing the effects of it. If everyone around you is showing the effects of an environment that is that stressful, and your coping mechanisms are small, that's not the optimal environment for anybody "(laughter)". And what we end up seeing in those experiences and with those patients is that moving them out to another environment that's calmer, less likely to be explosive, less likely to be chaotic is actually therapeutic. It calms them down and they do better. They have less emotional dis-regulation. The other thing that we see is in people that have difficulty maintaining their own safety is if there's always that safety net there, if there's always the staff-'I know they won't let me hurt myself really,'-it's very easy to take a step back and let the staff control your safety. I don't think people do it deliberately but that is a pattern that we see routinely and that's why in people who have that chronic pattern of self-harm they get worse, they tend to do more self-harm when they're in the hospital setting because they're no longer responsible for their own safety ultimately. In a community, I have to be the one to-if I'm someone who does self-harm behavior, I have to be the one to draw the line and say 'this is the furthest I can safely go.'

00:56:03

INTERVEIWER: Being in the hospital there's a risk of all the controls being externalized?

CLINICIAN: When all of the control is external, when all of the safety regulation is external and you know that, it's probably not really a conscious decision but what you see is that over time a pattern develops where behavior dis-regulation becomes more and more extreme because it's somebody else's job to keep me safe. So again, putting that person in a community setting they're actually much more likely to pull it together and maintain their own safety. They're much less likely to do highly emotionally disregulatory things that involve a lot of self-harm or harm to other people. It can certainly still happen, but the risk is substantially lower.

INTERVEIWER: The long-term hospitalization is maybe ( ) isn't so good for many people?

CLINICIAN: There's a certain subset of people for whom extended hospitalization is actively a bad idea. That particular patient is one of them.

INTERVEIWER: Do you think you convinced the DA?

CLINICIAN: I don't know that I convinced the assistant attorney general about that, but you know that was a one-time discussion. Frankly, I was talking more to the PSRB in terms of that than I was to the assistant attorney general. I didn't expect to convince the 
attorney general's office. I needed to convince the PSRB about that, and that fortunately for me and for the patient was successful.

INTERVEIWER: And on that day you were the patient's advocate?

CLINICIAN: On that day I was the patient's advocate. I'm not always, well, that's not true. I am always the patient's advocate. I don't always agree with the patient as to what I think is the right course of action. I'll put it that way.

INTERVEIWER: But that day you and ( ) did agree on how—she described-

CLINICIAN: She was considerably more ambivalent about it than I was. I had much stronger feelings in that direction then she did.

INTERVEIWER: You're saying because she has had hard time in terms of leaving the hospital?

CLINICIAN: She has, she has. And she will continue to have a difficult time with it. I think she will have a difficult time until she's been in the community for a while. I think it will take a while for her to really settle down. But that's - that's normal, that's expected, and I am hopeful that she'll be able to do it.

( )

CLINICIAN: I've gotta go.

INTERVEIWER: She's gotta go ( ). Okay, so your job...in meeting patients when they first come onto the unit - they've made the plea ( ) -

CLINICIAN: If it's someone who is newly placed under the board, they've newly pled GEI and the court has ordered them to come to the hospital, which is not always the case. Some people are conditionally released directly from the court, usually to the county that they were adjudicated in. More often they do order that the patient to come to the hospital.

00:59:03

INTERVEIWER: Is there a problem with that sound in the background? ( )

CLINICIAN: - Saying if someone is found GEI it's usually a plea bargain, rather than a jury trial. More often than not, the court subsequently orders them to come to the hospital for further treatment. It's rare, but it does occur that a conditional release plan is developed at the time and that person leaves court and goes directly into the community. More often we see them come into the hospital. Sometimes it's the first time they've ever been here, sometimes not. It sort of depends on if they've ever been civilly committed or if they've ever been here to be restored to competency to stand trial. Often the discussion 
that I have with them at the time when they're initially admitted is the usual psychiatric interview stuff: what's going on? What kind of symptoms are you having? What medications have you been taking? Or what have you taken in the past? What diagnoses have you been given in the past? I usually do talk to them a little bit about the circumstances of the crime that they were adjudicated for just so that I get a sense of what's their understanding of what all happened. I often find that people are told by the attorney, told by the judge, 'go ahead, take this plea, go to the hospital, you'll only have to be there for a few months.' It's very rare that someone has a true understanding of how the Psychiatric Security Review Board process works, and what's really expected of them when they're in the hospital, and how to get back out of the hospital. So a big part of the job of the treatment team that usually starts with me is saying, 'okay, I don't think they gave you all the information that you're going to need, so here's how it works.' And that's never a pleasant discussion to have with somebody who's walking into my treatment room thinking they're going to get out of here in a month or a couple of weeks. Some people are genuinely unaware that a psychiatric forensic hospitalization is fundamentally different than an acute care hospitalization. It's very common that people assume that they'll be able to be discharged on my say so within a couple of weeks, or a month maybe, which would be ordinarily the way that it would go in the community. And if they've been repeatedly hospitalized in the community voluntarily or civilly committed, that's what they're used to. So, explaining how the forensic process works, and how different it is takes some time usually, and it usually happens over the course of several conversations. But what needs - what people do need to understand fundamentally before the PSRB's even going to consider letting them out of the hospital is that there are specific expectations of them. We usually talk about what these expectations are. The person needs to be safe to themselves and others. They need to be sober. If they've had drug or alcohol problems, they need to be making progress in treatment. They need to be following the rules. And that I can make a recommendation that someone is ready to leave the hospital on clinical grounds, but ultimately it's not my say so. Ultimately, it's the Psychiatric Security Review Board that makes the decisionis this person okay to be in the community? And they're looking at a combination of factors. Not just clinical readiness, but also safety factors. Because their primary charge is to maintain safety in the community. Ideally, when the system works right, the people who are placed under PSRB jurisdiction are those who, once their mental illness is under good control, are not likely to commit another crime. So my job is to help them get as stable and well as humanly possible, work on whatever it was that was influencing their difficulty with following the law in the community, and once I feel like we've got that under good control, advocate on their behalf to the PSRB. So when I walk into a hearing, I've got those two things in mind-I need to be thinking about, is the PSRB going to be thinking about this person as a risk in the community? And do I think this person is clinically read to be out of the hospital? And those are not always the same sorts of considerations. It depends a lot on what the original crime was. Someone who stole a 10dollar roll of quarters - that's a very different crime than somebody who severely assaulted someone or someone who killed somebody or someone who set a fire. And generally speaking, the PSRB is going to be considerably more cautious in allowing 
someone who's committed a very severe crime to leave the hospital. They usually end up spending longer here, even when they're doing well, just to verify that they're really really doing well.

INTERVEIWER: Even though the risk-management psychologists- 


\section{Appendix C - PSRB Proceedings Outline}

1. Introduction

a. PSRB spokesperson greets all.

b. Identifies matter at hand

i. A hearing before the Oregon Psychiatric Security Review Board

ii. Date of hearing

iii. Identifies Patient and Defense Attorney

iv. Identifies Assistant District Attorney representing State

c. Identifies any anomalies or points of interest

i. Number of board members sitting - if less than required by law

1. Requires Patient approval to move forward

d. Identifies Board members present, including spokesperson

e. Classifies type of hearing and locates burden of proof:

i. 2 year hearing - burden of proof with State

ii. Hearing at patient request - burden with defense

iii. Hearing at OSH request - burden with defense (?)

iv. The side that has burden of proof has the right to speak first in opening closing statements, and in calling witnesses

f. Introduces evidentiary exhibits - by citing number of exhibits

i. Asks for objections

ii. In all hearings no objection

g. Asks for stipulations

i. Gets stipulation from the defense - "Yes, at this time we are stipulating to the propriety of your jurisdiction over my client in that she does suffer from a mental disease or defect which when active can cause her to represent a substantial danger to others."

ii. Nearly identical wording every time.

iii. Only one case where stipulation slightly different, stipulated to mental illness but not dangerousness.

2. Body of the Hearing

a. Opening Statements - side which carries burden of proof goes first, then other side.

b. First side presents Case (with burden of proof)

i. Witnesses called

1. Witness sworn in

2. Witness identifies self and relationship to Patient

3. First side questions witness

4. Second side questions witness 
5. PSRB members question witness

6. First then second side allowed to ask further questions to clarify questions asked by opposition or PSRB

ii. Additional witnesses called if any - Same procedures as outlined above.

c. Second side presents case - without burden of proof

i. Witnesses called

1. Witness sworn in

2. Witness identifies self and relationship to Patient

3. Second side questions witness

4. First side questions witness

5. PSRB members question witness

6. Second then first side allowed to ask further questions to clarify questions asked by opposition or PSRB

ii. Additional witnesses called if any - Same procedures as outlined above.

d. In half the hearings in this analysis the Clinician was the only witness called, and thus was questioned by both sides once.

e. Closing statements

i. Burden of Proof goes first

3. Deliberation - In order to deliberate the room is cleared to give the board some privacy.

a. In two of the cases this did not occur, I believe because there was no question or request brought before the board. In one it was a 2 year update with no request attached, and the other was a hearing where the request had been withdrawn. In these cases the deliberation was done in front of the participants, and the question that was quickly addressed was whether or not the patient suffered from mental illness that when active caused them to pose a substantial danger to the community. Outline of that proceeding below, it was very fast.

i. Move by spokesperson to accept stipulation

ii. Board votes verbally

iii. Stipulation accepted

4. Reconvened

a. PSRB Spokesperson:

i. Accepts Stipulation

ii. Properly placed under jurisdiction of board 
iii. Here in some cases the PSRB explains some of their reasoning behind why they made the decision they did, and or addresses some aspect or need of the patient.

iv. Explains Defense Attorney will have paperwork to sign

v. Patient notified of right of appeal

b. Thanks the group, ends. 


\section{Appendix D - Compiled questions from District Attorney}

[Clinician], just to clarify, the hospital does believe that [Patient] has a mental disease or defect?

It looks like the axis I diagnosis has changed some?

So maybe I can get that but um, the second part of it would be just to clarify, when it, whatever she has is active she presents a substantial danger to others?

As I understand it at this point the hospital is asking for an evaluation?

And I wanted to maybe just help clarify for me, where we are on her diagnoses?

Then we move to January 2008 exhibit 27, it had moved, bi-polar disorder had moved to just bi-polar disorder by history?

Now, I wanted to ask, generally the bi-polar sort of brute layman's terms, you have fairly dramatic mood swings?

The depressive symptoms of a bi-polar of, currently she does have a depressive disorder NOS?

Now that could also be considered I would assume at least the depressive part of a bipolar disease right?

What I wondered um, well, what's the somatoform disorder?

Which of those do you think potentially at least relate to the somatoform...?

I am just trying to figure out what has she complained about that you would think relates to that?

I wanted to look at the manic part of the bi-polar diagnosis, at least as you'd had it previously, and in exhibit 32 in the record, we have a number of reports from security basically that starting at least the first one I saw in the records in June of 2008 run up through Feb 18 of this year, are you familiar with those reports?

Ok, incidents?

Alright if, how do you control that behavior then?

Well and but it's gonna have to be a fairly secure place correct? 
Well if you just said you can't predict how she is going to react, if it's not secure, it has to be a low drama place correct?

And um, that would probably mean you would have to have a fairly secure because, right?

Well I mean something where the staff have the ability to control what's going on in the given area correct?

Do you have any place like that in mind?

A concern I would have, is when you said she could get around by herself, aren't you looking for something where she's in a rather controlled environment that's not going to cause her stress?

Does she have frequent contact with her family?

So at this point the hospital is essentially just gonna go out and talk to somebody about placement, is that what you are asking?

Anything else in the structure?

Is um, as I looked at this exhibit 32 it looks like there is something basically every month, I guess she missed July of 08 , but um... how frequent would an outburst have to be I guess to say well she's doing better?

Is there any way the hospital has anyplace else she can go?

For the reason of the outbursts?

You've got this threat there um, that the longer you stay in the hospital, the more challenging it would be to get out. How do you back away from this cougar that's staring you in the face?

What's the approach?

So you don't want too much support, but you want supervision?

Ok, you're familiar with the index crime here?

Ok can I, cut to the chase here if you were going to, if you were in the woman's center?

Women's house, to do this evaluation, would you anticipate the hospital communicating directly with them about the nature of this paradox? 
So the women's house might say. The staff might say, we are willing to take that risk we think we can meet that criteria and keep a proper distance, or they might say, not our cup of tea?

And it looks like when they had evaluated her, it must have been before Jan 82007 that they said um, they weren't going to accept her based on her current violent behavior?

So then the Board did order the evaluation, I think it was in March of 2007, do you know if somebody went back to X county back in 2007 ?

Ok, Ok, how often are you on the unit?

Ok, now would you also agree that and I assume this happens but uh, when you go to a provider in the community, do you tell the what kind of behavior somebodies had at the hospital?

When the incident occurred that lead her to the board's jurisdiction, do you know that?

Previous exhibits have noted that this individual needs close supervision and quote ample structure, that's exhibit 20 page 3 . But Lane counties recommendation or recommended plan only requires 3 hours a day 5 days a week of structured activity. So you see a disconnect between what they are offering and what has previously been suggested?

Oh so this isn't actually the plan?

What is [Patient]'s axis I diagnosis?

And is he currently on medication?

For schizo-affective disorder?

What is his insight into his need for medication?

How about his insight into his mental illness?

Now when his mental illness is active is he a substantial danger to others?

How long has he been on 41B?

Ok, and that's a transitional ward?

And while he has been on that ward is he, had off ground privileges?

So there haven't been any incident during those activities? 
How have those visits gone?

It's ah; the hospital is recommending conditional release at this time?

And you believe that level of security is appropriate?

What if [Patient] were to use drugs or alcohol, would he present a risk to others?

And so there is a conditional release plan currently in place?

Ok, you're familiar with that plan?

Do you think that plan is appropriate?

Um, has [Patient] completed all programs in the hospital that might be beneficial to him?

Is there a spot currently available at [this facility]?

And it sounds like [Patient] does have contact with part of his family?

In your progress note update you indicated a recent event at a shopping center, could you describe that?

My review of the risk assessment indicates that there is a high risk of violence in a community setting if [Patient] faces stress or interpersonal conflict. Is that something you would agree with?

And given [Patient] s resistance to taking medication does that, do you feel he can be adequately supervised in the community?

When did [Patient] start admitting her diagnosis or her mental disease or defect?

The reason that I ask, have you been able to review exhibit 54 which is an OSH interdisciplinary annual review from October of 2007 ?

There was a reference that her insight and judgment is fair, that she recognizes the diagnosis but tends to chalk most of the difficulties up to a physical illness. Can you explain what your understanding is of that? Is she recognizing the diagnosis but minimizing to some degree? Or, how do you reconcile that?

Now, earlier you mentioned that she was too friendly at times. What did you mean by that? 
In preparation for evaluation or conditional release, what further investigation is necessary to try to prevent for example, um, her leaving a conditional release facility which has happened in the past. Are there any steps that are being taken to try to evaluate that risk or to, to prevent it in the future?

So it would be fair to say that the board's jurisdiction has benefited [Patient] and will continue to do so?

Are you familiar with the reasons for why the revocation occurred from the most recent conditional release?

Can you tell us why he was revoked back in October of $2006 ?$

Was there any conflict with other peers or members of the house that we was conditionally released to?

Do you recall the nature of that conflict?

Now was he following staff, uh, at the conditional release placement in their requests?

Do you recall the nature of the reason for the revocation from the initial conditional release placement?

You indicated that there has been some substance abuse problems continuing with [Patient] while he is on the wards at the hospital is that right?

And this was [Patient] second conditional release placement at X County correct?

I think you testified specifically that there was a positive test for cocaine, is that right?

Also I believe this is in exhibit 58, in December of 2007 the hospital staff was concerned of Ambien abuse is that correct?

And what was of concern?

And has [Patient] been honest with the treatment team about his substance abuse use while in the hospital?

You communicated that [Patient] has a, I believe you said degree of awareness about his mental disorder, but then I think I also heard you say he at times has often stated that he did not have a mental disorder. Is it a fluctuating response? Could you clarify? 
The fact that he sometimes disavows having a mental disorder does that cause you concern that he may not be compliant with any medication of treatment if he was to be conditionally released or discharged?

And I believe I just want to clarify; at this point the risk board has not approved [Patient] for privileges is that right?

And has [Patient] been recommended for an evaluation?

Has there been a placement identified for [Patient]?

You indicated I believe at this time there is not a relapse prevention plan at this time, is that correct?

And did [Patient] identify the triggers that would lead to a manic episode or a bi-polar problem?

As part of, do you know [Patient]'s plan if he was to be discharged, what where he believes he would live and seek treatment?

And are you aware of any difficulties that surround his contact with his family?

So would that be a concern for [Patient] maintaining his sobriety?

What are some of your other warning signs?

You can be around alcohol and not drink it is that what you just said?

And what are, I guess I'm specifically asking your warning signs for you mental illness. What are those warning signs?

And are those listed in your relapse prevention plan?

And your substance abuse warning signs what are those?

Ok, you indicated that was your sister, is that right?

That you indicated that you were unaware that the treatment team thought that you were seeking Ambien to alter your mental state. Is this the first time you are hearing this?

And so are you denying that that's accurate?

And you never talked to [Clinician] or anyone else in the hospital about that issue? 
What is you plan if you should be discharged, where would you live?

So you have a job at $\mathrm{X}$ doing what? What's your job?

And how about treatment and medication and maintaining your sobriety, what are your plans?

And how about Substance abuse treatment?

Is gambling an addiction for you?

And do you go to treatment for that?

And would you do treatment for it if you were to be discharged?

It's not something you think you need to do always?

What's your relapse prevention plan for that?

Have you been evaluated recently by them?

And is it accurate that you observed those warning signs and saw that he was using marijuana?

And you didn't observe any warning signs during the trip of a reemergence of his mental illness?

Do you think that at your house you can provide a sufficiently structured environment for [Patient] to be released to immediately?

I just want to make sure I'm clear that [Patient] still currently on medium security ward $50 \mathrm{~F}$ right?

And is there a current transition plan in place to transition him back to a minimum security ward?

Are there any additional classes or treatment aspects that [Patient] needs to complete before he would be ready or appropriate for a transition?

And is there a specific area that you have identified, or they have identified for [Patient] that he needs to work on in order to be ready?

And ah, at this time does [Patient] pose a substantial danger to others? 
If he was to use drugs or alcohol and if that disorder were to become active would he pose a substantial danger to others? 


\section{Appendix E - Compiled questions from Defense Attorney}

So my understanding is that you have been treating my client for 2 years?

And that, during that period of time she's been under 24 hour observation by you and your staff?

And that based on those 2 and a half years of observation, that's how you have arrived at the diagnosis that you are presenting?

Is she um, is she taking medication for her condition?

What is she taking?

And does she do so voluntarily?

So would, and you mentioned a hearing two years ago which we had, would it be fair to say then that she's doing as well or better today than she was when the board ordered an evaluation two years ago?

Um, to your knowledge, has she admitted to you or your staff that in fact she does have a mental illness?

In your opinion, what if any insight does she have into her need for medication? Now um our exhibit 36 is your FEB 24200 update, and based on that it appears that my clients, would it be fair to say that based on that my clients most significant difficulty really is her borderline personality disorder?

How does that manifest itself?

Does that include fights and other disruptions?

Well let me ask you first you mentioned that there are no other options in the hospital. It's my understanding that there is only one all-female ward in the hospital? 
It sounds like based on your previous testimony that a co-ed ward probably would not be the best place for her?

Um, now we talked a lot about diagnosis and one of them is a post-traumatic stress disorder, can you tell us what the basis of that is?

So you think that there might be some contribution to a borderline personality disorder based on the abuse that she suffered?

Now the state has gone to great lengths to point out the various incident reports that we have on our record in the last 6-8 months and I'm wondering in your experience is my client one who can generally be redirected by trained staff?

It appears; I have read many of these incident reports and in fact she willingly went, was escorted by staff to the side room in many of them?

In your experience, what if any ability does she have to verbalize her concerns rather than acting on them?

As I understand your previous testimony as well, she is involved in class and related treatment on the ward?

And overall how is she doing in class?

Does she have privileges do you know?

And does she (react?) appropriately?

In your opinion, could she be adequately treated and supervised in the community? And what is your position considering our request for evaluation? 
I understand based on your previous testimony, and correct me if I'm wrong, the elements; an all-female relatively small group living situation with DBT kinds of treatment as well as trained staff?

As well as some sort of place of safety within the house that she can retreat to at those times when she is feeling anxious?

As part of your work here at the hospital as a social worker, are you involved in transitioning?

And what does the transition team do?

There's been, as you heard our exhibit 24 indicates that board ordered an evaluation 2 years ago, do you know whether that evaluation happened?

So because the placement option went away, the transition went away?

In your opinion would a long period of transition be necessary for my client?

OK, what, how big is the house and what kinds of services do they provide?

How big, approximately how big is the house, how many residents?

There's an opening?

Have you spoken to providence about my client or the possibility...?

And do you think that would be a viable option in your opinion for an evaluation?

[Patient] do you get any benefit from the medication you are taking currently?

What does it do for you?

How long do you think you'll need medication?

Would you, before making any change of medication would you, um rely on your doctor's opinion? 
So you wouldn't make changes on your own?

When your illness is becoming active are there particular warning signs that you experience?

If you were in the community and began to experience those kinds of symptoms what if anything would you do?

Now [Clinician] testified today that you do have privileges at the hospital, can you tell us what privileges you have?

Approximately how many off ground passes have you had?

Have you ever tried to run away?

Do you have a job here at the hospital?

Do you have any other jobs?

If this board were to allow the evaluation we are asking for today and that evaluation came back positive and you were ultimately conditionally released would you agree to follow the rules put forth in your release plan?

You understand that any violation of a rule could bring you back here?

The first is, what is my clients current status?

Would it be fair to say that his illness is in pretty good remission at this point? Approximately how long has his mental status been as you described?

As I understand your previous testimony my client has admitted to you the fact that he does have a mental illness?

And I think you've also touched on this, but would it be fair to say that he is actively involved in treatment here at the hospital? 
And as a residential unit, is it fair to describe that unit as a minimal security unit?

And overall how has he done there from your perspective?

You mentioned earlier that he is in individual treatment with Dr. Wilson?

How is the therapy going from your perspective?

And to your knowledge has he experienced any thoughts about the underlying [crime] that brought him onto this board's jurisdiction?

I'm wondering in terms of how my client is dealing with it, has there been some remorse?

How would you describe his behavior in your ward? Any assaultive or threatening behaviors?

You mention that he is employed? Is he employed on grounds?

And are you proposing any modifications to this proposal right now?

Do you think he could be adequately treated and supervised on conditional release under this plan?

Can you tell me how you are employed?

And can we assume that you are my clients treating psychiatrist?

And approximately how long has that been the case?

What is his current diagnosis?

And what is his current mental status?

Would it be fair to say then that he has been free of major psychiatric symptomology for several years?

Would it be also be accurate to state that my client has not any psychotropic medication for several years as well? 
And that's what, for anxiety?

To your knowledge has he admitted to you or your staff that he does have a mental illness?

And has he been deemed competent to... to um, for example to refuse medication if he so chose?

Um, is he involved in classes and related treatment here at the hospital?

Does that include substance abuse treatment?

In your opinion overall how is he doing in treatment?

How long did he have the solo pass privilege? Approximately

That's fine. How would you describe his overall behavior on your ward?

So there has been no assaultive or threatening conduct?

And he one who responds to staff cues?

And how much queuing does he generally require?

Was there any evidence that my client was attempting to escape or evade staff?

What's your position concerning our request for evaluation?

OK, can you tell me; approximately you've worked with my client as her treating psychiatrist?

Can we assume then that you are familiar with her case?

Do you know approximately how long she has been under the PSRB, in other words been a resident either at $\mathrm{OSH}$ ?

Is she taking any medication for that?

And what is she taking? 
$\mathrm{OK}$, and does she take the medication voluntarily?

Just in looking at my records it appears that she was placed under the PSRB in the year 2000. Does this jibe with your records at all?

$\mathrm{Ok}$, um, what is her current mental status?

In your opinion is she close to being about as good as she will get in terms of her mental status?

To your knowledge has she admitted to you or your staff that a she does in fact have a mental illness?

And to your knowledge has she admitted to you or your staff that she knows that she needs medications to treat her mental illness?

Is she involved in any classes or treatment on the ward?

Would it be fair to say that she is a fully engaged in treatment?

How would you describe her physical behavior towards others?

Is she one who responds to staff cues?

Based on your knowledge of my client, in your opinion have there been any significant changes in her presentation while at the Portland campus of OSH?

Well as I look at our written record, it appears that she was on a watch or a constant for a while, and there was some concerns... has there been any change in that?

So would you say that these changes that have taken place while under your care have been fairly both positive and significant?

Our exhibit 56 is a Sept. $2^{\text {th }} 2008$, OSH progress note which has your signature on it. Are you familiar with that document? 
Are you the treating psychologist for [Patient]?

And how long have you treated him?

Ok, and did you prepare the progress note update that I believe is dated February $13^{\text {th }}$ ?

What is your diagnosis of [Patient] mental illness?

And, as a result of being his treating psychiatrist, you are on his treatment team?

Has the treatment team reached a conclusion about what they are recommending for [Patient]?

Have you prescribed medication for [Patient]?

What type of medication is he on?

Ok, do you believe that he has insight into his mental illness? The bi-polar issues that you speak of, as well as the other various issues?

Do you believe that he appreciates the importance of his medication?

Does he take the medication voluntarily?

And do you believe that the medication has had a positive effect on [Patient]?

Ok, um do you believe that he has insight into what caused his crime, that mental illness caused his crime?

Ok, does he attend classes er, any classes or group discussions?

And what type of classes or group is he in?

And are these classes targeted toward his diagnosis, his illness?

And are they also, they are also targeted like the matrix class toward his drug and alcohol issues?

Ok, is his attendance good at these classes? 
Not even, do you have any information as to the classes he has attended on your ward?

Do you find that he is cooperative?

With respect to scheduling classes and things like that?

And do you find him to be a person who is engaged, you know, interacts, is involved in asking questions discussing issues with you?

Ok, and could you describe his progress I guess in the time that he has been here at the hospital, do you have a feel for how he is progressing in being able to, in the treatment I guess, for his mental illness?

$\mathrm{Ok}$, and are you aware of whether he has worked in the past?

Do you find that [Patient] gets along well with the residents on the ward?

Ok and does he get along well with the staff?

OK, does he have, do you guys, I don't know if you have write ups, or formal disciplinary proceedings or anything like that, but does he have any glitches I guess with respect to write ups or disciplinary proceedings?

And uh, does [Patient] have any passes right now that you are aware of? Are you aware if [Patient] has prepared a relapse prevention plan?

Ok, do you believe [Patient] has changed since he came to the hospital?

Ok. So with respect to the bi-polar treatment, could it get any better? Could his response be any better or basically we have reached the limit of what we can expect on the bi-polar treatment? 
So you are saying that if he has a, kind of has a realistic relapse prevention plan and appreciates the need for I think you said structure and supervision, those are the kinds of things that would allow him to evolve and possibly move out toward conditional release?

Ok, ok. Do you believe [Patient] is supervisable in the community?

If he was granted conditional release do you believe he would earnestly attempt to work with the people that he assigned to work with?

First of all, there is some discussion about whether you have a mental illness or not.

Could you please clarify your position on your medical situation here?

Was his recitation of your medications accurate?

Ok, and do you take those medications voluntarily?

And how long do you believe you will have to take those medications?

Ok and what would happen if you stopped taking those medications?

Ok, and have you prepared a relapse prevention plan?

And what are your warning signs, warning that a relapse may occur?

Ok, if you were out in the community and you started feeling these feelings that you are just describing now what would you do?

Ok that's excellent, is that what your relapse prevention plan indicates to?

Ok, and do you believe that you have a substance abuse problem?

Are you in groups or classes here that address substance abuse issues?

Ok and do you feel like you benefit from these groups? 
Ok, and when you are in these groups do you personally express yourself, do you actively involve yourself in the discussions?

Ok, you talk through your problems in there?

Ok, what, how long will you need to stay in groups whether in the hospital or out on the streets?

Ok, what do you need to do, if you were let out, what do you need to do to stay sober? Would you be open to placement in say a group home or someplace like that as opposed to your family?

Are you working now in the hospital?

Ok, have you worked here in the past?

And where'd you work?

And what was your work schedule like on atypical week when you were working?

Ok, Ok, and do you get along well with the residents in your ward?

Ok and any problems with them at all?

Ok, you get along well with the staff?

Ok, any problems at all? Write ups or?

Ok, I appreciate that you've gone, you went to 40A briefly, and now you are back, did you have privileges on $40 \mathrm{~A}$ ?

And are you working back towards regaining those privileges now?

You indicated that if you stop taking your medications you'd become psychotic, you realize that your bi-polar condition may come back in the future? 
What do you believe would happen if you start drinking or taking drugs again, how would that impact your life?

Do you believe you have changed since you have entered the hospital here?

You've been out on conditional release once and there were some problems almost immediately and you came back, do you believe that if they released you a second time that those problems would re-occur?

And what would you do to make sure they don't re-occur?

Do you believe you; you now understand your mental illness better than you did when you enter the hospital and when you came back under conditional release?

And finally I guess question I asked previously, if they did grant you conditional release would you agree to follow all rules?

And finally I guess question I asked previously, if they did grant you conditional release would you agree to follow all rules? 


\section{Appendix F - Table: examples illustrating theme content}

Table 6 - Examples Illustrating Theme Content

\begin{tabular}{|c|c|}
\hline Themes & Coded Content \\
\hline \multirow{6}{*}{ 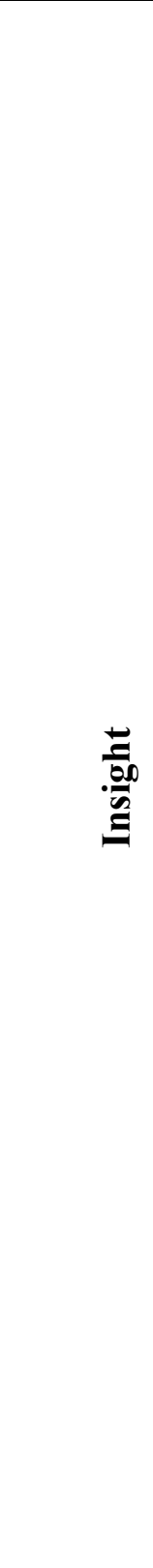 } & $\begin{array}{l}\text { Defense Attorney: Um, to your knowledge, has she admitted to you } \\
\text { or your staff that in fact she does have a mental illness? Clinician: } \\
\text { Yes. }\end{array}$ \\
\hline & $\begin{array}{l}\text { Defense Attorney: In your opinion, what if any insight does she have } \\
\text { into her need for medication? Clinician: I think she's got pretty good } \\
\text { insight. I think she recognizes that the medications help a lot with } \\
\text { anxiety and depression although she is also, I think very clearly that } \\
\text { they are not the end all be all and that she really does have an } \\
\text { investment in therapy. }\end{array}$ \\
\hline & $\begin{array}{l}\text { District Attorney: What is his insight into his need for medication? } \\
\text { Clinician: He has really worked on that. I, he tends to be a kind of } \\
\text { quiet guy, but he is working very productively in group therapy. He } \\
\text { had done a lot of groups in the past, but our psychologist, does } \\
\text { individual psychotherapy with him and he is developed a good early } \\
\text { relapse prevention plan. Knows his target symptoms, warning signs } \\
\text { and combines you know, working on his rehabilitation with the rest of } \\
\text { his daily routine. }\end{array}$ \\
\hline & $\begin{array}{l}\text { Patient Attorney: Would you, before making any change of } \\
\text { medication would you, um rely on your doctor's opinion? Patient: } \\
\text { Yes. }\end{array}$ \\
\hline & $\begin{array}{l}\text { District Attorney: How about his insight into his mental illness? } \\
\text { Clinician: He's quite ah, mindful of his mental illness. In that he has } \\
\text { you know, he had had prior to the crime } 11 \text { years of active symptoms } \\
\text { in the community. And had been variable compliant with south Lane } \\
\text { mental health and I think what, the record supports is that he's just } \\
\text { gotten considerable more serious about the need to banish his illness } \\
\text { given the tragic outcome in } 2000 \text {. }\end{array}$ \\
\hline & $\begin{array}{l}\text { Defense Attorney: As I understand your previous testimony my client } \\
\text { has admitted to you the fact that he does have a mental illness? } \\
\text { Clinician: Absolutely. }\end{array}$ \\
\hline
\end{tabular}




\begin{tabular}{|c|c|}
\hline & $\begin{array}{l}\text { Defense Attorney: To your knowledge has he admitted to you or your } \\
\text { staff that he does have a mental illness? Clinician: Yes he has, he } \\
\text { has has had some difficulty understanding the basis of that, because he } \\
\text { reports memory difficulties around the time of the offence. }\end{array}$ \\
\hline & $\begin{array}{l}\text { Defense Attorney: To your knowledge has she admitted to you or } \\
\text { your staff that a she does in fact have a mental illness? Clinician: } \\
\text { Yes. }\end{array}$ \\
\hline & $\begin{array}{l}\text { Defense Attorney: And to your knowledge has she admitted to you or } \\
\text { your staff that she knows that she needs medications to treat her } \\
\text { mental illness? Clinician: Yes. }\end{array}$ \\
\hline \multirow{7}{*}{ 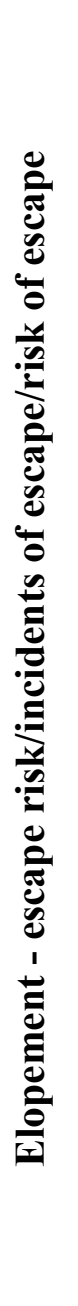 } & $\begin{array}{l}\text { Patient: I would, it would be safe to say that I have been on close to } \\
20 \text { or } 30 \text { different outings. Defense Attorney: Have you ever tried to } \\
\text { run away? Patient: No. }\end{array}$ \\
\hline & $\begin{array}{l}\text { Defense Attorney: You mention that he is employed? Is he employed } \\
\text { on grounds? Clinician: Solo on grounds, by himself. Defense } \\
\text { Attorney: And he's not tried to run off? Clinician: No. }\end{array}$ \\
\hline & $\begin{array}{l}\text { Clinician: There wasn't any indication that he meant to escape, he } \\
\text { simply kind of walked away from the person, apparently not } \\
\text { understanding the importance of being under that person's constant } \\
\text { supervision. }\end{array}$ \\
\hline & $\begin{array}{l}\text { Clinician: And he up until recently had the unescorted privilege on } \\
\text { grounds so he could walk to work and back without staff or peer } \\
\text { escort and there was never any difficulty with that. }\end{array}$ \\
\hline & $\begin{array}{l}\text { Clinician: I do think it's [elopement] not an unimagined risk, but I } \\
\text { think his risk is mitigated by this type of transition. I do think that } \\
\text { would be a good choice. }\end{array}$ \\
\hline & $\begin{array}{l}\text { Defense Attorney: Was there any evidence that my client was } \\
\text { attempting to escape or evade staff? Clinician: No, no, we don't } \\
\text { think he was. }\end{array}$ \\
\hline & $\begin{array}{l}\text { District Attorney: In preparation for evaluation or conditional release, } \\
\text { what further investigation is necessary to try to prevent for example, } \\
\text { um, her leaving a conditional release facility which has happened in } \\
\text { the past. Are there any steps that are being taken to try to evaluate } \\
\text { that risk or to, to prevent it in the future? }\end{array}$ \\
\hline
\end{tabular}


Defense Attorney: Now the state has gone to great lengths to point out the various incident reports that we have on our record in the last 6-8 months and I'm wondering in your experience is my client one who can generally be redirected by trained staff? Clinician:

Generally speaking, yes. There are certain instances, and many of those that you have the incident reports to describe are, among them are instances where [Patient] was bound and determined for whatever reason, to be in the side room. And like I said, sometimes it's a matter of having, having to have a place where she can go where she feels safe.

Defense Attorney: It appears; I have read many of these incident reports and in fact she willingly went, was escorted by staff to the side room in many of them. Clinician: That's, that's the most common.

Defense Attorney: If this board were to allow the evaluation we are asking for today and that evaluation came back positive and you were ultimately conditionally released would you agree to follow the rules put forth in your release plan? Patient: Yes.

Clinician: He's not been in any verbal or physical outbursts, his privilege levels include up to the solo on grounds he works in the yard, maintenance, grounds crew, they cut the grass and take care of the trees on campus.

Clinician: No, he has not required any coming back early or PRN's or anything.

Defense Attorney: How would you describe his behavior in your ward? Any assaultive or threatening behaviors? Clinician: Oh no, oh no, he's a standup guy, keeps his quarters very tidy. He tries to counsel when other people are getting loud of obnoxious, if he's around, he's gone much of the day with his job.

Clinician: a violation of any of those expectations - failing to show up for an appointment with a psychiatrist for example, stopping medications, stopping going to psychiatric groups which is required, refusing to provide a urinalysis, all of which are relatively minor potentially compared to things like leaving without authorization, or actually committing another crime - any of those things - documented recurrence of substance use - any of these things can result in the PSRB saying 'nope, you don't get to stay in the community anymore, you're going back to the hospital because we don't trust you to continue on the road of being safe in the community.' 
District Attorney: Ok, and you had also acknowledged that at least there is verbally violent behavior she is still exhibiting? Other: I had not seen that.

Clinician: I think she recognizes that the medications help a lot with anxiety and depression although she is also, I think very clearly that they are not the end all be all and that she really does have an investment in therapy.

Patient Attorney: Thank you [Patient] do you get any benefit from the medication you are taking currently? Patient: It helps me so that the anxiety is a little bit more manageable. It's not completely gone but it is more manageable with medication.

Defense Attorney: How long do you think you'll need medication? Patient: I'll probably be on some kind of medication for the rest of my life. Hopefully some of the anti-anxiety medications that I'm on will decrease in its number of how many I take and how often I take it.

Defense Attorney: And has he been deemed competent to... to um, for example to refuse medication if he so chose?

Clinician: I believe that he is competent and that question was also put to Doctor in his review and he agreed that [Patient] was competent to refuse medicine.

Clinician: Every now and again we get blood levels just to see how everything is going, and I have no concerns regarding her blood levels of medication on this medication it seems to be working quite well for her psychosis, and I think with a combination of a medication that is actually being absorbed and is being effective, and the cessation of that particular purging behavior, she is definitely moving in the right direction.

District Attorney: What if Mr. Olsen were to use drugs or alcohol, would he present a risk to others? Clinician: I do think so, he would get disinhibited I believe. In, possibly paranoid with delusions if he used stimulants, particularly. But I think that his recovery is such, and the surveillance of his recovery would be such that we could know this rapidly.

District Attorney: Well let me ask you this, in the, this is a big move into a community setting, albeit a secure one, they telecare is proposing a once a month random unannounced screens, do you think that's enough given the change that we are looking at? Clinician: I do, but let me qualify that, I think [Patient] would say his biggest risk or drug is alcohol. And that's hard to pick up on a UA. 
District Attorney: The state would also oppose a conditional release or evaluation at this time. Our position is based on in part, [Patient]'s recent drug use.

District Attorney: $\mathrm{He}$, this is October of 2006, we have a full year and then he again uses cocaine in October of 2007 approximately 4 months ago.

District Attorney: After going off his medication experiencing manic symptoms threatening or at least harassing female staff and becoming oppositional with other peers within the house during that period of time he was violating the rules with having contact with his sister.

District Attorney: Specifically on page 1 of 4 on exhibit 37 as well as concern about Mr. York's disinclination to follow a conditional release plan. His impulsive behaviors that included lying and compulsive gambling um and as well as using smoking marijuana around family members.

Defense Attorney: As I understand your previous testimony as well, she is involved in class and related treatment on the ward?

Clinician: Yes, she does a lot of classes actually.

Defense Attorney: In your opinion, could she be adequately treated and supervised in the community? Clinician: Yes I do think she could.

Clinician: He does very well in treatment. Participates actively in the psychosocial treatments that we offer him, he's employed here at the hospital. He works in the canteen. There never any difficulty around that.

Clinician: That is the classic difficulty with having someone with severe trauma history and borderline personality disorder in the hospital setting, particularly in a hospital setting that is chaotic, and chronically unsafe. It absolutely creates a paradox in which it is very hard to get someone to have the stable safe behaviors that you want, or would ordinarily expect to recommend release option, particularly in this setting. And at the same time, part of the reason for that is that the environment facilitates those behaviors. 
Defense Attorney: The legislature, in their wisdom, also recognized that people can and do change with treatment. Even though they may have an illness, when they get to a point where they fully understand that illness and fully understand how to treat it and what they need to do to maintain themselves in good remission, that they can be discharged as no longer being a substantial danger to others.

Defense Attorney: And I think you've also touched on this, but would it be fair to say that he is actively involved in treatment here at the hospital? Clinician: He has been, he's done all the group to get too residential with kind of crime he did, he certainly had to have an exemplary type record and since he has been on 41B, he has done a great job again of balancing treatment with his work. 


\section{Appendix G - Table: Individual counts of themes by hearing}

Table 7 - Individual Counts of Themes by Hearing

\begin{tabular}{|c|c|c|c|c|c|c|c|}
\hline \multirow[b]{2}{*}{ Themes } & \multicolumn{7}{|c|}{ PSRB Hearings } \\
\hline & $\begin{array}{l}\text { Hearing } \\
1\end{array}$ & $\begin{array}{l}\text { Hearing } \\
2\end{array}$ & $\begin{array}{l}\text { Hearing } \\
3\end{array}$ & $\begin{array}{l}\text { Hearing } \\
4\end{array}$ & $\begin{array}{l}\text { Hearing } \\
5\end{array}$ & $\begin{array}{l}\text { Hearing } \\
6\end{array}$ & $\begin{array}{l}\text { Hearing } \\
7\end{array}$ \\
\hline Insight & 15 & 0 & 8 & 2 & 0 & 7 & 24 \\
\hline Elopement & 5 & 0 & 6 & 10 & 0 & 2 & 0 \\
\hline Compliance & 24 & 1 & 2 & 10 & 3 & 4 & 20 \\
\hline Drug Use & & & & & & & \\
\hline Authorized & 10 & 2 & 3 & 5 & 1 & 3 & 16 \\
\hline $\begin{array}{l}\text { Un- } \\
\text { authorized }\end{array}$ & 0 & 0 & 6 & 5 & 0 & 0 & 18 \\
\hline Treatment & 17 & 1 & 11 & 11 & 0 & 2 & 16 \\
\hline
\end{tabular}

